ERNEST IRLANDQ LAWRENEE

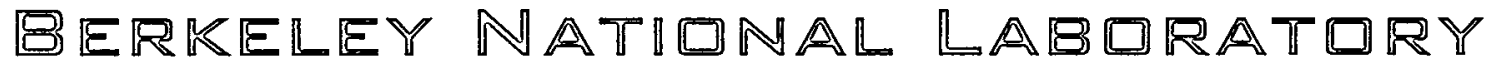

\title{
Evaluation of Conceptual, Mathematical and Physical-and- Chemical Models for Describing Subsurface Radionuclide Transport at the Lake Karachai Waste Disposal Site
}

V.G. Rumynin, V.A. Mironenko, L.N. Sindalovsky, A.V. Boronina, P.K. Konosavsky, and S.P. Pozdniakov Earth Sciences Division

June 1998

REORWER

APR 131999

OSTI 


\section{DISCLAIMER}

This document was prepared as an account of work sponsored by the United States Government. While this document is believed to contain correct information, neither the United States Government nor any agency thereof, nor The Regents of the University of California, nor any of their employees, makes any warranty, express or implied, or assumes any legal responsibility for the accuracy, completeness, or usefulness of any information, apparatus, product, or process disclosed, or represents that its use would not infringe privately owned rights. Reference herein to any specific commercial product, process, or service by its trade name, trademark, manufacturer, or otherwise, does not necessarily constitute or imply its endorsement, recommendation, or favoring by the United States Government or any agency thereof, or The Regents of the University of California. The views and opinions of authors expressed herein do not necessarily state or reflect those of the United States Government or any agency thereof, or The Regents of the University of California.

This report has been reproduced directly from the best available copy.

Available to DOE and DOE Contractors from the Office of Scientific and Technical Information

P.O. Box 62, Oak Ridge, TN 37831

Prices available from (615) $576-8401$

Available to the public from the National Technical Information Service

U.S. Department of Commerce

5285 Port Royal Road, Springfield, VA 22161

Ernest Orlando Lawrence Berkeley National Laboratory is an equal opportunity employer. 


\section{DISCLAIMER}

Portions of this document may be illegible in electronic image products. Images are produced from the best available original document. 
LBNL - 41974

\title{
Evaluation of conceptual, mathematical and physical-and-chemical Models for describing subsurface radionuclide transport At the Lake Karachai waste disposal site
}

\author{
V. G. Rumynin, ${ }^{(1)}$ V. A. Mironenko ${ }^{(2)}$ L. N. Sindalovsky, ${ }^{(2)}$ \\ A. V. Boronina, ${ }^{(2)}$ P. K. Konosavsky, ${ }^{(3)}$ and S. P. Pozdniakov ${ }^{(4)}$
}

1. Earth Sciences Division, Ernest Orlando Lawrence Berkeley National Laboratory, University of California, Berkeley, California 94720, on Fulbright Fellowship from the St. Petersburg Division of the Institute of Environmental Geology of the Russian Academy of Sciences, 14 Linia, 20, St. Petersburg, Russia 199178

2. The St. Petersburg Division of the Institute of Environmental Geology of the Russian Academy of Sciences, 14 Linia, 29, St. Petersburg, Russia, 199178

3. The Department of Engineering Geology of the St. Petersburg State Mining Institute, 21 Linia, 2, St. Petersburg, Russian, 199026

4. The Department of Hydrogeology of the Moscow State University, Vorob'ovy Gory, Moscow, Russia, 119899

\section{June 1998}

This work was supported jointly by the Director, Office of Energy Research, Office of Basic Energy Sciences, of the U. S. Department of Energy, under Contract No. DE-AC03-76SF00098 and EC "Inco-Copernicus" program, under Contract No. ERBIC15CT960211. 


\section{Table of contents}

1. Introduction

2. Characterization of the contaminated site 4

2.1. Hydrogeological setting 4

2.2. Water balance of the reservoir and chemical composition of the wastes 5

2.3. Generalization of pumping test data and transmissivity field construction 8

2.3.1. Characterization of available test data $\quad 8$

2.3.2. Spatial variability of transmissivity 9

2.3.3. Stochastic interpolation of transmissivity 9

2.3.4. Vertical distribution of permeability and its relationship with

fracturing porosity 11

3. Identification of migration processes and their preliminary modeling analysis 12

3.1. General description of the migration process $\quad 12$

3.2. A general concept for modeling analysis 13

3.3. 2D regional flow model development $\quad 17$

3.4. 3D problem investigation $\quad 20$

3.5. Influence of the capacity of the conventional aquitard on the migration process 22

4. The major results of laboratory experiments 23

4.1. Study of the adsorption process

4.2. Diffusion experiments 34

4.3. Assessment of the cation exchange capacity 35

$\begin{array}{ll}\text { 4.4. Conclusions } & 37\end{array}$

5. Development of analytical and numerical models for studying subsurface 39 transport of the irreversibly adsorbing components

5.1. Exponential dual-site adsorption model $\quad 39$

5.2. Analytical description of the multi-wave migration process 43

5.2.1. Equilibrium model $\quad 43$

5.2.2. Non-equilibrium models $\quad 46$

1. Analytical model $\quad 46$

2. Numerical model $\quad 47$

5.2.3. Preliminary results of the numerical assessment 49

6. Study of multi-solute transport in the double-porosity reservoir 52

6.1. Geochemistry of the contaminated subsurface waters 52

6.1.1. Introductory remarks $\quad 52$

6.1.2. The main modeling results 53

6.2. 1D model for multicomponent transport study 55

6.2.1. Model description $\quad 55$

6.2.2. Verification and application $\quad 56$

1. Verification $\quad 56$

2. Application $\quad 56$

7. Conclusions 64

$\begin{array}{ll}\text { References } & 67\end{array}$ 


\section{Introduction}

The goal of this work was to develop the methodology and to improve understanding of subsurface radionuclide transport for application to the Lake Karachai Site and to identify the influence of the processes and interactions involved into transport and fate of the radionuclides. The report is focused on two sets of problems, which have to do both with, hydrodynamic and hydrogeochemical aspects of the contaminant transport.

The Lake Karachai Site places a unique role in the advancement of knowledge of the subsurface behavior and fate of many hazardous radionuclides. It is located within one of the South Ural provinces in Russia (Drozhko and Glagolenko, 1997; Drozhko et al., 1997; Petrov et al.,1994; Solodov et. al., 1994; Solodov et. al., 1998). There are several surface waste reservoirs between two rivers that have been used over 45 years for storage of low-and-medium-radioactivity liquid wastes. The largest of them is the reservoir known as Karachai Lake, which contains the total of $120 \mathrm{Mln} \mathrm{Ci}$ (Myasoedov, 1997). The leakage from the reservoir has resulted in a contamination plume traveling through the aquifer comprise of fractured metavolcanic rocks. This is probably the most contaminated (by radionuclides) site in the world.

The high waste density and aquifer heterogeneity with no welldeveloped aquitard has caused a complex three-dimensional spreading of the plume. Increasing in volume, the plume moves towards the zones of groundwater discharge threatening surface water and ground-waterwellfields.

Subsurface radionuclide transport at the Lake Karachai site is accompanied by a range of physical and chemical processes and interactions including: advection, mechanical dispersion, chemical diffusion, radioactive decay, chemical reaction, and adsorption. Depending on the process or interaction, the mass transport potential of the contaminant may be either enhanced or diminished.

Many individuals and organizations have contributed to the development of effective ground water monitoring system, experimental and modeling studies. Foremost among contributing organizations have been the Mayak Amalgamated Industry (MAI), the Hydrospetzgeology Enterprise, the Institute of Geology of Ore Deposits, Petrography, Mineralogy, and Geochemistry, Russian Academy of Sciences (IGEM).

The first part of this work is dedicated to developments of flow and non-reactive transport models. They are based on published data (Drozhko and Glagolenko, 1997; Drozhko et al., 1997; Samsonova and Drozhko, 1996; 
Petrov et al.,1994; Solodov et. al., 1994; Belkin and Petrov, 1993). In this context, the previous investigations have been reviewed, analyzed and generalized. The second part of the report deals with analyzing experimental data obtained by report's authors and with new developments of analytical and numerical models for non-conservative component transport study.

\section{Characterization of the contaminated site}

\subsection{Hydrogeological setting}

A volcanic-rock reservoir is unconfined, the ground-water potentiometric surface (Fig. 2.1) lies at a depth of $0.1-20 \mathrm{~m}$ (5-7 m on average). Under natural conditions, the aquifer is recharged primarily by precipitation. The ground water recharge varies seasonally, with the main bulk of the recharge during April-May. The recharge distribution is areally uneven depending on topography, the weathered zone thickness and the depth to ground water level. The average annual recharge rate is about $10-25 \%$ of the annual precipitation. The ground-water discharge area is associated with the river-plains and lakes.

According to the data obtained by means of different types of the field techniques (pumping tests and geophysical logging of boreholes aimed at fractured massif structural investigations as well as core-sample descriptions) the water bearing rocks must be considered as a highly heterogeneous media (Section 2.3). The transmissivity was shown to vary from 1 to $800 \mathrm{~m}^{2} /$ day. The logarithmic transmissivity variance is rather high (Section 2.3.1). According to published data (Belkin and Petrov, 1993; Pozdniakov, 1996; Drozhko et al., 1997), fractured porosity values within the depth of $0-100 \mathrm{~m}$ vary from 0.017 to 0.002 ( 0.005 on the average). The mean distance between the fractures ranges from 0.1 to $0.05 \mathrm{~m}$ (on the top of the cross section) to 1 to $5 \mathrm{~m}$ (near the bottom). The porosity of the rock matrix is within the range of $0.2-1.0 \%$.

The position of the underlying bedrock is uncertain in cross section due to the monotonous decrease of permeability and fracturing. The choice for assigning the elevation of the bottom boundary of the fractured permeability zone is a matter of convention. In the previous publications it was assumed that conditional bedrock lies at depth of about $100 \mathrm{~m}$ below land surface (Petrov et al., 1994). 
At present, the Lake Karachai is filled with wastes. Additional reservoirs have been created in the main river (Techa) valley, and individual water-supply wells have been put in operation in the studied area. All this has resulted in changes of ground-water discharge/recharge conditions, but the principal flow structure stays approximately the same.

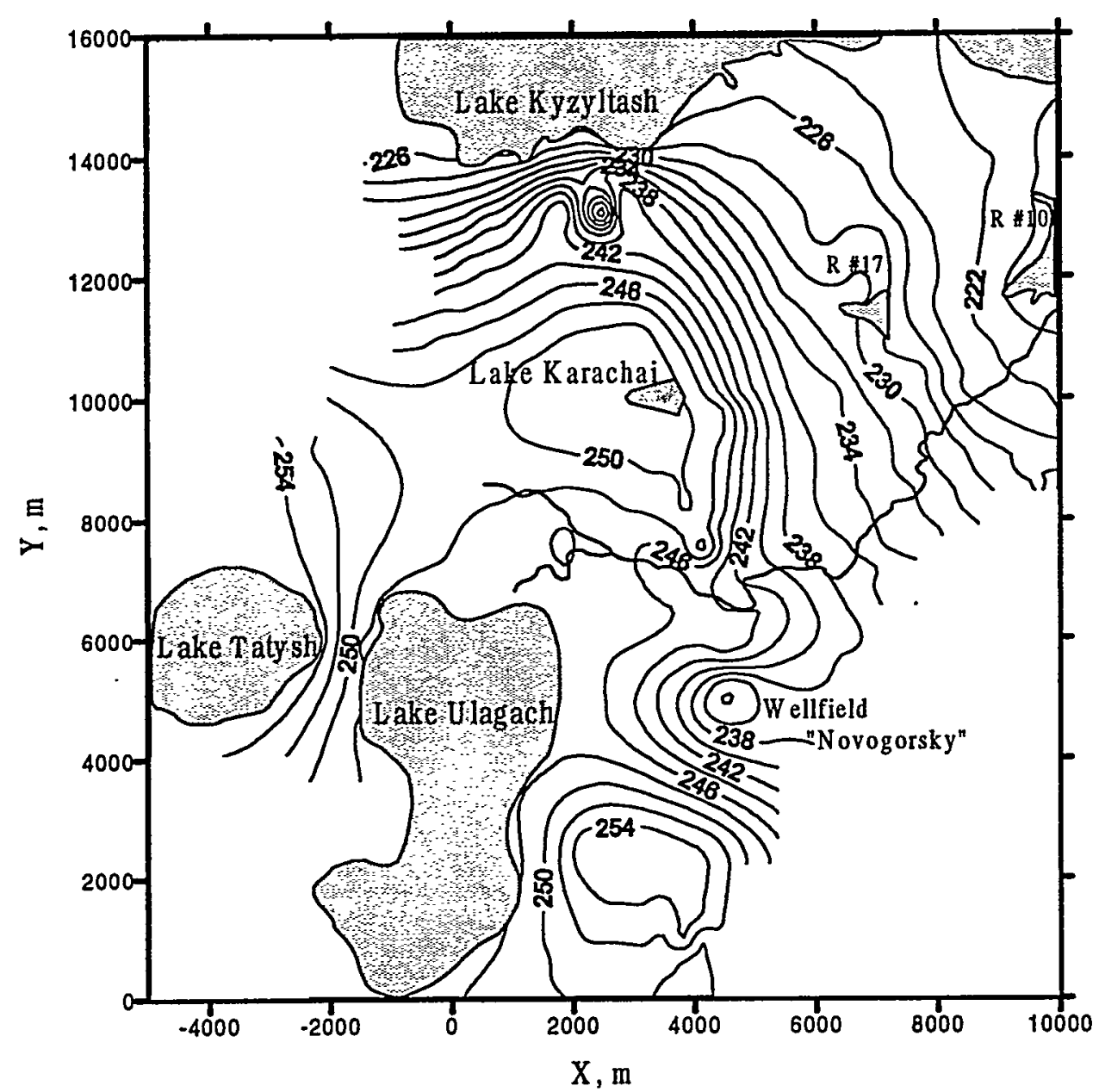

Fig. 2.1. A schematic map of the ground water potentiometric surface (elevations are meters above sea level)

2.2. Water balance of the reservoir and chemical composition of the wastes

The main pollution occurs due to leakage of highly concentrated wastes from the Lake. The surface reservoir is located at the watershed area between the Techa and Myshelyak rivers therefore for relatively dry periods, the 
balance of the accumulated solutions is determined by the rate of the liquid waste discharged into the Lake, evaporation from the surface, and liquid waste leakage through the bottom sedinnents. Variations of the leakage rate over the period of the waste management have been established according to the water budget. The leakage rate over the period of waste management varies from tens to hundreds of cubic meters per day (Fig. 2.2). The total volume of leakage amount is about 3.6 million cubic meters over the period 1951-1996. The influence of the waste release into the subsurface environment on the ground water flow is not too noticeable (Fig. 2.1).

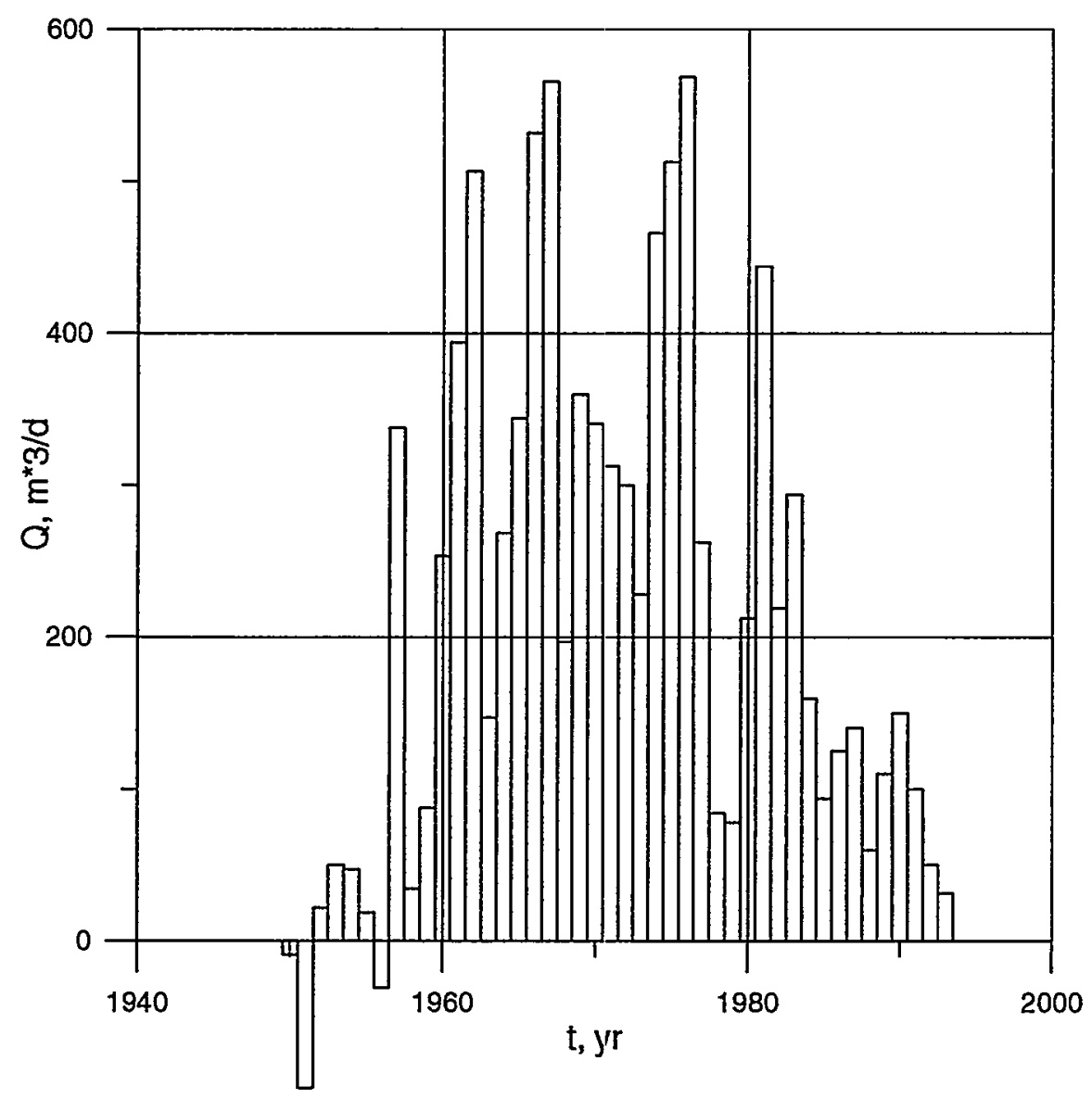

Fig. 2.2. Estimated variation of the leakage rate

The wastes are radioactive and of height density. The latter is due to their salt content (mainly, sodium nitrates up to $150 \mathrm{~g} / \mathrm{l}$ ) causing density variations from 1.01 to $1.09 \mathrm{~g} / \mathrm{cm}^{3}$. The chemical composition of the wastes 
can be associated with data obtained from sampling observation wells (Table 2.1, Solodov et al., 1994) along the flow path from Lake Karachai to

Table 2.1. Chemical composition (in $\mathrm{mg} / \mathrm{L}$ ) of the subsurface contaminated brines in the reservoir (40-100 $\mathrm{m}$ below the surface) along the flow path from LakeKarachai to the Novogorneyi wellfield (August, 1993), Solodov et al., 1994

\begin{tabular}{|c|c|c|c|c|c|c|c|c|}
\hline Well \# & $41 / 77$ & $63 / 68$ & $10 / 68$ & $3 / 68$ & $9 / 68$ & 176 & $50 / 79$ & 209 \\
\hline Depth, $\mathrm{m}$ & 45 & 100 & 100 & 90 & 100 & 80 & 40 & 40 \\
\hline $\begin{array}{c}\text { Distance, } \\
\mathrm{m}\end{array}$ & 50 & 1100 & 1500 & 1900 & 2150 & 2500 & 2800 & 4000 \\
\hline $\begin{array}{c}\mathrm{HCO}_{3}^{-} \\
\mathrm{H}_{4} \mathrm{SiO}_{4} \\
\mathrm{~F} \\
\mathrm{CH}_{3} \mathrm{COO}^{-} \\
\mathrm{C}_{2} \mathrm{O}_{4}^{2-} \\
\mathrm{H}_{2} \mathrm{Fulv}^{2-}\end{array}$ & $\begin{array}{c}4760 \\
3.2 \\
2.0 \\
25 . \\
2.5 \\
0\end{array}$ & $\begin{array}{c}1220 \\
9.6 \\
1.5 \\
150 . \\
2.5 \\
0\end{array}$ & $\begin{array}{c}1830 \\
9.6 \\
2.0 \\
90 . \\
2.5 \\
0\end{array}$ & $\begin{array}{c}1160 \\
25.6 \\
1.3 \\
50 . \\
2.5 \\
0\end{array}$ & $\begin{array}{c}952 \\
25.6 \\
1.5 \\
300 . \\
1.8 \\
0\end{array}$ & $\begin{array}{c}251 \\
33.6 \\
0.8 \\
0.18 \\
.009 \\
22.4\end{array}$ & $\begin{array}{c}220 \\
33.6 \\
0.3 \\
.01 \\
.0005 \\
3.5\end{array}$ & $\begin{array}{c}129 \\
4.0 \\
0.3 \\
.02 \\
.0005 \\
.05\end{array}$ \\
\hline $\begin{array}{c}\mathrm{Cl} \\
\mathrm{NO}_{2}^{-} \\
\mathrm{NO}_{3}^{-} \\
\mathrm{SO}_{4}^{2-}\end{array}$ & $\begin{array}{c}120 \text {. } \\
4100 \text {. } \\
45000 \text {. } \\
360 \text {. }\end{array}$ & $\begin{array}{c}90 . \\
3600 \text {. } \\
45000 \text {. } \\
400 \text {. }\end{array}$ & $\begin{array}{c}105 . \\
6000 . \\
52000 . \\
350 .\end{array}$ & $\begin{array}{c}80 . \\
3800 . \\
32000 . \\
165 .\end{array}$ & $\begin{array}{c}88 . \\
3200 . \\
27100 . \\
287 .\end{array}$ & $\begin{array}{c}162 . \\
250 . \\
3910 . \\
200 .\end{array}$ & $\begin{array}{c}54 . \\
0.7 \\
43.0 \\
111 .\end{array}$ & $\begin{array}{c}46.9 \\
0 . \\
0 . \\
42.2\end{array}$ \\
\hline $\begin{array}{c}\mathrm{Na}^{+} \\
\mathrm{K}^{+} \\
\mathrm{NH}_{4}^{+} \\
\mathrm{Cs}^{+} \\
\mathrm{Mg}^{2+} \\
\mathrm{Ca}^{2+} \\
\mathrm{Sr}^{2+} \\
\mathrm{UO}_{2}^{2+} \\
\mathrm{Co}^{2+} \\
\mathrm{Ru}(\mathrm{OH})_{3}{ }^{+}\end{array}$ & $\begin{array}{c}19000 . \\
310 . \\
48 . \\
1.6 \cdot 10^{-5} \\
300 . \\
10 . \\
210 . \\
46.5 \\
7.1 \cdot 10^{-7} \\
9.0 \cdot 10^{-8}\end{array}$ & $\begin{array}{c}16000 . \\
260 . \\
20 . \\
0 . \\
200 . \\
1400 . \\
260 . \\
39.7 \\
0 . \\
0 .\end{array}$ & $\begin{array}{c}9000 . \\
140 . \\
52 . \\
0 . \\
2900 . \\
6300 . \\
250 . \\
46.5 \\
0 . \\
0 .\end{array}$ & $\begin{array}{c}3500 . \\
130 . \\
26 . \\
0 . \\
2500 . \\
5300 \\
250 . \\
31.8 \\
0 .\end{array}$ & $\begin{array}{c}2200 . \\
60 . \\
25 . \\
0 . \\
2100 . \\
4800 . \\
180 . \\
26.1 \\
0 . \\
0 .\end{array}$ & $\begin{array}{c}46.3 \\
18 . \\
2.9 \\
0 . \\
408 . \\
720 . \\
2.2 \\
.0042 \\
0 . \\
0 .\end{array}$ & $\begin{array}{c}42.5 \\
22 . \\
0 . \\
0 . \\
23.8 \\
66.4 \\
0.31 \\
.0048 \\
0 . \\
0 .\end{array}$ & $\begin{array}{c}35.0 \\
4 . \\
1.8 \\
0 . \\
3.8 \\
1.6 \\
0.03 \\
.0019 \\
0 . \\
0 .\end{array}$ \\
\hline $\mathrm{pH}$ & 8.1 & 7.3 & 6.6 & 6.5 & 5.9 & 7.33 & 8.42 & 7.62 \\
\hline
\end{tabular}


Novogorney well field (see Fig 2.1$)$. Liquid wastes are slightly alkaline $(\mathrm{pH} \cong$ 7.9-9.3).

The solutions contain different long-lived decay products. The more dangerous radionuclides are: Sr-90 (up to $4 \cdot 10^{-3} \mathrm{Ci} / \mathrm{L}$ ), Cs-137 (up to $9 \cdot 10^{-3}$ $\mathrm{Ci} / \mathrm{L}$ ), $\mathrm{Co}-60$ (up to $8 \cdot 10^{-7} \mathrm{Ci} / \mathrm{L}$ ), $\mathrm{Ru}-106$ (up to $2 \cdot 10^{-7} \mathrm{Ci} / \mathrm{L}$ ). So, nitrates, acetates, strontium, cobalt, tritium and ruthenium serve as indicators of pollution.

\subsection{Generalization of pumping test data} and transmissivity field construction

\subsubsection{Characterization of available test data}

The major source of information on hydraulic conductivity distribution is the pumping test data. Starting in the 1950s, several organizations performed more than 300 tests. However, their operation and interpretation have permitted us to obtain only transmissivity which is a parameter characterizing an average areal flow condition in which possible fluctuations of permeability in the profile of the strata has been smoothed or averaged.

All the test data may generally be divided into two subsets (Pozdniakov, 1996): the hard data fraction and the soft data fraction. In the hard data subset the transmissivities are estimated reasonably precisely, and in the soft data subset just the specific discharges are measured correctly during each test; for the latter the transmissivities were calculated for the given specific discharge by using the regression equation: $T=4.22 \cdot q^{0.84}$ (Pozdniakov, 1996; Drozhko et al., 1997).

Selected transmissivity values (275) were analyzed to estimate the probabilistic law of distribution. It was found (Pozdniakov, 1996) that they could be approximated by a lognormal distribution. The fitted parameters of the lognormal distribution for $\ln (T)$ are: $M_{\ln (T)}=3.62, \sigma_{\ln (T)}^{2}=2.61$. Essentially better fit is obtained by using a Gaussian distribution on $F$, where $F$ is the limited logarithmic transmissivity $F=\ln \left[\left(T-T_{\min }\right) /\left(T_{\max }-T\right)\right]$, known as Johnson's $S-V$ distribution. The fitted parameters for the transformed function $F$ are: $T_{\min }=0.4 \mathrm{~m}^{2} /$ day, $T_{\max }=900 \mathrm{~m}^{2} /$ day $M_{F}=3.08 \sigma_{F}^{2}=3.56$. The most critical difference between Johnson's $S-V$ distribution and the theoretical Gaussian curve lies in the range of probabilities greater than $85-90 \%$, where there is usually a lack of data. Therefore, for study of spatial variability of 
transmissivity, the stochastic interpolation of the logarithms of transmissivity would be used.

\subsubsection{Spatial variability of transmissivity}

For analysis of field data spatial correlation, the empirical semivariograms $\operatorname{Var}(h)$ of logarithms of transmissivity have been calculated (Pozdniakov, 1996). The semivariogram for all directions were fitted by the theoretical curve $\operatorname{Var}(h)$, which has the following components: nugget effect $\sigma_{e}^{2}$ and exponential micro-scale and large-scale semivariograms (Pozdniakov, 1996; Drozhko et al., 1997),

$$
\operatorname{Var}(h)=\sigma_{e}^{2}+\sigma_{m}^{2}\left[1-\exp \left(-h / \lambda_{m}\right)\right]+\sigma_{l}^{2}\left[1-\exp \left(-h / \lambda_{l}\right)\right]
$$

where $\sigma_{m}^{2}, \sigma_{l}^{2}$ are the ranges variances and $\lambda_{m}, \lambda_{l}$ are the scales of correlation for the given exponential components.

Parameters $\sigma_{\mathrm{e}}{ }^{2}, \sigma_{\mathrm{m}}{ }^{2}$ and $\sigma_{1}{ }^{2}$ were found to be $0.1,0.7,1.85$, respectively. Correlation scales 0.4 and 2.5 in conditional units were obtained as well, corresponding to 100 and 625 meters respectively. The total correlation scale of transmissivity is therefore of the order of seven hundred meters. From semivariogram analysis it follows that about $30 \%$ of transmissivity variability is the sum of the nugget effect $\sigma_{e}^{2}$ and the small scale variation $\sigma_{m}^{2}$, with the spatial correlation scale of about one hundred meters. Such a behavior of semivariograms demonstrates that the transmissivity field is poorly predicted by interpolation of spatial distributed data if average distances between points are greater a hundred meters.

\subsubsection{Stochastic interpolation of transmissivity}

The ordinary kriging of logarithms of transmissivity was used for creating the map of expected transmissivity value (Pozdniakov, 1996). The hard and the soft data were used together in the data set for kriging interpolation with the theoretical semivariogram described by the equation (2.1). As the result of kriging interpolation the conditional expected mean $m_{\ln (T)}$ of logarithms of transitivity in the grid nodes were defined. The conditional expected mean of transmissivity were calculated as $T=\exp \left[m_{\ln (T)}\right]$. The resulting transmissivity map is shown in Fig. 2.3. As one can see the areal distribution of the parameter proves to be complex and 


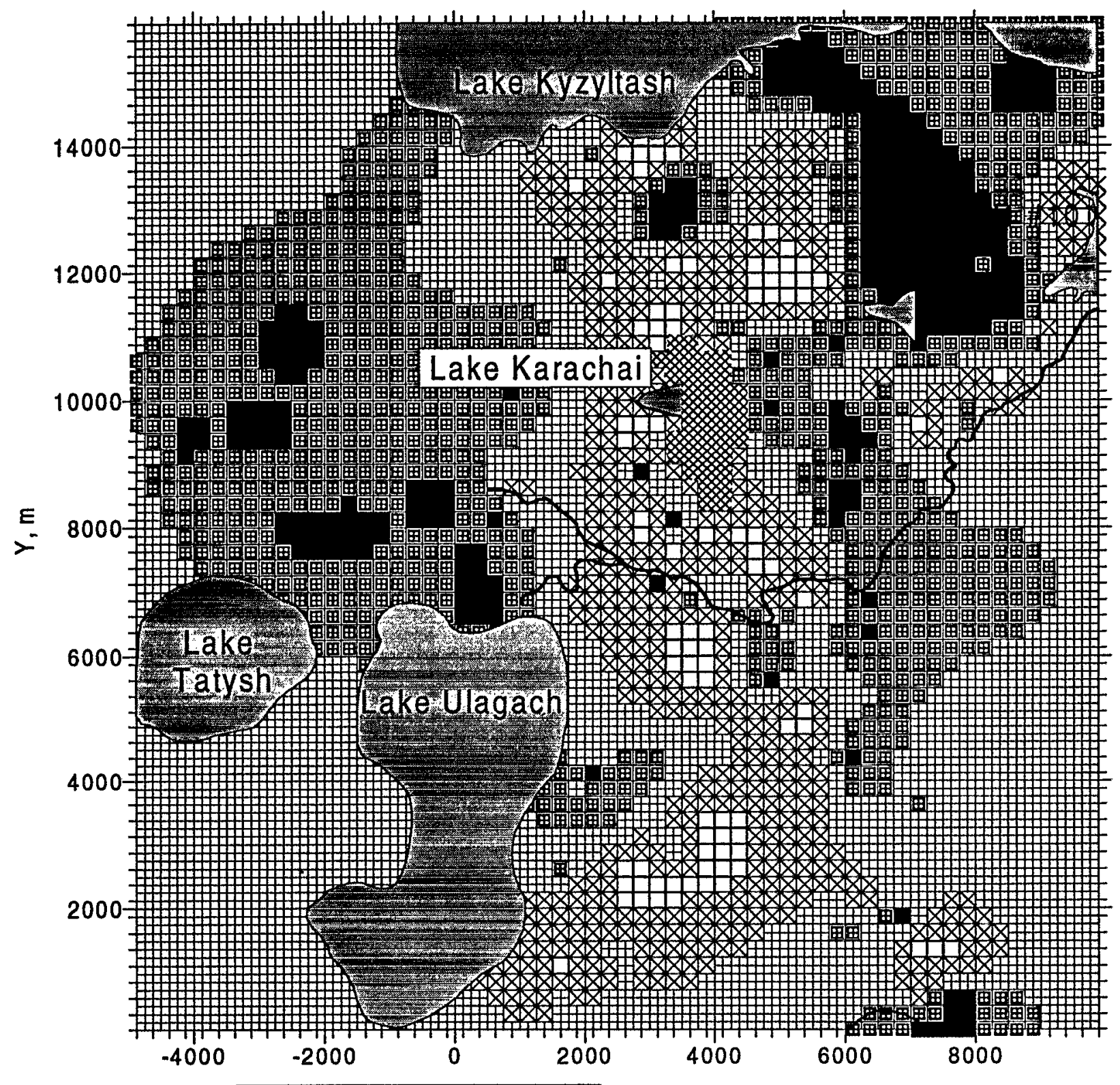

Transm issivity range, sq.m/day

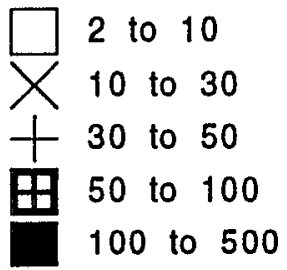

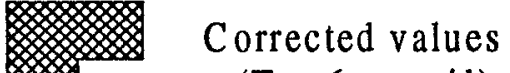

$(\mathrm{T}=6 \mathrm{sq} . \mathrm{m} / \mathrm{d})$

Fig. 2.3. A map of transmissivity classes (smoothed values) 
almost unpredictable. It represents a combination of large blocks of low transmissivity and narrow elongated zones of hightransmissivity values.

Additional analysis shows that the conditional variation very quickly grows with distance from the point of test. In the most tested area between the Lake Karachai and the Mishelyak River bank the conditional variations can increase up to 1.2 - 1.4; about half of the unconditional global variation of transmissivity field. It once again testifies "bad" predictivitivity of transmissivity field in the given region as mentioned above.

\subsubsection{Vertical distribution of permeability and its relationship with fracturing porosity}

The hydraulic conductivity distribution is nonuniform in the vertical cross-section, and one can discern 3 to 4 zones here (Mironenko et al.,1994). These are (from top to bottom):

- a low-permeability zone- 1 ( $k=0.1$ to $0.5 \mathrm{~m} /$ day),

- a relatively high-permeability zone $-2(\mathrm{k}=0.5$ to $5.0 \mathrm{~m} /$ day), and

- a low-permeability zone-3 $(\mathrm{k}<0.1 \mathrm{~m} /$ day $)$.

The existence of the upper low-permeability zone (20-40 m thick) may be due to the filling of the fractures with weathering products, and a downward permeability decrease may be accounted for by the attenuation of fracturing and/or lack of the weathering products within fractures.

Hydrogeological assessments of contaminant transport in any fractured groundwater reservoir require quantifying the relationship between hydraulic conductivity $k$ and fractured porosity $n$. This relationship could be established on the basis of the geostatistic analysis as well. Some preliminary theoretical developments supplemented with fracture frequency measurements in boreholes (Pozdniakov, 1996) shows that the field data may be approximated by equation:

$$
\frac{k}{\bar{k}} \approx\left(\frac{n}{\bar{n}}\right)^{a},
$$

where $a \approx 0.5$; when $\bar{k}=1 \mathrm{~m} /$ day, $\bar{n}=0.005$. 


\section{Identification of migration processes and their preliminary modeling analysis}

\subsection{General description of the migration process}

Based on generalized monitoring data on $\mathrm{NO}_{3}$ ion distribution hydrogeochemical cross-sections were drawn (Fig. 3.1). As one can see, due to the increased density, the plume sinks first to the aquifer bottom, then migrates laterally. The plume boundaries mapped using nitrate (a conservative component) concentrations (Drozhko and Glagolenko, 1997) are moving largely southwards and northwards from the reservoir (Fig. 3.2) at the velocity of 70 to $80 \mathrm{~m} / \mathrm{yr}$. Velocities of the radionuclides movement are noticeably lower. In the south, the advancing front of the $\mathrm{NO}_{3}$ plume has reached the Myshelyak River at depth of over $60 \mathrm{~m}$.

The predominant direction of the brine migration as well as the plume shape are not consistent with the monitored hydrodynamic data:

maximum values of potentiometric gradients take place in the northeasterly directions while the actual plume moves to the south (compare Fig. 2.1 and Fig. 3.2). This strong contradictions between hydrodynamic and ground water quality monitoring data require the development of new conceptual approaches. We are therefore faced here with a problem, which is beyond the scope of traditional hydrogeological analysis (Section 3.2).

Thus, the major factors in the unique complexity and unconventional character of the migration process at the Lake Karachai site are:

a) the complicated structure of the crystalline fractured rock, due to the presence of joints, erosion cuts, zones of weathering, etc., which predetermine strong nonhomogeneity and anisotropy in the flow properties at several scales;

b) the extensive development of 3-D density convection, complicated by large undulations of the semipermeable aquitard which result in highly irregular movement of the brine's "body";

c) the additional 3-D spreading of contaminants because of transverse dispersion and convective flow fluctuations due to periodical changes in the recharge-discharge conditions;

d) the influence of solutes diffusion into porous matrix;

e) the possible strong impact of adsorption and of some other retarding physical-and-chemical interactions onto fracture wall surfaces (modified by secondary geochemical processes) and within porous blocks; 
f) the possible enhancing migration of radionuclides due to complexation in the aqueous phase; colloid facilitated transport may play a certain role in migration potential as well;

g) the manifestation of several heterogeneity levels during the migration process, which could be quite different for some of the processes mentioned above.

\subsection{A general concept for modeling analysis}

Preliminary analysis has showed that migration of the radioactive brines is governed by parameters that have not been represented properly by the field tests and monitoring data. The plume shape is not consistent with the ground water flownet, which was obtained by water table monitoring and confirmed by numerical modeling results. One possible explanation of this situation could be that there are some structural elements in the bottom part of the aquifer, which influence the prevailing brine flow paths but do not affect the regional flow.

Thus, further analysis has to take into consideration the lack of information that may be important to this issue. Among the data which could be of interest in this context are:

1) structure of the volcanogenic bedrock at the depths associated with exogenic (weathering) fracturing development; these structural elements control the relief of the aquitard;

2) profile of the hydraulic conductivity and fractured porosity fields within the identified zones of transmissivity heterogeneity:

3) areal and cross-sectional anisotropy of hydraulic conductivity;

4) matrix porosity for different zones and rock associations;

5) rock fracture porosity within the semipermeable aquitard;

6) hydraulic resistance of the river bottom at the area of ground water discharge.

Field study of the above-mentioned characteristics meets with great difficulties. Therefore, the further development of modeling investigations requires:

- first, introduction into the modeling analysis of some strong a priori assumptions; these assumptions could be based on indirect geological-andstructural information as well as on reconstruction of a hydraulic conductivity profile with the help of borehole logging creating an initial basis for applying more sophisticated 3-D models; 

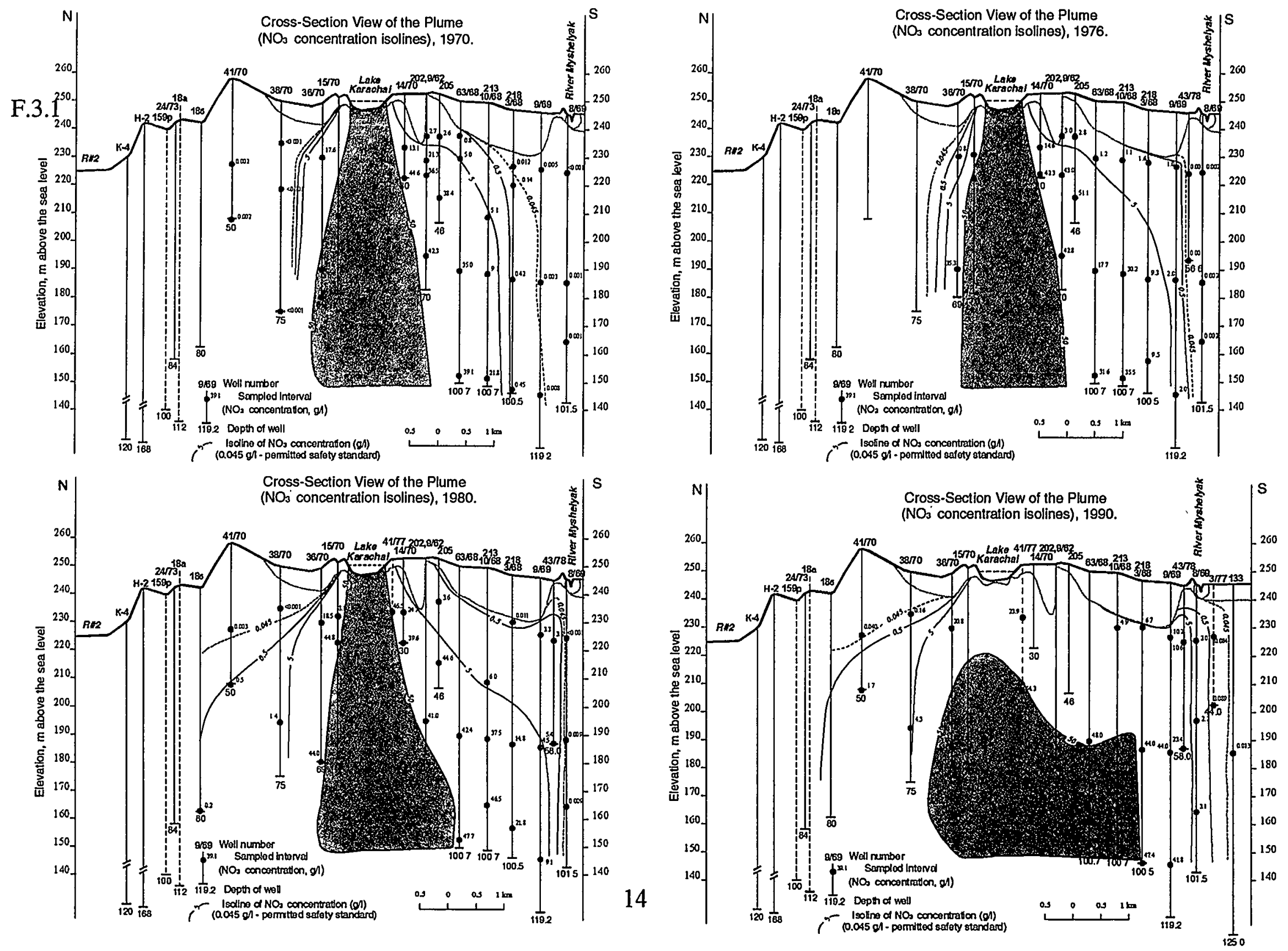


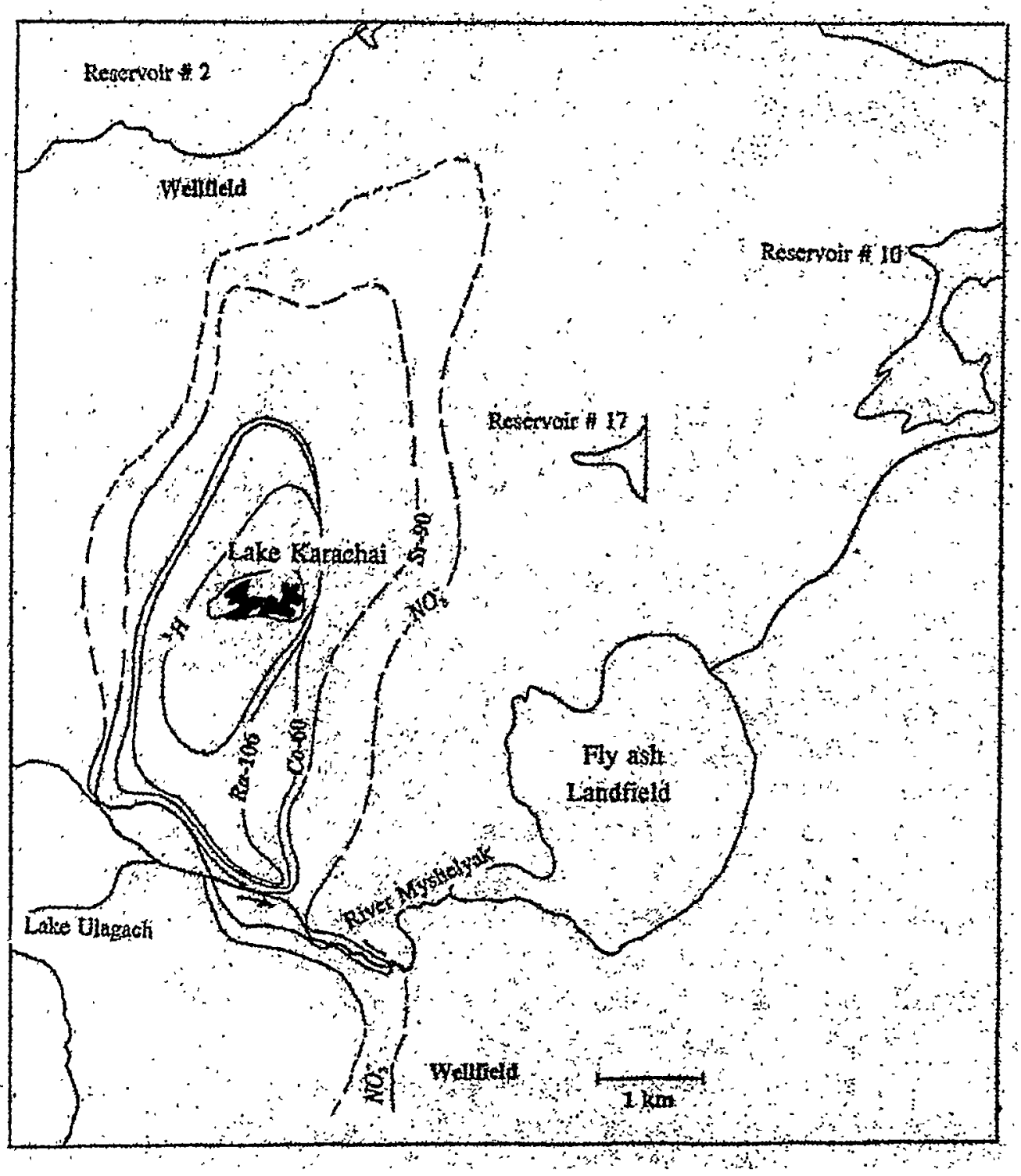

Fig. 3.2. The plume of ground water contaminated by radioactive wastes (Data of the Mayak Amalgamated Industry, 1994). Isolines corresponds to the Safety Standard Concentration Level 
- second, development of a set of alternative models, incorporating different ideas on flow-parameters and geological-and-structural features of the strata; the alternative modeling approach supplemented with the sensitivity analysis permits us to establish whether the model simulation are good enough.

For the alternative models we hypothesize the possibilities as follows: 1) the aquifer is anisotropic in hydraulic conductivity which doesn't contradict regional geological-and-structural information: sub-meridian systems of faults dominate, while sub-latitude ones are less developed; significance of the stratum anisotropy increases with depth because weathering fractures decrease;

2) there is a regional trend in the slope of the aquitard "roof" which provides for predominant salt movement in the southerly direction;

3) the two above-mentioned factors can occur simultaneously;

4) the relief of the aquitard is not flat: the depth of weathering (fractures development) varies over the area, i.e. the subsurface interface between the upper and bottom zones undulates significantly according to the surface elevation;

5) the storage capacity of the stratum is determined by both fractured and matrix porosity.

An assessment the potential fractures void within the bedrock (traditionally considered as aquitard) for contaminant accumulation could be of major importance. The problem of storage capacity is complicated due to the expected double porosity in the upper part of the water bearing rocks (above the top of the conventional aquitard). So the two types of salt storage capacity act competitively and both of them may essentially retard the lateral spreading of contaminants. However lack of monitoring data and absence of hydrogeological tests for the deep (over $100 \mathrm{~m}$ ) zone of the strata make it most difficult to determine the contribution of these factors into the contaminant migration process.

The further differentiation of the modeling approaches is based on some additional conceptual assumptions. First of all, the mass-transport potential is determined mostly by the bulk salt flux which is characterized by the current content of the total dissolved solids and solution density; the concentration of nitrate ion which dominates in the solution and correlates with its density can serve as a major nonreactive marking component. Meanwhile, spatial and temporary alterations in concentrations of the minor species (e.g. radionuclides) do not affect the overall transport potential and can be excluded from consideration. 
On the other hand, the radionuclides behavior is governed by the concentration distribution of many other dissolved components and complexed species. Therefore the prediction of radionuclides' fate requires the use of reactive solute transport models. The relevant analysis can be based on a simplified Kd approach taking into account the variability of coefficients of equilibrium distribution, or on the basis of multicomponent approach in the framework of hydrogeochemical coupled models. Physical and chemical processes can not be properly simulated separately in all cases.

The calibration and validation procedures are aimed at the proper identification of two sets of parameters:

1) one that governs the bulk flow and solute transport, and

2) one that controls radionuclides retardation.

The dependent variables are hydraulic head, concentration of nitrate, and density of solution. Calibration reliability is significantly enhanced if the model result is checked against the mass balance of solutes and flow at the outlet boundary associated with the discharge areas. Therefore the data on surface water chemistry and stream discharge rates are of special interest.

Model calibration involves a comparison between some specific simulation results and the available field observation data in order to determine applicable parameter values. The basic problem of model validation is concerned with assessing whether the assumptions and parameterizations used in the models are consistent with and able to reproduce the observed effects and processes such as advection, dispersion, and the contaminated water-rock interactions.

\subsection{D regional flow model development}

The first step of ground water dynamic and contaminant transport analysis is concerned with development of a two-dimensional regional flow model. The purposes of the relevant simulation are to:

- assess the applicability of the calculated transmissivity field (see Section

2.3) for reconstruction of the monitoring data;

- calibrate the model regarding flow parameters and regional recharge of the aquifer;

- illustrate the significance of the three-dimensional effects, taking into account the efficiency of field methods for studying parameters governing 3D solute transport;

- distinguish an appropriate sub-area for further three-dimensional analysis. 
The outlines of the modelled area coincide with the geographical borders of the regional map (Fig. 3.3). Thus the area $(15 \times 16 \mathrm{~km})$ includes major sources of ground water recharge as well as major discharging boundaries (river valleys and water supply systems) within two main watershed sub-regions (Myshelyak-Techa and Myshelyak-Zyuzelga). The area's scale significantly exceeds the detected size of the contaminant plume.

External flow boundaries of the model are associated with hydrodynamic constant head boundaries (lakes and surface artificial reservoirs) and no-flow boundaries (lines dividing ground water flow within watershed areas).

The main internal flow boundaries are the Myshelyak River valley and Lake Karachai - correspondingly boundaries of Neuman and Cauchy types. Water supply systems were modeled as a Neuman type condition. Time variations of the rate of waste leakage through the lake bottom sediments were assumed according to the actual schedule (Fig. 2.2).Water supply discharge rates were assumed to be: $1500 \mathrm{~m}^{3} / \mathrm{d}$ - for the Northern wellfield and $1000 \mathrm{~m}^{3} / \mathrm{d}$ - for the Southern (Novogorski) wellfield (Fig. 2.1).

The size of the model grids was assumed to be $250 \times 250 \mathrm{~m}$. Each model block is characterized by a transmissivity value obtained by means of the kriging interpolation procedure generalizing pumping tests data (Section 2.3.3, Fig. 2.3).

MODFLOW (Mc Donald and Harbough, 1988) and HST3D (Kipp, 1987) computer codes were concurrently used for numerical simulation.

Having assigned the transmissivity field, the first stage of model calibration was an assessment of the recharge rate distribution over the computed area. Zones of different recharge values were selected and delineated according to an assumption that there is a certain relationship between recharge rate and forms of the surface relief: the higher the elevations of the relief, the higher the values of infiltration. With the help of multi-variant steady-state computer simulation it was found that recharge rates vary for different zones of infiltration from $1.4 * 10^{-4} \mathrm{~m} / \mathrm{d}$ to $4 * 10^{-5} \mathrm{~m} / \mathrm{d}$. They are in good agreement with the range (11 to $55 \mathrm{~mm} /$ year) established by the regional balance approach.

As one can conclude from the map of the potentiometric ground 


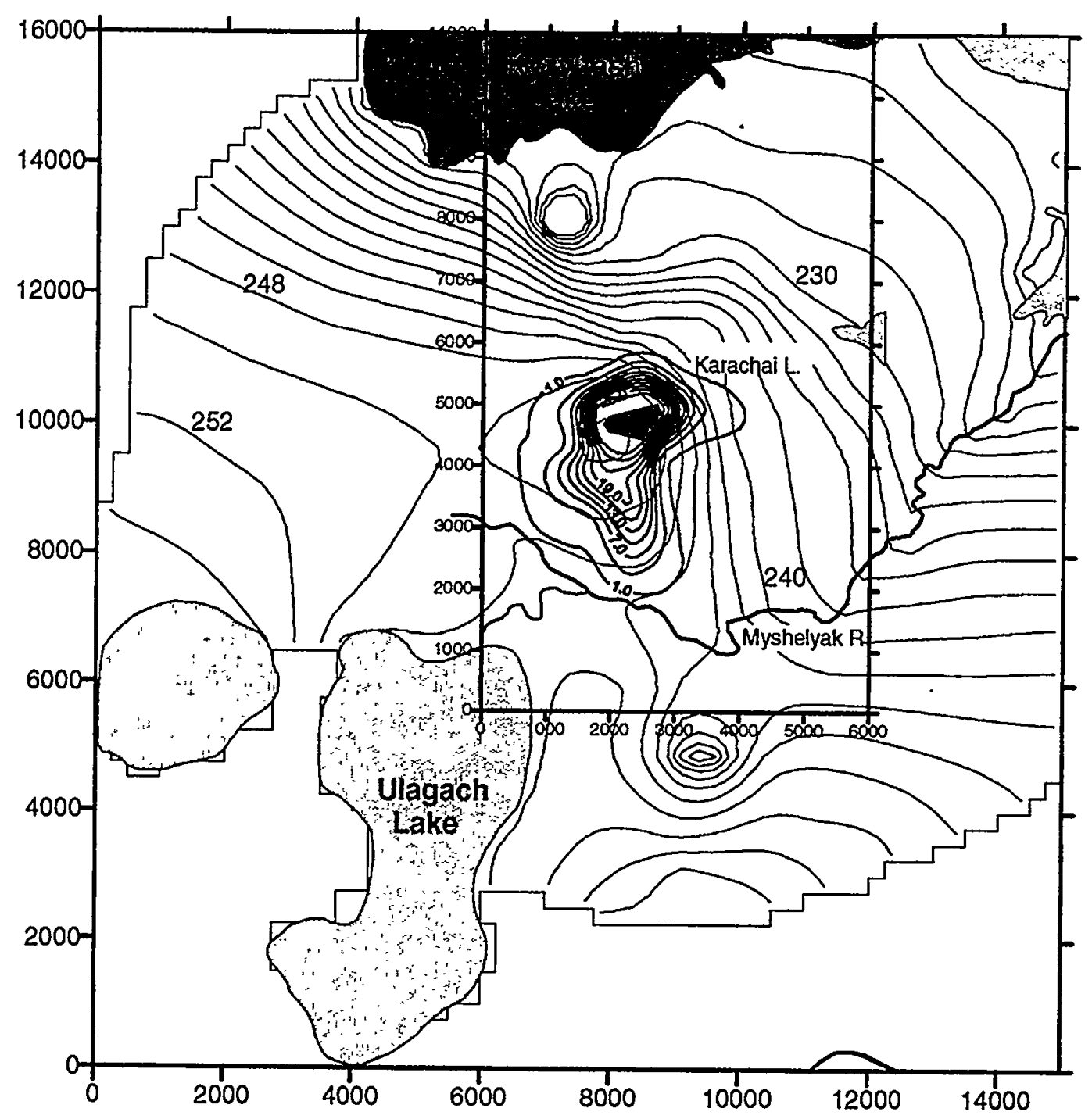

Fig. 3.3. The plume in the regional modeling frame - (elevations are meters above sea level; the plume contours are nitrate concentrations in $\mathrm{g} / \mathrm{L}$ )

water surface (Fig. 2.1), there is a high hydraulic gradient east of Lake Karachi. It is in contradiction with the interpolated transmissivity field (Fig. 2.3 ), where the area located to the east of the lake is characterized by relatively high values of transmissivity $\left(30-120 \mathrm{~m}^{2} /\right.$ day). Therefore the transmissivity within the eastern block shown in Fig. 2.3 was corrected to the value $6 \mathrm{~m}^{2} /$ day. 
Modeling results obtained on the basis of two different computer codes were rather similar. Fig. 3.3 shows the results of modeling reconstruction of the ground water potentiometric surface that is consistent with observed data (Fig. 2.1).

Meanwhile incorporation of transport module for simulating concentration distribution into the calculation procedures has shown serious drawbacks of the areal two-dimensional idealization of the flow and transport processes. Direction of predominant migration of the brines as well as the plume shape are not consistent with the monitored hydrogeochemical data: according to the 2D modeling results, contaminated water spreads into the north-eastern directions while the actual plume moves to the south. By the way, this result could be predicted from general analysis of the flow network structure as well.

\subsection{D problem investigation}

One of the working hypothesis (Section 3.2) is based on the idea that the preferable flowpaths for the high density brines are formed due to the relief of the conventional aquitard. To study the plume spreading under these conditions as well as to analyze a contribution of other factors into the migration process, a 3D model has been developed.

A 3D sub-area is selected within the regional model frame, as is shown in Fig. 3.3. The outlines of the new computed area are chosen in a manner that does not affect the plume development. The grid size was assumed to be equal to the previous regional modeling variant. The overall modeling period was divided into 9 stress-periods to specify the waste release from the surface reservoir (Table 3.1). The results of solving the $2 \mathrm{D}$ flow problem serve to set the boundary conditions for the designated 3D area.

The coarse grid doesn't permit us to obtain numerical solutions with high accuracy. Nevertheless the general tendency of the migration process and the role of factors under study is supposed be evaluated.

By variations of the permeability values for the lower layers, the relief of the aquifer bottom (shape of the subsurface interface between zones noticeably differing in hydraulic conductivity) was assigned. It was assumed that there are some degree of correlations between elevations of the surface relief and subsurface interface. The hydraulic conductivity of rocks below the interface was assumed to be $0.01 \mathrm{~m} /$ day which is at least one order of magnitude lower than the hydraulic conductivity of the upper zones. The latter conductivity was distributed according to the initial map of transmissivity. 
Two hypotheses for effective porosity of the model domain were regarded as the basic ones. The first modeling series assumed that the fractured porosity is distributed according to the relationship (2.1), e.g. ranging between 0.002 and 0.006 . The second modeling series assumed that the matrix porosity is predominant, and due to it the matrix diffusion and effective porosity can rise up to $2 \%$ (maximum value).

Multivariant modeling assessments have enabled us to come to the major results as follows.

1. In the case of neglecting the additional capacity contributed by porous blocks, the simulated plume moves towards the discharge areas with enhanced velocity that exceeds two to three times the velocity of the actual plume movement.

2. Correspondingly, an increased value of effective porosity (which is associated, in this case, with the matrix) has lead to more appropriate

Table 3.1. Characteristics of the waste leakage from Lake Karachai over stress periods

\begin{tabular}{|c|c|c|c|c|c|}
\hline & (j) & 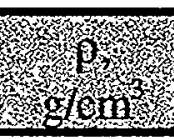 & Hy & Wha & 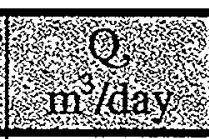 \\
\hline & $1952-1960$ & 1.09 & 65 & 1.5 & 250 \\
\hline & $1961-1967$ & 1.09 & 60 & 1.5 & 350 \\
\hline & $1968-1972$ & 1.08 & 50 & 1.5 & 320 \\
\hline & $1973-1978$ & 1.03 & 25 & 1.0 & 200 \\
\hline & $1979-1980$ & 1.03 & 26 & 1.5 & 120 \\
\hline 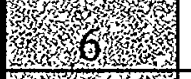 & 1981-1985 & 1.025 & 20 & 1.5 & 220 \\
\hline & $1986-1990$ & 1.025 & 18 & 2.5 & 110 \\
\hline & 1991-1992 & 1.02 & 14 & 2.0 & 60 \\
\hline & 1993-1994 & 1.02 & 12 & 2.0 & 40 \\
\hline 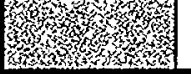 & & & & & $\sum 3.4 \mathrm{Mln} \mathrm{m}^{3}$ \\
\hline
\end{tabular}


results, i.e. to much better agreement between modeling and observed data. Plan views of the modeling plume are illustrated in Fig. 3.3.

3. Both observed and computed plumes are characterized by a presence of a high density brine intrusion - "nucleus" of solution body - in the lower part of aquifer. However, there are certain discrepancies in the corresponding maximum values of the nitrate concentration: they are up to $50 \mathrm{~g} / \mathrm{L}$ for the actual plume (Fig. 3.1), and 30-35 $\mathrm{g} / \mathrm{L}$ for the calculated plume (Fig. 3.3). The differences can be explained by numerical dispersion due to the large spatial discretization of the model domain with the coarse grid. This results in a smoothed water-brine interface.

4. Plume spreading in the southern direction is restricted by the drainage effect of the Myshelyak river valley: the contaminated water flux is separated from the area at the right bank of the Myshelyak river (Fig.3.3).

First of all the obtained results should be regarded as a confirmation of the fracture void deficit for accumulating all the volume of brines within the existing plume's boundaries above the bottom aquitard. After considering the matrix porosity as a potential capacity for waste accumulation, the model results were improved. Meanwhile, there is the another potential subsurface void which is also able to accumulate liquid wastes, i.e. fractured lowpermeability bedrock below the upper zone of the predominant sublateral flow. Development of the relevant numerical model is the subject for the special modeling analysis.

\subsection{Influence of the capacity of the conventionalaquitard on the migration process}

Among the factors that may determine the preferable flow paths for brine movement and potential rock capacity is the loss of the brines into the low-permeability zones (referred to as bedrock or conventional aquitard) confining (underlying) the upper highly permeable zone of the water bearing stratum. To study the exhibition of this factor a 3D test case model (on base of HST3D) has been created. It can be considered as a simplified variant of the 3D sub-model described above (Section 3.4). The size of the model domain, its hydrogeological characteristics and parameters (such as permeability, recharge rate and hydrodynamic gradient for background flow) were assumed to correspond to the averaged characteristics of the 3D submodel.

However the test case domain is added a deeper low- permeability zone up to $500 \mathrm{~m}$ in thickness (below the upper 100m thick zone) - Fig. 3.4. 
Permeability of this zone decreases exponentially: $\mathrm{k}(\mathrm{i})=0.5 \mathrm{e}^{-0.3 z(\mathrm{i})}[\mathrm{z}(\mathrm{i})$ is the depth from the bottom of the upper zone, $\mathrm{m} ; \mathrm{k}(\mathrm{i}), \mathrm{m} / \mathrm{d}]$. Fracture porosity decreases with depth as well because of the accepted relationship (2.1).

The main results of the modeling simulation are as follows.

1) Density-induced convection results in fast migration of the plume down to the bottom of the upper zone of the fractured massif. Then the brines start their sub-vertical movement within the low permeable zone. Despite the strong decrease of permeability with depth, brines reach the bottom of the lower zone (Fig. 3.4). Only after that, the plume spreads laterally.

2) The volume of the brines accumulated in the underlying rocks and their lateral mass-flux may be comparable with or even exceed the relevant volume for the upper zone. Obtained results and lack of monitoring data on the plume migration within the lower zone of the water bearing rocks give us an analogy with a floating iceberg, when an observer can monitor only what protrudes above the water-surface while the submerged part is invisible.

3) Interpretation of the relevant restricted data, neglecting the loss of the brines into the low-permeability zones, can lead to an unrealistic increasing calculated value of effective porosity of the fractured massif and thus to misleading forecasting results.

Therefor the conceptual modeling study disclosed the significant role of bedrock storage capacity in subsurface liquid waste accumulation and spreading.

\section{The major results of laboratory experiments}

Laboratory experiments were aimed at the study of physical and chemical mechanisms governing the transport processes at "microlevel". Among them are adsorption onto a fracture's surface and molecular diffusion into the porous matrix. Thus, matrix porosity, diffusion coefficient, cation exchange capacity, coefficients of equilibrium distribution for adsorption/desorption, influence of the concentration of sodium nitrate $\left(\mathrm{NaNO}_{3}\right)$ on sorption interactions, adsorption-desorption hysteresis (in particular, irreversibility of the adsorption process) have been studied under laboratory condition. The results of the experiments may affect the direction of theoretical study of subsurface radionuclides migration, modeling activity and numerical codes developments.

Samples of undisturbed rock core taken fromboreholes in the 


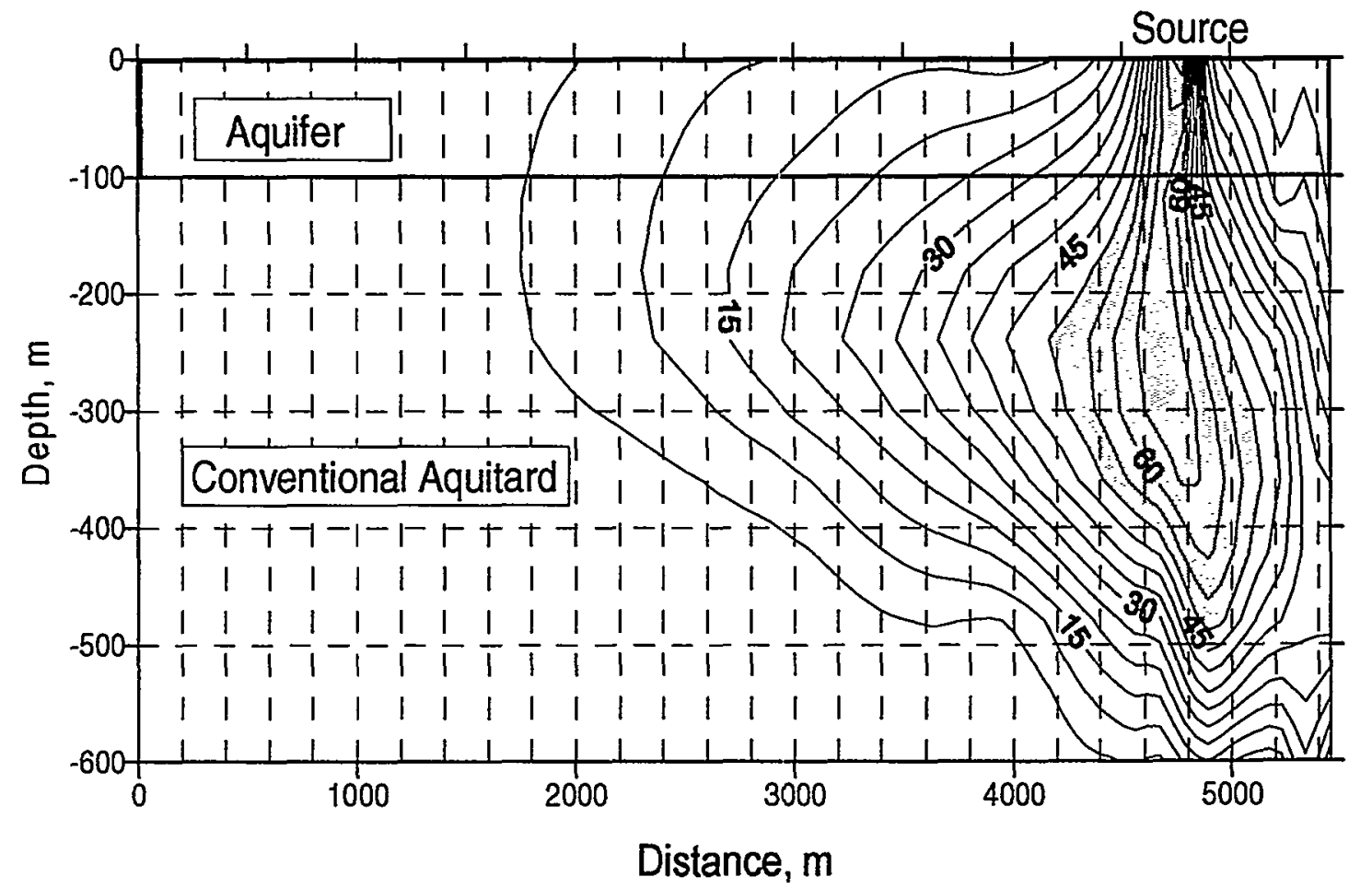

Fig. 3.4. The test case modeling result $(\mathrm{t}=30 \mathrm{yr}$.)

periphery of the plume body were used to quantify these mechanisms and parameters. The samples are represented by welded tuffs, scoriaceous lavas, tuffs, and tuff breccias moderately metamorphosed to greenschist facies; according to published data (Omelianeniko et al., 1994) the average chemical composition of the rocks in weight \% is: $\mathrm{SiO}_{2}-50.96, \mathrm{TiO}_{2}-0.84, \mathrm{Al}_{2} \mathrm{O}_{3}-$ 15.35, $\mathrm{Fe}_{2} \mathrm{O}_{3}-5.59, \mathrm{FeO}-4.84, \mathrm{MnO}-0.15, \mathrm{MgO}-8.89, \mathrm{CaO}-9.88$, $\mathrm{Na}_{2} \mathrm{O}-2.99, \mathrm{~K}_{2} \mathrm{O}-0.51$. The rocks are composed of variable quantities of pyroxene, plagioclase, amphibole, epidote, chlorite, and carbonate; pyrite, zeolite, and quartz are present as admixtures.

\subsection{Study of the adsorption process}

A set of adsorption experiments has been carried out for studying radioactive isotope of strontium sorption onto fracture walls. Three major aspects of the problem have been evaluated:

(a) type of adsorbtion/desorbtion isotherrns;

(b) influence of the $\mathrm{NaNO}_{3}$ concentration on the coefficient of equilibrium distribution $\left(K_{a}\right)$ at adsorption and desorption stages; 
(c) irreversibility of the adsorption process.

The core material (obtained from the IGEM) was taken from three different boreholes (located northwest from the Lake - uncontaminated area) within separated depth-intervals (Table 4.1). Core samples were cut into slabs in the shape of discs up to $90 \mathrm{~mm}$ in diameter and 2-4 mm thick. Sets of discs were placed into glass containers filled with $\mathrm{NaNO}_{3}$ solutions containing radiostrontium (Sr-90 or Sr-85). Three basic concentrations of $\mathrm{NaNO}_{3}$ were selected for creating hydrogeochemical environment related to the site under consideration: 1,15 and $70 \mathrm{~g} / \mathrm{L}$. This gradation corresponds to typical hydogeochemical zones of ground water contamination. The concentration of $\mathrm{NaNO}_{3}$ is considered here as a "potential - specifying function" $(M)$ because it is well known from numerous previous investigations that the content of major dissolved components like $\mathrm{NaNO}_{3}$ dramatically enhanced the intensity of interactions between dissolved trace species and mineral phases of the rock.

At the desorption step the solutions were replaced by background (noncontaminated) water.

Fig. 4.1 shows that a time period of about 100 hours is sufficient to attain chemical equilibrium between liquid and solid phases at adsorption and desorption stages.

The first set of the experiments was conducted with the goal of establishing the type of adsorption isotherms. Then, Fig. 4.2 shows an example of adsorption isotherms obtained for samples taken from borehole \#8002 (depth $938 \mathrm{~m}$ ). It is seen that the equilibrium relationship between the Sr- 85 concentration on surfaces of the discs and in liquid phases is nearly linear for all ranges of $\mathrm{NaNO}_{3}$ content in the solution.

The calculated values of the equilibrium adsorption coefficient $\left(K_{a}\right)$ strongly depend on the concentration of sodium nitrate: the more diluted the solution, the greater the value of $K_{a}$. In the majority of the experiments with highly concentrated solutions ( $70 \mathrm{~g} / \mathrm{L})$, values of $K_{a}$ were found to be less then $0.04 \mathrm{~cm}$ (Table 4.2$)^{1} ;$. In the diluted solutions ( $1 \mathrm{~g} / \mathrm{L}$ ) values of $K_{a}$ are at least 5 to 10 times greater.

The relationship between $K_{a}$ and $\mathrm{NaNO}_{3}$ content $(M)$ can be approximated by the following equation:

\footnotetext{
${ }^{1}$ No correction made for matrix diffusion/sorption.
} 
Table 4.1. Characteristics of studied rock-samples

\begin{tabular}{|c|c|c|c|c|c|c|}
\hline $\begin{array}{c}\text { Rock } \\
\text { characteristic }\end{array}$ & $\begin{array}{l}\text { Number } \\
\text { of } \\
\text { borehole }\end{array}$ & $\begin{array}{c}\text { Interval, } \\
\mathrm{m}\end{array}$ & $\begin{array}{l}\text { Num- } \\
\text { ber of } \\
\text { expe- } \\
\text { riment }\end{array}$ & $\begin{array}{c}\text { Sample } \\
\text { weight, } \\
\mathrm{g}\end{array}$ & $\begin{array}{c}\text { Square } \\
\text { of } \\
\text { surface, } \\
\mathrm{cm}^{2}\end{array}$ & $\begin{array}{c}\text { Porosity } \\
\text { (determined by } \\
\text { water saturati- } \\
\text { on method), \% }\end{array}$ \\
\hline \multirow{3}{*}{$\begin{array}{l}\text { Tuff-and-lava, } \\
\text { tuff }\end{array}$} & \multirow{3}{*}{$1-96$} & \multirow{3}{*}{$98-100$} & 1 & $=$ & 287 & $=$ \\
\hline & & & 2 & 89.45 & 254 & 0.11 \\
\hline & & & 3 & 100.9 & 222 & 0.26 \\
\hline Tuff-and-lava & $1-96$ & 16 & 4 & 96.0 & 278 & 0.20 \\
\hline Lava breccias & 8002 & 690 & 5 & - & 221 & - \\
\hline \multirow{3}{*}{ Tuff-and-lava } & \multirow{3}{*}{$1-96$} & \multirow{3}{*}{71} & 6 & 61.13 & 139 & 0.13 \\
\hline & & & 7 & 61.00 & 133 & 0.11 \\
\hline & & & 8 & 60.00 & 150 & 0.15 \\
\hline \multirow{3}{*}{ Tuff } & \multirow{3}{*}{$1-96$} & \multirow{3}{*}{26} & 9 & 128.35 & 173 & 0.20 \\
\hline & & & 10 & 91.51 & 172 & 0.38 \\
\hline & & & 11 & 81.62 & 171 & 0.44 \\
\hline \multirow{3}{*}{ Lava breccias } & \multirow{3}{*}{$211^{A}$} & \multirow{3}{*}{-} & 12 & 76.14 & 231 & 0.20 \\
\hline & & & 13 & 96.30 & 256 & 0.18 \\
\hline & & & 14 & 71.34 & 160 & 0.18 \\
\hline
\end{tabular}

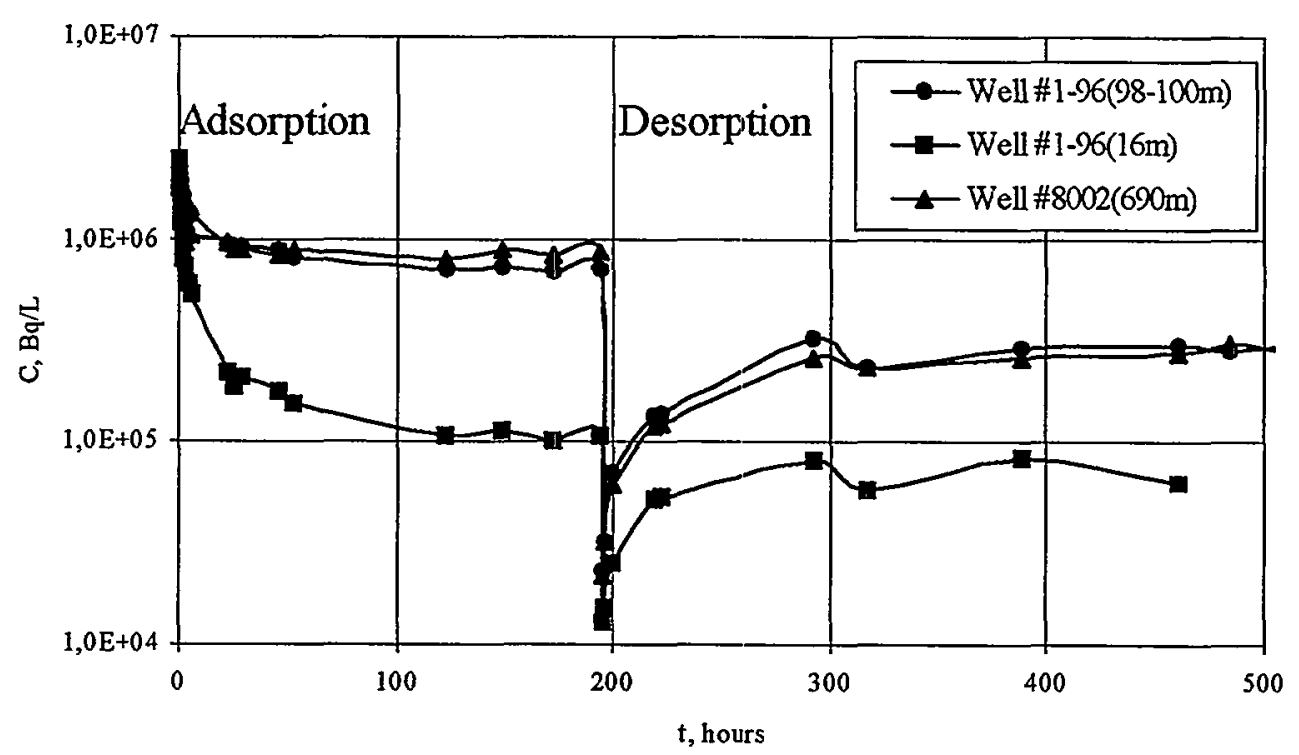

Fig. 4.1. The kinetic curves of adsorption and desorption (radiostrontium) processes 


$$
K_{a}=K_{a_{1}} e^{-i M}+K_{a_{2}},
$$

where the sum of $K_{a 1}$ and $K_{a 2}$ correspond to the coefficients of adsorption in diluted solutions and $K_{a 2}$ - in concentrated solutions. The average value of $\gamma$ is $0.2 \mathrm{~L} / \mathrm{g}$ - Fig. 4.3. In section 5.1 it will be shown that coefficients $K_{a I}$ and $K_{a 2}$ characterize adsorption in different types of reaction sites in the mineral phase of the rock.

Table 4.2. Calculation of the equilibrium distribution coefficients

\begin{tabular}{|c|c|c|c|c|c|c|c|c|}
\hline $\begin{array}{l}\text { Num- } \\
\text { ber of } \\
\text { expe- } \\
\text { ri- } \\
\text { ment }{ }^{1)}\end{array}$ & $\begin{array}{l}\mathrm{Ra}- \\
\text { dio- } \\
\text { nuc- } \\
\text { lide }\end{array}$ & 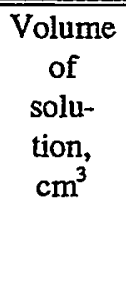 & $\begin{array}{c}\mathrm{NaNO}_{3} \\
\text { content, } \\
\mathrm{g} / \mathrm{L}\end{array}$ & $\begin{array}{l}\text { Initial } \\
\text { concent- } \\
\text { ration of } \\
\text { radio- } \\
\text { nuclide } \\
\cdot \mathrm{Bq} / \mathrm{L}\end{array}$ & $\begin{array}{l}\text { Adsorp- } \\
\text { tion step: } \\
\text { Equilib- } \\
\text { rium } \\
\text { concent- } \\
\text { ration } \\
\mathrm{Bq} / \mathrm{L}\end{array}$ & $\begin{array}{c}\text { Desorp- } \\
\text { tion step: } \\
\text { Equilib- } \\
\text { rium } \\
\text { concent- } \\
\text { ration } \\
\mathrm{Bq} / \mathrm{L}\end{array}$ & $\begin{array}{l}\text { Adsorp- } \\
\text { tion } \\
\text { distribu- } \\
\text { tion } \\
\text { coeffi- } \\
\text { cient, } \\
\mathrm{K}_{\mathrm{d}}^{\mathrm{s}}, \mathrm{cm}\end{array}$ & $\begin{array}{c}\text { Desorp- } \\
\text { tion } \\
\text { distribu- } \\
\text { tion } \\
\text { coeffi- } \\
\text { cient }^{33} \text {, } \\
\mathrm{K}_{\mathrm{a}}{ }^{d}, \mathrm{~cm}\end{array}$ \\
\hline 1 & Sr-90 & 120 & 1.0 & $2.5 \cdot 10^{6}$ & $1.06 \cdot 10^{6}$ & $3.07 \cdot 10^{5}$ & 0.57 & 1.54 \\
\hline 2 & Sr-90 & 100 & 15 & $2.54 \cdot 10^{6}$ & $1.67 \cdot 10^{6}$ & $1.2 \cdot 10^{52)}$ & 0.21 & 1.0 \\
\hline 3 & Sr-90 & 100 & 70 & $3.0 \cdot 10^{6}$ & $2.13 \cdot 10^{6}$ & $0.3 \cdot 10^{52)}$ & 0.18 & 11.7 \\
\hline 4 & Sr -90 & 120 & 1.0 & $2.5 \cdot 10^{6}$ & $4.65 \cdot 10^{5}$ & $6.45 \cdot 10^{4}$ & 1.89 & 12.8 \\
\hline 5 & Sr-90 & 120 & 1.0 & $2.5 \cdot 10^{6}$ & $1.22 \cdot 10^{6}$ & $2.9 \cdot 10^{5}$ & 0.57 & 1.85 \\
\hline 6 & $\mathrm{Sr}-85$ & 100 & 1.0 & $5.28 \cdot 10^{6}$ & $3.72 \cdot 10^{6}$ & $3.1 \cdot 10^{5}$ & 0.31 & 2.9 \\
\hline 7 & Sr-85 & 60 & 15 & $7.38 \cdot 10^{6}$ & $6.62 \cdot 10^{6}$ & $7.6 \cdot 10^{4}$ & 0.05 & 4.1 \\
\hline 8 & $\mathrm{Sr}-85$ & 70 & 70 & $4.22 \cdot 10^{6}$ & $3.90 \cdot 10^{6}$ & $2.1 \cdot 10^{4}$ & 0.04 & 6.6 \\
\hline 9 & Sr-85 & 100 & 1.0 & $5.28 \cdot 10^{6}$ & $0.75 \cdot 10^{6}$ & $6.0 \cdot 10^{3}$ & 3.49 & 436 \\
\hline 10 & Sr-85 & 70 & 15 & $7.38^{-1} 10^{6}$ & $4.45 \cdot 10^{6}$ & $1.2 \cdot 10^{4}$ & 0.27 & 99 \\
\hline 11 & Sr-85 & 70 & 70 & $4.22 \cdot 10^{6}$ & $3.88 \cdot 10^{6}$ & $2.0 \cdot 10^{3}$ & 0.04 & 69 \\
\hline 12 & Sr-85 & 100 & 1.0 & $5.28 \cdot 10^{6}$ & $3.60 \cdot 10^{6}$ & $2.99 \cdot 10^{5}$ & 0.20 & 2.0 \\
\hline 13 & Sr-85 & 120 & 15 & $7.38 \cdot 10^{6}$ & $6.83 \cdot 10^{6}$ & $2.70 \cdot 10^{4}$ & 0.04 & 9.1 \\
\hline 14 & Sr-85 & 100 & 70 & $4.22: 10^{6}$ & $3.97 \cdot 10^{6}$ & $1.60 \cdot 10^{4}$ & 0.03 & 9.1 \\
\hline
\end{tabular}

Notes: '1) column's numbering corresponds to Table $4.1{ }^{2)}$ desorption under constant $\mathrm{NaNO}_{3}$ content; ${ }^{3)}$ no correction made for irreversibility of adsorption process.

Obtained values of $K_{a}$ can serve as a basis for calculation of the retardation factor $(R)$, characterizing the relationship between velocities of the subsurface migration of water particles and strontium:

$$
R=1+\frac{K_{a} S_{b}}{n},
$$

where $S_{b}$ is the specific area of fractures. The values of this parameter 


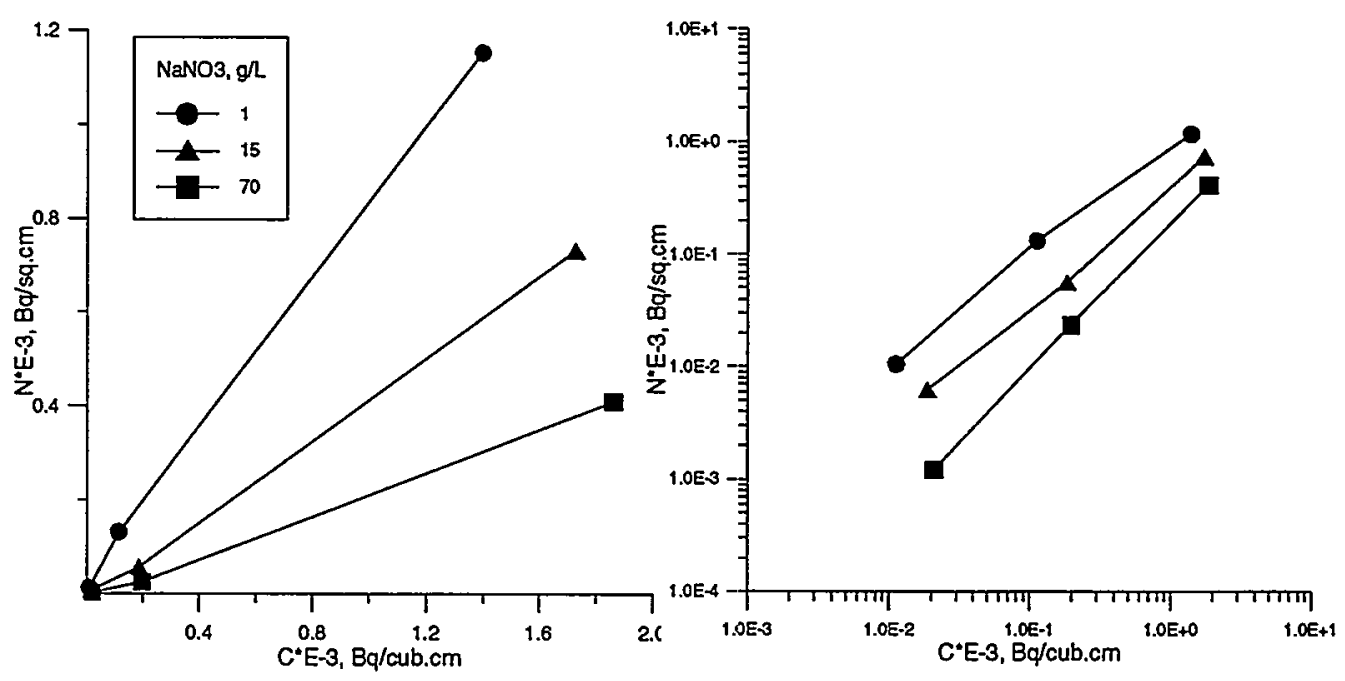

Fig. 4.2. Adsorption isotherms: linear- scaled (a) and log- scaled (b) axes (well \#8002, depth $938 \mathrm{~m}$ )

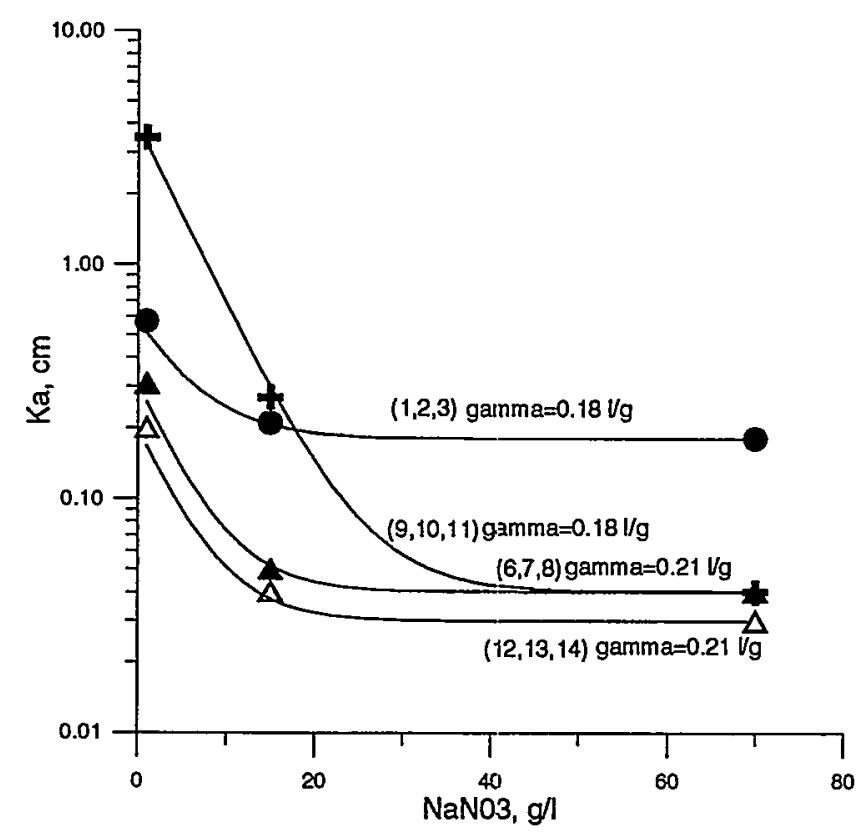

Fig. 4.3. Influence of $\mathrm{NaNO}_{3}$ content on the distribution coefficient (theoretical curves are calculated on base of equation 4.1) 
vary in range 0.5 to $5.0 \mathrm{~m}^{-1}$. For this range and the average fractured porosity $n=0.5 \%$ the retardation factor has been obtained according to the following Table.

\begin{tabular}{|l|l|l|l|}
\hline$K_{a, \mathrm{~cm}} S_{b}, \mathrm{~cm}^{-1}$ & 0.005 & 0.01 & 0.05 \\
\hline 1.0 & 2 & 3 & 11 \\
\hline 0.04 & 1.04 & 1.08 & 1.4 \\
\hline
\end{tabular}

As one can see from this Table and equation (4.1), the velocity of strontium migration within the plume body can vary depending on the extent of the water saturation by sodium nitrate. Radiostrontium in the highly concentrated solution (which forms the "nucleus" of the plume) behaves similarly to a conservative component $(R \approx 1)$; at the periphery of the plume strontium retards due to adsorption $(R>>1)$.

These characteristics of radiostrontium migration are confirmed by observation data. For instance, the revealed tendency is illustrated by a combined graph in Fig. 4.4, which generalizes hydrogeochemical data obtained in the process of sampling the observation wells located between Karachai Lake and Mishelyak River (the path of preferable radioactive waste migration). One can see that there is a strong relationship between strontium and nitrate concentrations in the aquifer: the field of strontium spreading in noticeable concentrations ( $>\mathrm{N} \cdot 10^{-8} \mathrm{Ci} / \mathrm{L}$ ) within the plume is confined by the nitrate concentration isoline of $10 \mathrm{~g} / \mathrm{L}$. Thus, the laboratory results do not contradict the observed data.

Hysteresis of adsorption was studied in the process of step-by-step desorption of previously adsorbed radiostrontium (at the end of each desorption step the radioactive solution was replaced by free-radioactivity water). Measured concentration points at the adsorption and two-step desorption stages of the laboratory experiments for two core-samples are depicted in Fig. 4.5 and Fig. 4.6.

Analysis of the obtained experimental results shows: 1) all desorption concentration points are located above the adsorption isotherms, i.e. desorption isotherms do not coincide with adsorption isotherms; because of strong changes in the chemical environment ( $\mathrm{NaNO}_{3}$ content in the solution), the equilibrium concentration points $N^{s}\left(C^{s}\right)$ obtained at the end of the adsorption stage do not belong to the desorption 

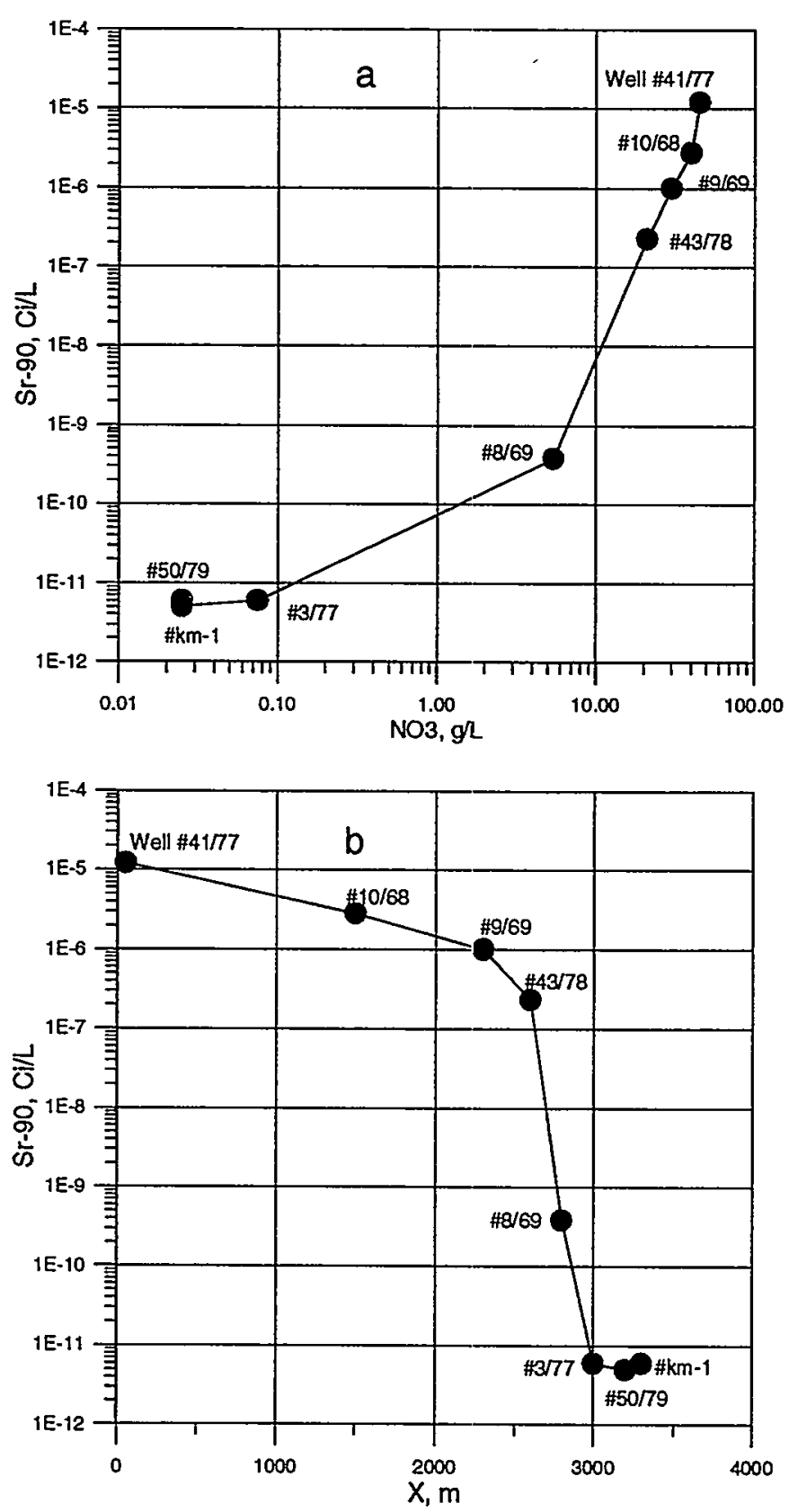

Fig. 4.4. Sr-90 distribution versus $\mathrm{NO}_{3}{ }^{-1}$ content (a) and distance from the source (b) 
a

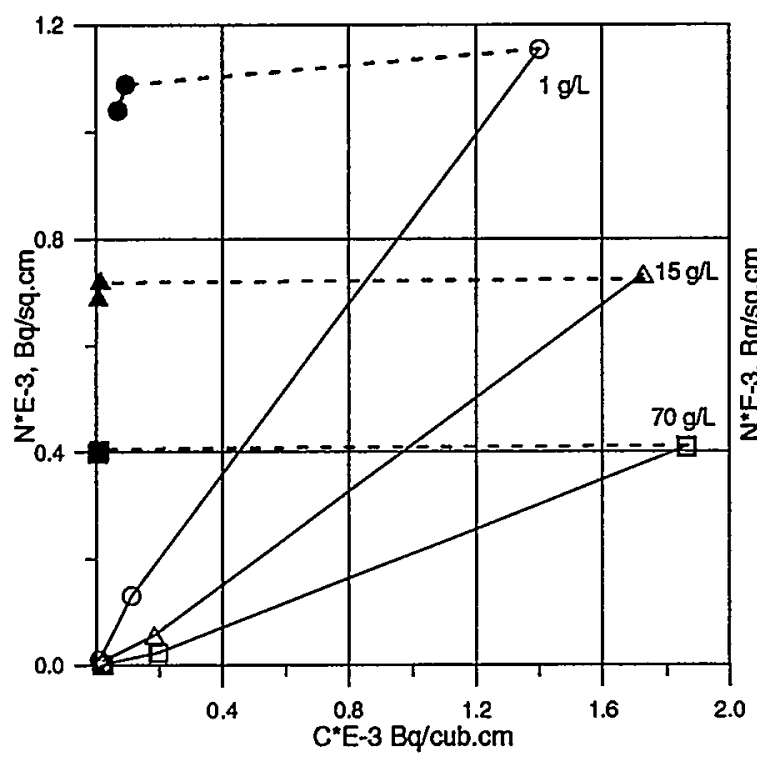

b

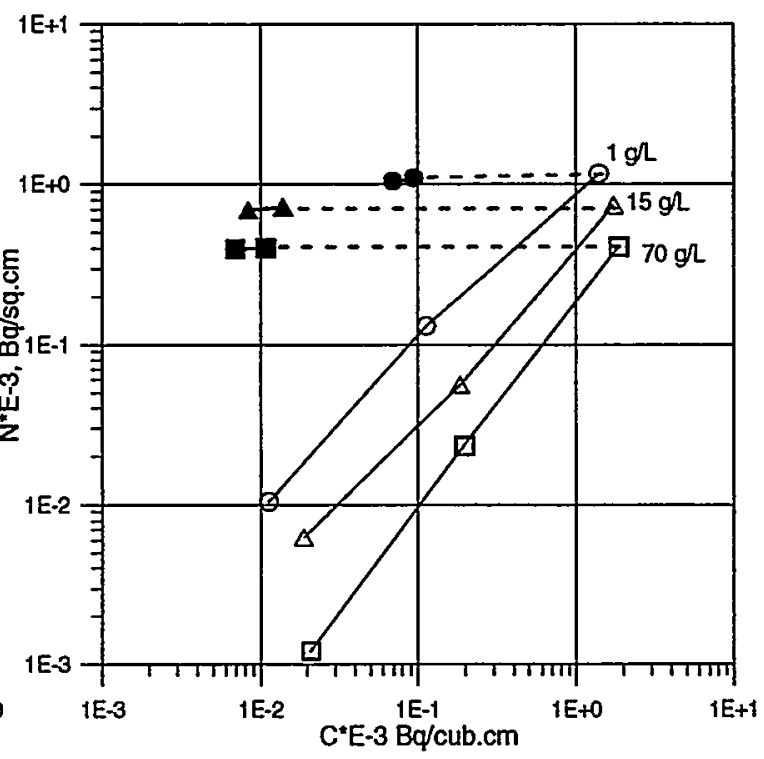

Fig. 4.5. Graphical representation of results of the adsorption/desorption experiments (core-samples from well \# 8002, depth $938 \mathrm{~m}$ ): linear-scaled (a) and log-scaled (b) axes

isotherms: $N(C)$-function doesn't exist between the concentration points $N^{s}\left(C^{s}\right)$ and $N^{d}\left(C^{d}\right)$ [where $N^{d}$ and $C^{d}$ are the equilibrium concentrations in the solid and liquid phases at the first desorption step]; 2) magnitude of the drop in the concentration of radiostrontium at the desorption stage (first step) is very low for high concentrated (regarding to $\mathrm{NaNO}_{3}$ content at the desorption stage) solution; it seems that the rock enables to adsorbnoticeable amount of radionuclides but is not able to release them at the desorption stage, i.e. $\mathrm{NaNO}_{3}$ content controls the reversible adsorption capacity of the solid phase.

Results of some multi-steps desorption experiments (Fig. 4.7) can be considered as an evidence of irreversibility of the adsorption process. For the concentrated solutions obtained values of the irreversible adsorption capacity $\left(N_{0}\right)$ tend to value $N_{0}=K_{a 2} * C_{0}$, where $C_{0}$ is the radionuclide concentration at the end of adsorption stage. 
a

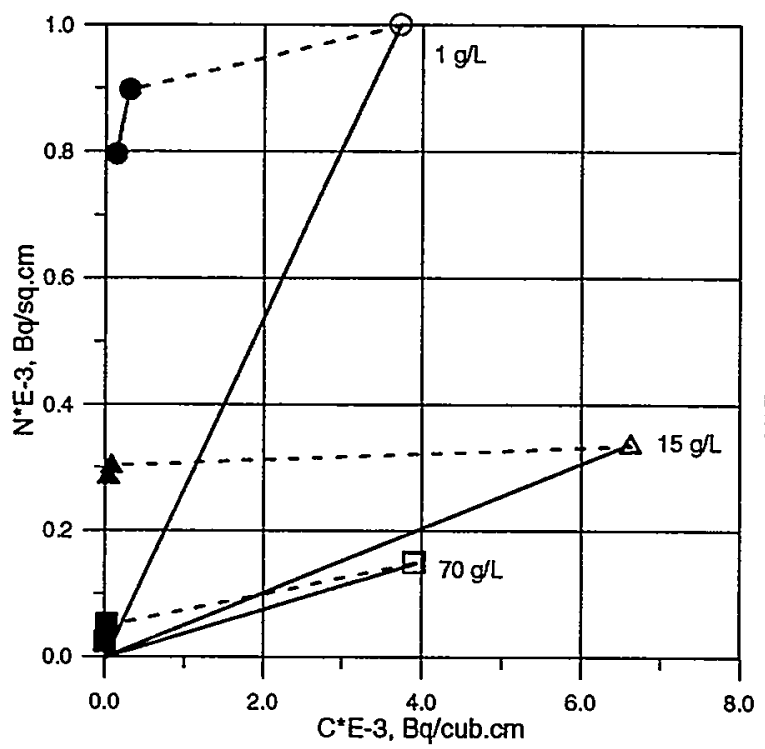

b

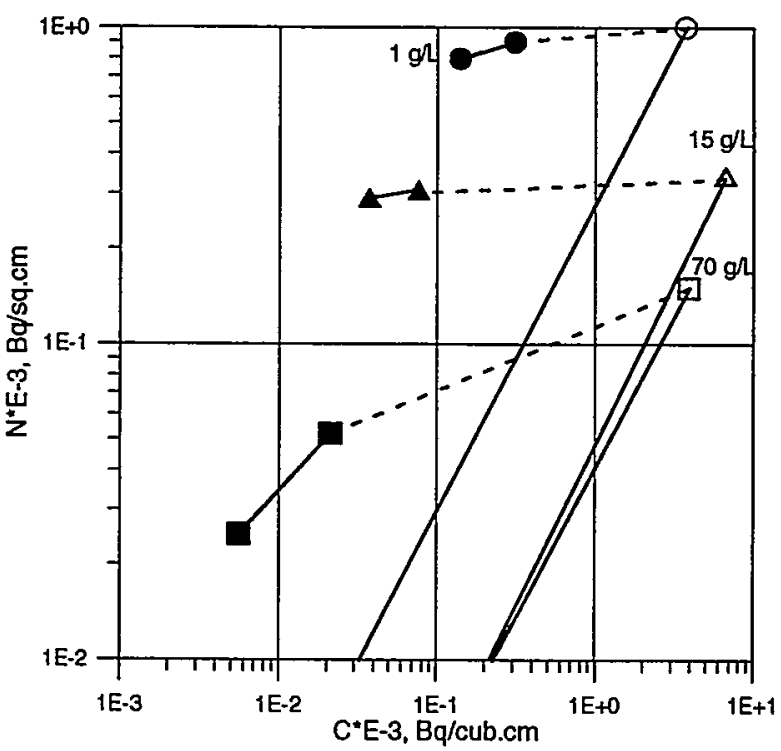

Fig. 4.6. Graphical representation of results of the adsorption/desorption experiments (core-samples from well \# 1-96, depth $71 \mathrm{~m}$ ): linear-scaled (a) and log-scaled (b) axes

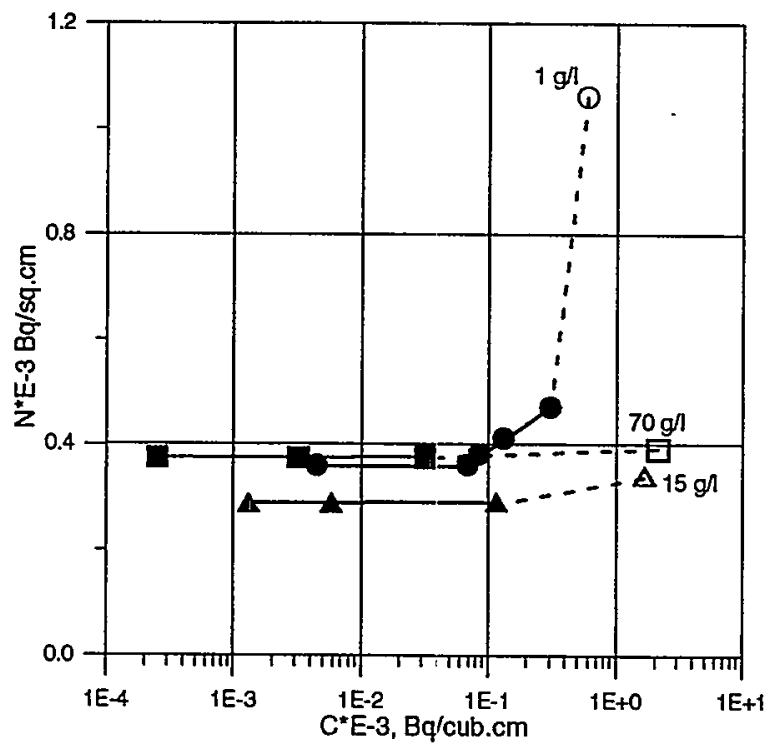

Fig. 4.7. Desorption curves for different concentrations of $\mathrm{NaNO}_{3}$ : well \# 1-96 (98-100 m) 


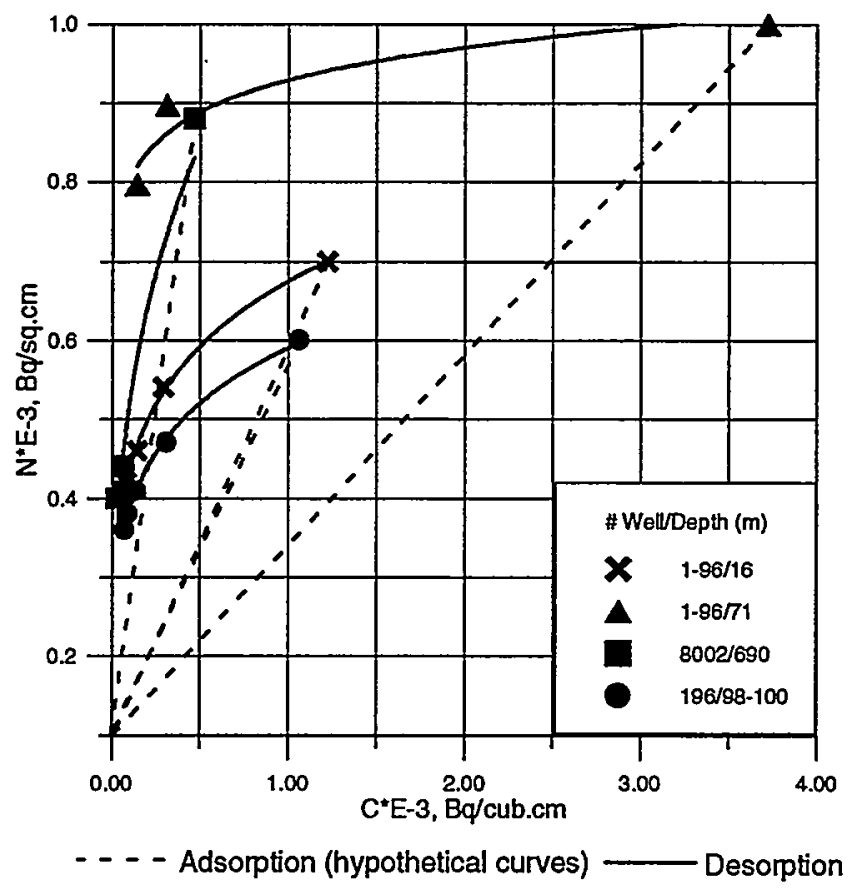

Fig. 4.8. Desorption isotherms $\left(C_{\mathrm{NaNO}}=1 \mathrm{~g} / \mathrm{L}\right)$

Fig. 4.8 shows the desorption isotherms which were obtained for a lowconcentrated solution $\left(C_{\mathrm{NaNO} 3}=1 \mathrm{~g} / \mathrm{L}\right)$. Because of small changes of the $\mathrm{NaNO}_{3}$ content we can consider the last concentration points $N^{s}\left(C^{s}\right)$ at the adsorption stage and the first desorption points in the graph $N(C)$ to be belonged to the adsorption and desorption isotherms: $N(C)$-function is uninterrupted. It is seen that in this case desorption isotherms exhibit a slightly nonlinear character. The irreversible adsorption capacity was estimated to be about $4 \cdot 10^{5} \mathrm{~Bq} / \mathrm{m}^{2}$.

Further, it was established that the desorption coefficients $K_{a}^{d}$ [calculated according to the traditional balance approach (Vandergraaf and Arby, 1982; Wels et al., 1996), which neglects the adsorption irreversibility] significantly exceed adsorption coefficients $K_{a}$ : the greater the concentration of $\mathrm{NaNO}_{3}$ in the solution at the adsorption stage, the greater is the calculated ratio $K_{a}^{d} / K_{a}$ (Fig. 4.9). This means that desorption of radionuclides initially adsorbed in the highly concentrated solutions is limited.

At the same time the provisional scheme of desorption experiments is rather questionable. So, in the further laboratory investigations it is supposed to be modified in favor of more realistic boundary conditions. 


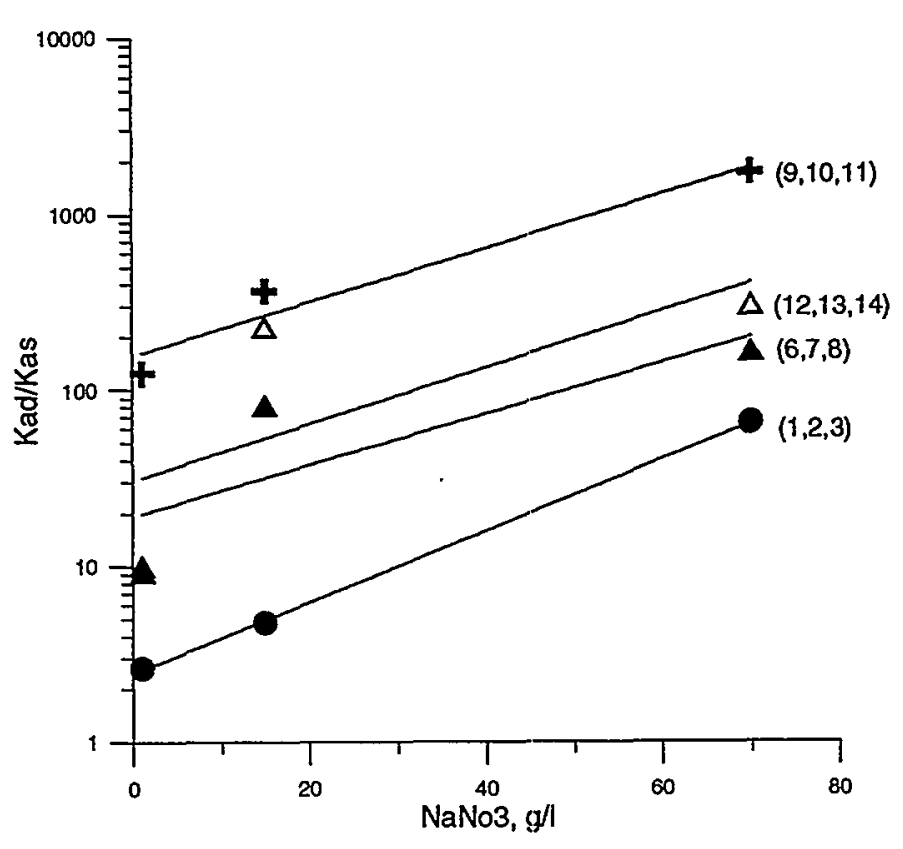

Fig. 4.9. Ratio $K_{a}^{d} / K_{a}$ versus $\mathrm{NaNO}_{3}$ content

\subsection{Diffusion experiments}

Molecular diffusion through discs prepared from the core samples has been studied with the help of the so-called "double-camera" device. It consists of a reception (measurement) camera filled before the experiment with distilled water (its volume is denoted as $V_{k}, 20-30 \mathrm{ml}$ ), and a camera containing the "working" solution (volume is $V_{0}>>V_{k}$ ). They are separated by the investigated core sample (thickness is $\mathrm{h}_{\mathrm{k}}, 2-4 \mathrm{~mm}$; area is $\mathrm{F}$ ). Iodide ion (in form of $\mathrm{KJ}$ electrolyte, $0.1 \mathrm{M}$ ) and an isotope of $\mathrm{Sr}\left({ }^{85} \mathrm{Sr}\right.$ ) served as major components to study nonreactive and reactive species diffusion.

For interpretative purpose a solution of the 1D mass-transport equation

$$
n_{o} \frac{\partial C}{\partial t}=D_{M} \frac{\partial^{2} C}{\partial x^{2}}
$$

has been obtained as follows: 


$$
\bar{C}_{k}=2\left[\operatorname{erfc}\left(\frac{1}{2} \sqrt{\frac{\alpha}{t}}\right)-e^{\sqrt{\alpha} \beta+\beta^{2} t} \operatorname{erfc}\left(\frac{1}{2} \sqrt{\frac{\alpha}{t}}+\beta \sqrt{t}\right)\right],
$$

where $\bar{C}_{k}=C_{k} / C_{0}\left(C_{0}\right.$ is the boundary concentration);

$$
\alpha=\mathrm{n}_{0} \mathrm{~h}^{2} / \mathrm{D}_{\mathrm{M}}, \beta=F \sqrt{n_{o} D_{M}} / V_{k} .
$$

The solution is valid when $t<0.1 h^{2} n_{d} / D_{M}$, therefore the initial part of breakthrough curves $C_{K}(t)$ are to be interpreted by means of matching theoretical curves (Equation 4.4) and adjusting the two dimensionless parameters $\alpha$ and $\beta$ (Equation 4.4,a).

Fig. 4.10 depicts an example of the interpretation of laboratory data on iodide-ion diffusion based on such an approach. With known values of $\alpha$ and $\beta$, one can calculate two parameters - the coefficient of molecular diffusion $\left(D_{M}\right)$ and the porosity of the rock matrix $\left(n_{0}\right)$. Table 4.3 summarizes the results of the experiments, and shows that coefficient $D_{M}$ varies within the range $10^{-7}$ to $10^{-8} \mathrm{~m}^{2} /$ day. It may be mentioned that the porosity values obtained in the diffusion cell are noticeably higher than the values found by the traditional water saturation approach - see Tables 4.1 and 4.3. In the majority of the experiments parameter $n_{0}$ exceeds $1 \%$. These results can be considered as evidence of the additional capacity of the double-porosity rocks regarding electrolyte solutions.

In some diffusion experiments the motion of solvent opposite to the direction of the dissolved components diffusion was monitored, i.e. osmosis took place. The role of this process in overall subsurface transport of the radioactive liquid wastes is to be determined by further laboratory experiments.

\subsection{Assessment of the cation exchange capacity}

This parameter has been evaluated in the latest stage of the diffusion experiments. For this purpose, the solution taken from the measurement cell was analyzed to establish concentration of $\mathrm{Ca}^{2+}$ and $\mathrm{Mg}^{2+}$ ions. It is assumed that these ions were replaced by the sodium ion. Additionally, the cation exchange capacity was assessed in batch experiments: the core material was placed into $\mathrm{NaNO}_{3}$ solution, so $\mathrm{Na}^{+}$- ion replaced calcium and magnesium in the mineral phase of the rock. All experimental results are included in Table 4.4 . 


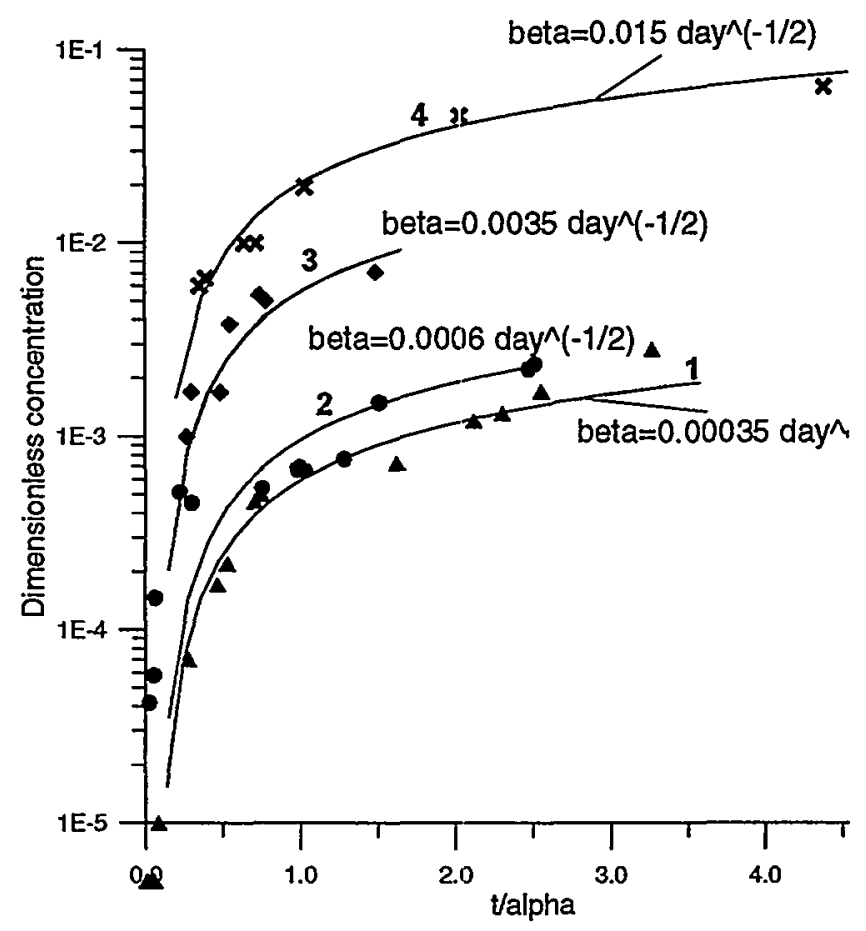

Fig. 4.10. Experimental data and their approximation by theoretical curves

Table 4.3. Results of interpretation of diffusion experiments

\begin{tabular}{|c|c|c|c|c|c|c|c|c|}
\hline No & Rock & $\begin{array}{c}\text { Well } \\
\#\end{array}$ & $\begin{array}{c}\text { Depth, } \\
\mathrm{m}\end{array}$ & $\begin{array}{c}\text { Com- } \\
\text { ponent }\end{array}$ & \multicolumn{2}{|c|}{ From curve fitting } & \multicolumn{2}{|c|}{ From Equation (4.4) } \\
\cline { 6 - 9 } & & & & & $\begin{array}{c}\alpha, \\
\mathrm{d}\end{array}$ & $\begin{array}{c}\beta, \\
\mathrm{d}^{-1 / 2}\end{array}$ & $\begin{array}{c}\mathrm{D}_{\mathrm{M}}, \\
\mathrm{m}^{2} / \mathrm{d}\end{array}$ & $\begin{array}{c}\mathrm{n} / \mathrm{n}_{0}{ }^{1)} \\
\%\end{array}$ \\
\hline 1 & Tuff-and-lava & $1-96$ & $98-100$ & $\mathrm{~J}$ & 4.0 & 0.0006 & $3.3 \cdot 10^{-8}$ & $1.4 / 0.2$ \\
\hline 2 & Tuff-and-lava & $1-96$ & 71 & $\mathrm{~J}$ & 4.5 & 0.00035 & $2.8 \cdot 10^{-8}$ & $0.7 / 0.13$ \\
\hline 3 & Tuff-and-lava & $1-96$ & 16 & $\mathrm{~J}$ & 3 & 0.015 & $5.1 \cdot 10^{-7}$ & $8.3 / 1.3$ \\
\hline 4 & Tuff & 8002 & 838 & $\mathrm{~J}$ & 4 & 0.0035 & $2.1 \cdot 10^{-7}$ & $7.7 / 0.1$ \\
\hline 5 & Tuff & $1-96$ & 26 & ${ }^{95} \mathrm{Sr}$ & 2.5 & 0.018 & $5.7 \cdot 10^{-7}$ & $8.1 /-$ \\
\hline 6 & Tuff-and-lava & $1-96$ & 62 & ${ }^{95} \mathrm{Si}$ & 4.2 & 0.0004 & $5.8 \cdot 10^{-9}$ & $0.3 /-$ \\
\hline
\end{tabular}

Note: ${ }^{1)}$ Diffusion experiment (Equation 4.4)/Water saturation method (Table 4.1). 
As one can, see the cation exchange capacity of the undisturbed rocksamples in the majority of experiments was found to be within a rather narrow range varying from 17 to $19 \mathrm{mg}$-eqv/L; there was only one value outside this range (Table 4.4).

Table 4.4. The cation exchange capacity

\begin{tabular}{|c|c|c|c|c|}
\hline Rock & Well's \# & Depth, $\mathrm{m}$ & $\mathrm{Q}_{\mathrm{v}}, \frac{m g-e q v}{L}$ & $\begin{array}{l}\mathrm{E}_{\mathrm{v}} \\
\frac{m g-e q v}{100 g}\end{array}$ \\
\hline Tuff-and-lava $^{1)}$ & $1-96$ & $98-100$ & $17.0(8.5+8.5)^{3)}$ & 0.6 \\
\hline Tuff-and-lava $^{1)}$ & $1-96$ & 71 & $17.8(9.6+8.2)$ & 0.6 \\
\hline Tuff-and-lava $^{1)}$ & $1-96$ & 16 & $16.0(8.0+8.0)$ & 0.5 \\
\hline Tuff $^{1)}$ & 8002 & 838 & $16.7(5.5+11.2)$ & 0.6 \\
\hline Tuff-and-lava $^{2)}$ & $1-96$ & $98-100$ & $19.0(10.0+9.0)$ & 0.6 \\
\hline Tuff-and-lava $^{2)}$ & $1-96$ & 16 & $86.0(50.0+36.0)$ & 3.0 \\
\hline
\end{tabular}

Notes: ${ }^{1)}$ experiments in the diffusion cells, ${ }^{2}$ batch experiments with $\mathrm{NaNO}_{3}$ solutions; ${ }^{3)}$ in brackets: $\mathrm{Ca}^{2+}+\mathrm{Mg}^{2+}$.

\subsection{Conclusions}

Laboratory experiments were aimed at the study of physical and physical-and-chemical mechanisms governing the transport processes at the "microlevel". Samples of undisturbed core-rock were used to quantify these mechanisms.

The major findings are as follows:

(1) A set of adsorption experiments have been carried out for studying radiostrontium sorption onto fracture walls; three aspects of the problem have been evaluated:

(a) type of adsorption and desorption isotherms; - it was found out that the adsorption isotherms are of near linear character while the desorption isotherms are slightly nonlinear;

(b) influence of the concentration of $\mathrm{NaNO}_{3}$ on the coefficients of equilibrium distribution $\left(K_{a}\right.$ and $\left.K_{a}^{d}\right)$, and on extent of the nonlinearity of the desorption isotherms, - it was found that values of the distribution adsorption coefficient tend to decrease with the increasing dissolved solutes content (concentration of $\mathrm{NaNO}_{3}$ ); the ratio $K_{a}^{d} / K_{a}$ increases with the increasing $\mathrm{NaNO}_{3}$ content; 
(c) irreversibility of the adsorption process, - laboratory experiments allowed us to reveal some adsorption-desorption hysteresis effects; in this context, the desorption "stage" of the experiments suggest processes that will take place at the Lake Karachai Site during the natural remediation period (the latter starts when wastes' leakage through the lake bottom will be completed); it follows that analytical and numerical models are to be developed to determine the impact of nonlinear and irreversible character of the adsorption/desorption upon the migration processes (Section 5).

(2) The subsurface geological environment represented by metavolcanic rocks is a media with fairly well (not too "strong") displayed double-porosity properties :

(a) matrix porosity $\left(n_{0}\right)$ established with the water saturation method varies within the range 0.1 to 0.5 percent;

(b) values of the same parameter determined in the diffusion cells with the help of chemically conservative (J-) tracer are found to be noticeably greater; the revealed phenomenon is known from the journal literature, and it has been noticed also in our previous experiments with other rocks; this phenomenon may play a significant role in evaluation of the rock storage capacity relating to the radioactive wastes at the site under consideration, and it has to be investigated on the theoretical level and checked in further laboratory experiments;

(c) the diffusion coefficient $\left(D_{M}\right)$ was found to be within the range $10^{-8}$ to $10^{-}$ ${ }^{7} \mathrm{~m}^{2} / \mathrm{d}$. This parameter characterizes the intensity of diffusion for nonreactive species (like $\mathrm{NO}_{3}{ }^{-}$ion) into the porous matrix; in some experiments osmosis occured;

(d) concurrently the exchange cation capacity of the undisturbed rocksamples was determined: with only one exception it varies from 17 to $19 \mathrm{mg}$ eqv/L.

These results help to specify the future modeling developments, - it seems reasonable, in particular:

1) to take into account in the numerical code's algorithms the kinetically controlled mass-exchange between fractured and matrix systems (through the first order kinetic term in the basic finite difference equations);

expected range of values of the mass-exchange parameter $\alpha_{\mathrm{M}}, \alpha_{\mathrm{M}}=S_{b}^{2}{ }^{2} D_{M}$, may be within $10^{-8}$ to $10^{-5}$ day $^{-1}$ (where $S_{b}$ is the specific surface of porous blocks, $D_{M}$ is the coefficient of matrix diffusion);

2) to develop approaches for modeling reactive (adsorbing) components' migration under variable ion strength conditions (for the brine migration forms a hydrogeochemical environment which controls radioactive species transport, 
i.e. total dissolved solutes variations within the plume body influence parameters of adsorption/desorption processes); in so doing the irreversible character of the sorption process is to be taken into account.

\section{Development of analytical and numerical models for studying the subsurface transport of the irreversibly adsorbing components}

The main purpose of the following analysis is to find out how the phenomena revealed by the laboratory investigations can affect the nonconservative component redistribution within the contaminated site. In fact, the revealed hysteresis of the sorption/desorption process has to be considered as an impotant factor during natural remediation of the subsurface environment, when the contaminants are supposed to be flushed out of fractures and matrix by fresh water. In this report one-dimensional transport of an adsorbing trace component will be considered under the condition of variable content of principal species (which specify the ionic and molecular forms of the component migration).

\subsection{Exponential dual-site adsorption model}

We hypothesize that there are two types of reaction sites within the mineral phases of the rock: those (reaction sites $D$ which appear to adsorb components rapidly and reversibly, and those (reaction sites II) which do not release components at the desorption stage, i.e. adsorption is irreversible. Such a division is facilitated by the differences in the nature of the physical and chemical interactions: for the reactive sites I the electrostatic (nonspecific or physical) interactions between solutes and the mineral surface are prevailing, while for the reactive sites II interactions are of a more strong, specific (or chemical) character (Pickens et al., 1981). The electrostatically adsorbed components desorb easier and move away from the contaminated zone of the aquifer, while the specifically adsorbed components (strongly bound to the mineral phase) are left within the initially contaminated zone.

A mathematical formulation of the problem can be derived using $\mathrm{Kd}$ approach. Adsorption and desorption stages (Fig. 5.1, a) of the reversible process can be described by the linear equations: 


$$
N_{l}=K_{l} C, \quad N_{l}^{d}=K_{l} C,
$$

where $N_{1}$ and $N_{1}^{d}$ are the adsorbed concentrations for the sites I at the adsorption and desorption stages, $C$ is the concentration in the liquid phase, and $K_{I}$ is the equilibrium constant.

Specific adsorption of the component is also of a linear character

$$
N_{2}=K_{2} C
$$

(Fig. 5.1, a), where $N_{2}$ is the adsorbed concentration at the reaction sites II, $K_{2}$ is the equilibrium constant.

During the desorption stage, the concentration at the sites II remains constant and is equal to value of $N_{o}$ which is reached at the end of desorption stage when $C=C_{0}$, i.e.

$$
N_{2}{ }^{d}=N_{0}\left(C_{0}\right),
$$

where $N_{o}$ is the "undesorbed" concentration (the irreversible adsorption capacity) of the specifically adsorbed component.

Total adsorption $N$ and desorption $N^{d}$ can be obtained by summing the adsorbed concentrations $N_{1}$ and $N_{2}, N_{l}{ }^{d}$ and $N_{2}{ }^{d}$ as follows :

$$
\begin{aligned}
& N=\left(K_{1}+K_{2}\right) C \\
& N^{d}=N_{0}\left(C_{0}\right)+K_{1} C .
\end{aligned}
$$

In this context, it is understandable that commonly used coefficient $K_{d}$ (or $K_{a}$, its analog for fractured reservoirs) is the sum of the partial coefficients

$$
K_{d}=\left(K_{I}+K_{2}\right) / \rho, \quad \text { or } \quad K_{a}=\left(K_{I}+K_{2}\right) / S_{b}
$$

The resulting isotherm is of a hysteresis character - Fig. 5.1, a : for the irreversible process the desorption curve of the isotherm crosses over its adsorption branch and could be characterized by two parameters namely $K_{1}$ and $N_{0}$.

Migration of non-conservative trace components within actual contaminant plumes occurs under a condition where the content of principal species is variable. The ionic strength I of dissolved solutes $M$ can be considered as an external potential specifying function (EPS-function) $\varphi$, which controls the intensity of chemical interactions between solid and liquid 
phases. In particular, one can expect that current values of equilibrium adsorption/desorption

a

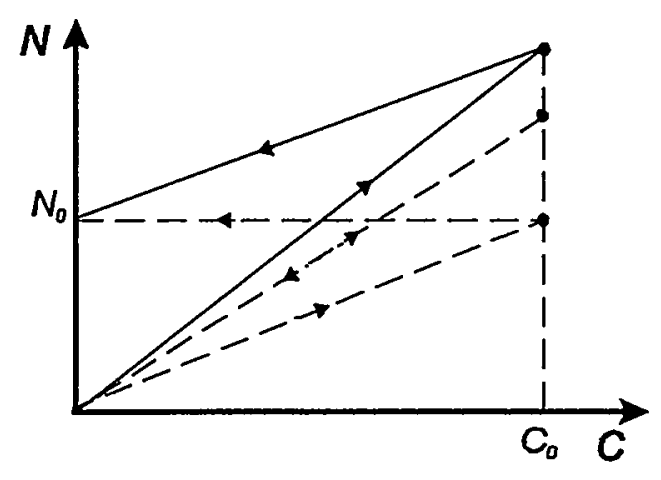

6

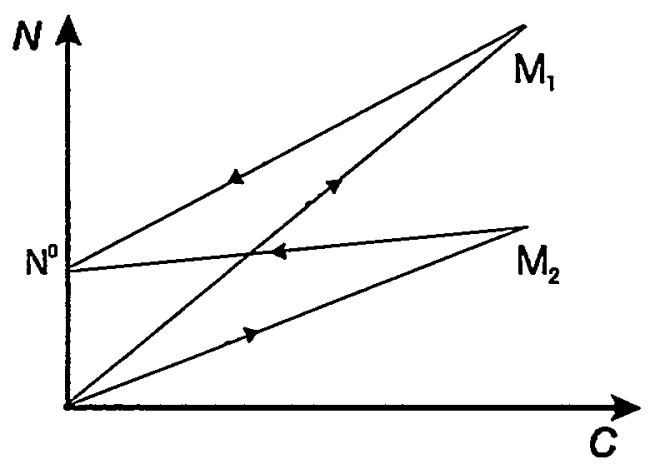

Fig. 5.1. Isotherms of the irreversible adsorption/desorption process $\left(M_{2}>M_{1}\right)$

coefficients depend on $M$. Equation (4.1) represents an example of the relationship between $K_{a}$ and $M$ characteristics.

It could be supposed that increasing $M$ leads to an exponentially decreasing intensity of the electrostatic interactions taking place at the reaction sites I, i.e. $K_{1}=k_{1} e^{-\gamma M}$ At the same time variations of $M$ weakly affect the intensity of the specific component adsorption at the reaction sites II, i.e. $K_{2}=k_{2}=$ const. Total adsorption and desorption isotherms (Fig. 5.1, b) are therefore as follows:

$$
\begin{aligned}
& N=k_{1} e^{-\gamma M} C+k_{2} C \equiv K(M) C \\
& N^{d}=N_{0}+k_{1} e^{-\gamma M} C \quad\left[N_{0}=k_{2} C_{0}\right] .
\end{aligned}
$$

The sum of the coefficients $k_{1}$ and $k_{2}$ is associated with the distribution coefficient in dilute solutions $\left(M \rightarrow 0, K \rightarrow k_{1}+k_{2}\right)$ while the 

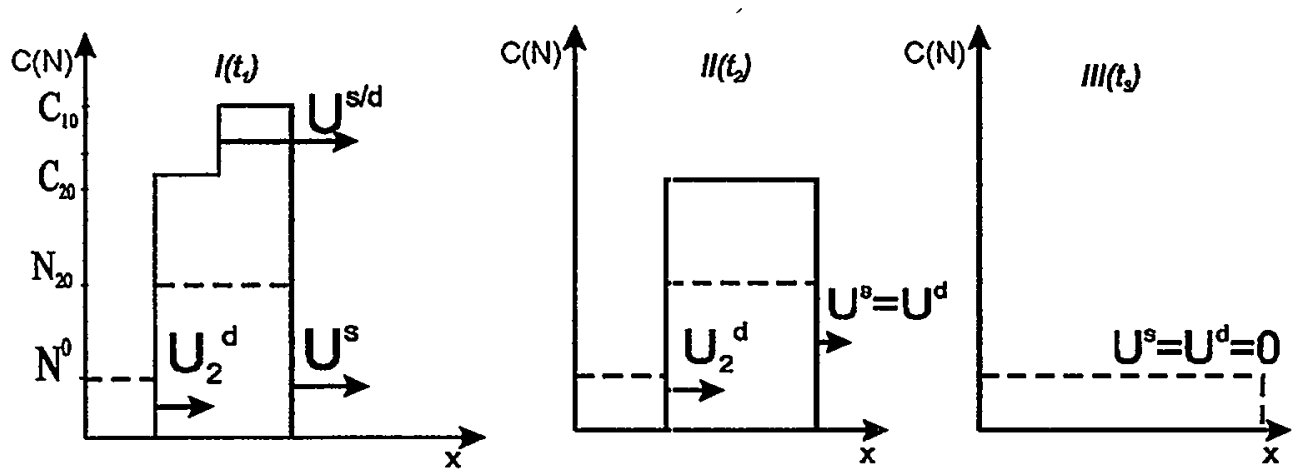

Fig. 5.2. Schematic representation of the evolution of $C$-sharpinterface wave at different stages of the migration process

coefficient $k_{2}$ is associated with the distribution coefficient in solution containing dissolved salts in high concentration ( $M>>0 K \rightarrow k_{2}$ ). By analyzing the relationships (5.5), we suggest that the mass-transport potential of the trace component might be changed by fluctuations of the boundary conditions or by hydrodynamic mechanisms resulting in dispersion (or dilution) of wastes within the plume.

Analytical expressions in form (5.5) for irreversible adsorption are fairly consistent with experimental data obtained for radiostrontium (Section 4.1). In this connection we are concerned with two aspects: 1) calculated adsorption distribution coefficients decrease exponentially with increasing $M$, which is associated with the sodium nitrate content in the solution (Fig. 4.2 and 4.3$) ; 2$ ) the intensity of desorption, or in other words, ability for releasing previously adsorbed components also depends strongly on $M$ : the greater the value of $M$ at the adsorption steps, the flatter the desorption curves with respect to the abscissa in graphs $N$-C (Fig. 4.6); the desorption coefficients increase correspondingly with increasing $M$ value. Thus, theoretical findings are in fair agreement with the experimental material.

The equilibrium model may be considered as a particular variant of a more general model which takes into account that desorption from reactive sites II that is rate limited. The non-equilibrium stage of the desorption process can be approximated by a first order kinetic equation as follows:

$$
\frac{\partial N}{\partial t}=\alpha^{d}\left(C-\frac{N}{K_{1}}\right),
$$

where $\alpha^{\mathrm{d}}$ is the kinetic constant; $N=N_{2}$. 


\subsection{Analytical description of the multi-wave migration process}

\subsubsection{Equilibrium model}

For convenience we assume that the contaminated water (waste) is represented by brine (solution containing dissolved salts in high concentrations and a trace component). The principal components of the dissolved salts behave as conservative species, or at least migrate with velocities $(u=v / n)$ that exceed the velocity of the trace component (its concentration is defined as $C$ ). This allows us to assume that the sorption/desorption process takes place in a steady-state hydrochemical setting, which is conditioned by the dissolved salts. In this case the concentrations of the salts are indifferent to variations of the trace element concentration in both the liquid and solid phases. The total concentration $M$ of dissolved salts can be considered as a magnitude of the EPS-function $\varphi$. We will further assume that the type of the input $\varphi$ - and $C$ - functions is of a discontinuous (package-wise) character, resulting from changes in composition of the inflowing solution.

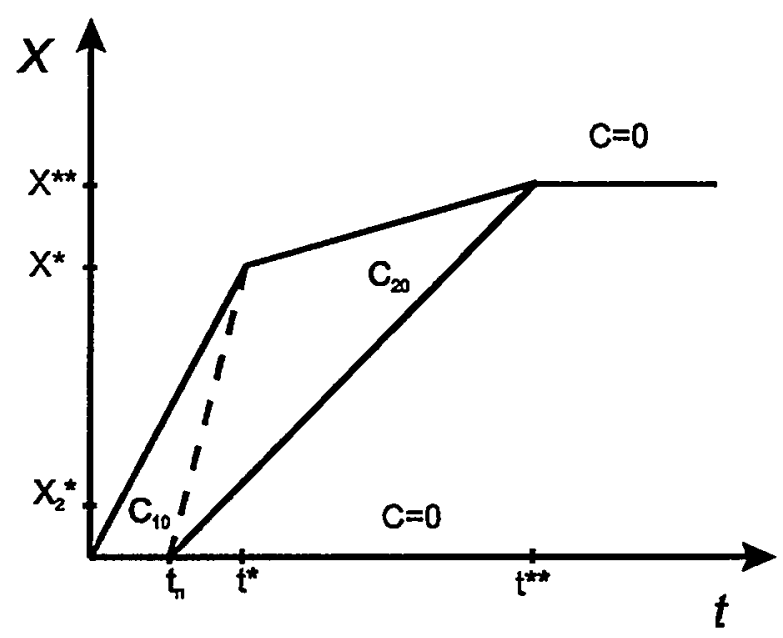

Fig. 5.3. Graph of the characteristics 
This can be occur when at a certain moment $t=t_{n}$ the initially contaminated zone within the 1D domain $\left(M=M_{2}\right.$ - initial magnitude of the $\varphi$ - wave, $C=C_{10}$ - the boundary concentration of the adsorbed component in liquid phase $)$ is to be displaced by fresh water $\left(M=M_{I}, C=0\right)$.

Let us assume that the "package" (input functions) is characterized by sharp interfaces which are forming $M$ - and $C$ concentration waves (Fig. 5.2 and 5.3). At the initial stage of the transport process there are three principal concentration fronts of the C-wave: 1) an advancing interface which moves with the velocity $u^{s}$; obviously, the magnitude of $u^{s}$ is defined by adsorption constant $\left.K_{2}=K\left(M_{2}\right) ; 2\right)$ a back edge which migrates with the velocity $u_{2}^{d}$ which is determined by the desorption process $\left(u^{d}{ }_{2}\right.$ needs for special assessment) and 3) an intermediate (neutral) interface which migrate with the velocity of the principal component $u$.

An irreversibility of the adsorption process leads to formation of a contaminant-free zone $\left(C=0, N=N_{0}\right)$ between the desorption front and inflow boundary $(x=0)$. Due to the differences in $u_{2}^{d}$ and $u$ velocities, the original shape of the wave is distorted. A new equilibrium concentration $C_{20}$ (Fig. 5.2) can be found on base of isotherm analysis (Fig. 5.1) assuming that the amount of $N\left(C_{20}\right)$ is to be equal to $N\left(C_{10}\right)$ :

$$
C_{20}=\frac{K_{2} C_{10}-N_{0}}{K_{1}} \text {. }
$$

In order to determine the velocity $u_{2}^{d}$ a balance equation is composed as follows:

$$
\begin{aligned}
& C_{10} v t_{n}=N_{0} u_{2}^{d}\left(t-t_{n}\right)+\left[C_{20}\left(n+K_{1}\right)+N_{0}\right]\left(u^{s / d}-u_{2}^{d}\right)\left(t-t_{n}\right) \\
& +C_{10}\left(n+K_{2}\right)\left[u^{s} t-u^{s / d}\left(t-t^{n}\right)\right] .
\end{aligned}
$$

Hence

$$
u_{2}^{d}=\frac{v}{n+K_{1}} .
$$

One can see that the back edge of the adsorption wave migrates independently on amount of the irreversibly adsorbed component $\mathrm{N}_{0}$ ): 


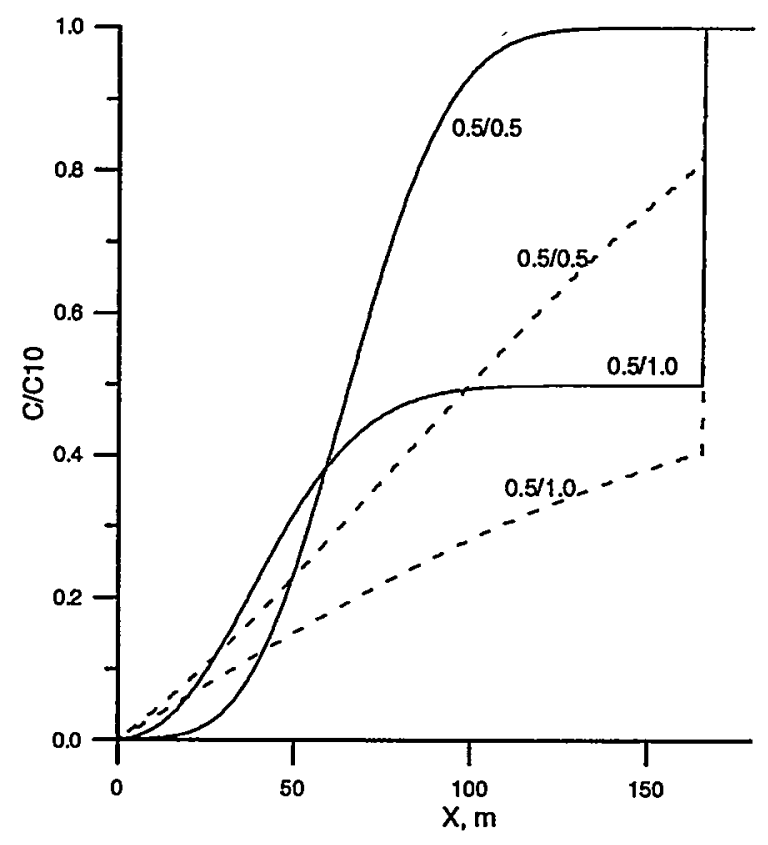

Fig. 5.4. Analytical solution to show the effect of the equilibrium coefficients ratio $K_{2} / K_{I}$ and the kinetic desorption constants $\left(\alpha_{1}\right)$ on the concentration distributions $\left(\alpha_{1}=0.01 \mathrm{~d}^{-1}\right.$ - solid-lines, $\alpha_{1}=0.001 \mathrm{~d}^{-1}$ dashed-lines); $v=0.1 \mathrm{~m} / \mathrm{d}, n=0.3, t_{n}=1000 \mathrm{~d}, \mathrm{t}=1000 \mathrm{~d}$

its velocity is defined only by value of $K_{1}$. Therefore at the beginning stage of migration when $u^{s}>u_{2}^{d}$, the concentration package tends to extend in width. This tendency will last as long as the passive (neutral) adsorption/desorption front (boundary between zones characterized by concentrations $C_{10}$ and $C_{20}$ ) lags behind the advancing adsorption front. Then, however due to the shockwise interaction between adsorption and passive fronts, an abrupt decrease of the passive-front displacement velocity takes place (Fig. 5.3). The resulting value of the new velocity can be obtained from the relationship:

$$
u^{s / n}=\frac{v}{n+K_{2} C_{10} / C_{20}}=\frac{v}{n+K_{1} /\left(1-\bar{N}_{0}\right)} .
$$

Starting from this moment, the concentration wave $C$ tends to contract. It means that the back desorption edge begins catching up with the advancing front. As it can been shown from simplekinematic equations the time 


$$
t^{* *}=\frac{K_{2} \bar{N}_{0}+K_{1}^{r}\left(1-\bar{N}_{0}\right)+n}{K_{2} \bar{N}_{0}} t_{n}
$$

(where $\bar{N}_{0}=N_{0} /\left(K_{2} C_{10}\right)$ characterizes the period of the trace component in the liquid phase; starting with time $t=t^{* *}$, the ground water is decontaminated. The length of the domain containing the component in the irreversibly adsorbed state is:

$$
x * *=\frac{1}{K_{2} \bar{N}_{0}} v t_{n} .
$$

It is interesting to note that the length of the zone of adsorptive accumulation of the component in rock is invariant to both adsorption and desorption equilibrium constants: $x^{* *}=\left(C_{1 d} N_{o}\right) v t_{n}$.

\subsubsection{Non-equilibrium models}

\section{Analytical model}

Three physical assumptions permit us to simplify the mathematical problem: 1) the desorption process is taking place under a condition that is characterized by a steady state distribution of parameters such as $K=K_{1}$ and $N_{0}$, 2) the desorption zone is restricted by the well defined boundaries [ $\left.0<x<v\left(t-t_{n}\right) / n\right]$, 3) concentrations $C_{20}$ can be calculated using on the equilibrium approach (Section 5.2.1), and 4) the adsorption rate noticeably exceeds the rate of desorption, so we need not consider the interaction between the sorption and desorption concentration waves.

The well-known solution for mass-transport processes complicated by chemical reaction of the first-order (Mironenko and Rumynin, 1986) can be modified as follows

$$
\begin{gathered}
\bar{C}=\psi\left(1-J\left(\eta, v_{\Delta}\right)\right), \\
\psi=\frac{C_{20}}{C_{10}}=\frac{K_{2}\left(1-\bar{N}_{0}\right)}{K_{1}},
\end{gathered}
$$

where $\eta=\frac{\alpha^{d} x}{v}, \tau_{\Delta}=\frac{\alpha^{d}}{K_{1}}\left(t-t_{0}-t_{n}\right), t_{0}=x n / v$.

Graphs in Fig. 5.4, which were calculated on the basis of solution (5.12), illustrate concentration distributions obtained for different values of 
the ratio $K_{2} / K_{1}$ and the kinetic constant $\alpha^{\alpha} \equiv \alpha_{1}$ (case $N_{0}=0$ ). It is seen that ratio $K_{2} / K_{1}$ controls the magnitude of the concentration wave between passive and back desorption fronts, while the value of $\alpha^{d}$ determines the extent of flushing of this zone.

\section{Numerical model}

Model development (implemented in the computer code NODEK) is based on the finite-difference solution of 1D nonlinear advection-dispersion equations taking into consideration irreversible and rate limited adsorption/desorption under condition of variable parameters of the EPSfunction $(\varphi \equiv M)$. The system of principal differential equations can be written as follows

$$
\begin{aligned}
& D \frac{\partial^{2} C}{\partial x^{2}}-v \frac{\partial C}{\partial x}=n \frac{\partial C}{\partial t}+\frac{\partial N}{\partial t}+\lambda n C \\
& \frac{\partial N}{\partial t}=\alpha_{i}\left(C-\frac{N}{K(\varphi)}\right)-\lambda N \\
& D \frac{\partial^{2} \varphi}{\partial x^{2}}-v \frac{\partial \varphi}{\partial x}=n \frac{\partial \varphi}{\partial t}+\frac{\partial N_{\varphi}}{\partial t} \\
& \frac{\partial N_{\varphi}}{\partial t}=\alpha_{\varphi}\left(C-\frac{N}{K_{\varphi}}\right)
\end{aligned}
$$

where $v$ is the Darcy velocity, $D$ is the longitudinal dispersion coefficient, $\mathrm{n}$ is the porosity (or fractured porosity), $C$ and $N$ are dissolved and adsorbed concentrations, $K(\varphi)$ is the equilibrium coefficient depending on the magnitude of the $\varphi$ - function, $K_{\varphi}$ is the distribution coefficient for the $M$ characteristic of $\varphi$ - function, $\alpha_{1}$ and $\alpha_{2}$ are kinetic constants for the desorption and adsorption stages of the heterogeneous exchange process, $\alpha_{3}$ is the kinetic constant for the $\varphi$-function, $\lambda$ is the radioactive decay constant.

The relationship between $K$ and $\varphi$ is given by formula ( 5.5 ). As a further consideration, the $\varphi$ - function is assumed to be invariant of any chemical interactions in the model domain, i.e. $K_{\varphi}=0$.

To solve the system represented by equations $(5.13-5.16)$, an implicit finite-difference scheme coupled with the Gauss-Seidel iteration procedure with over-relaxation has been applied. Current values of $K(\varphi)$ are calculated at every inner iteration. The value of $\alpha_{i}$ chosen depends on the type of process 
taking place at the given time-space interval, i.e. adsorption (then $\alpha_{i}=\alpha_{2}$ ) or desorption $\left(\alpha_{\mathrm{i}}=\alpha_{1}\right)$.

Fig. 5.5 illustrates the effect of the adsorption $\left(\mathrm{K}_{2}\right)$ and desorption $\left(\mathrm{K}_{1}\right)$ parameters and kinetic constants on the character of concentration distribution. The curves were obtained for the basic migration parameters that were introduced in Fig. 5.4, but the numerical model additionally took into consideration hydrodynamic solutedispersivity and non-

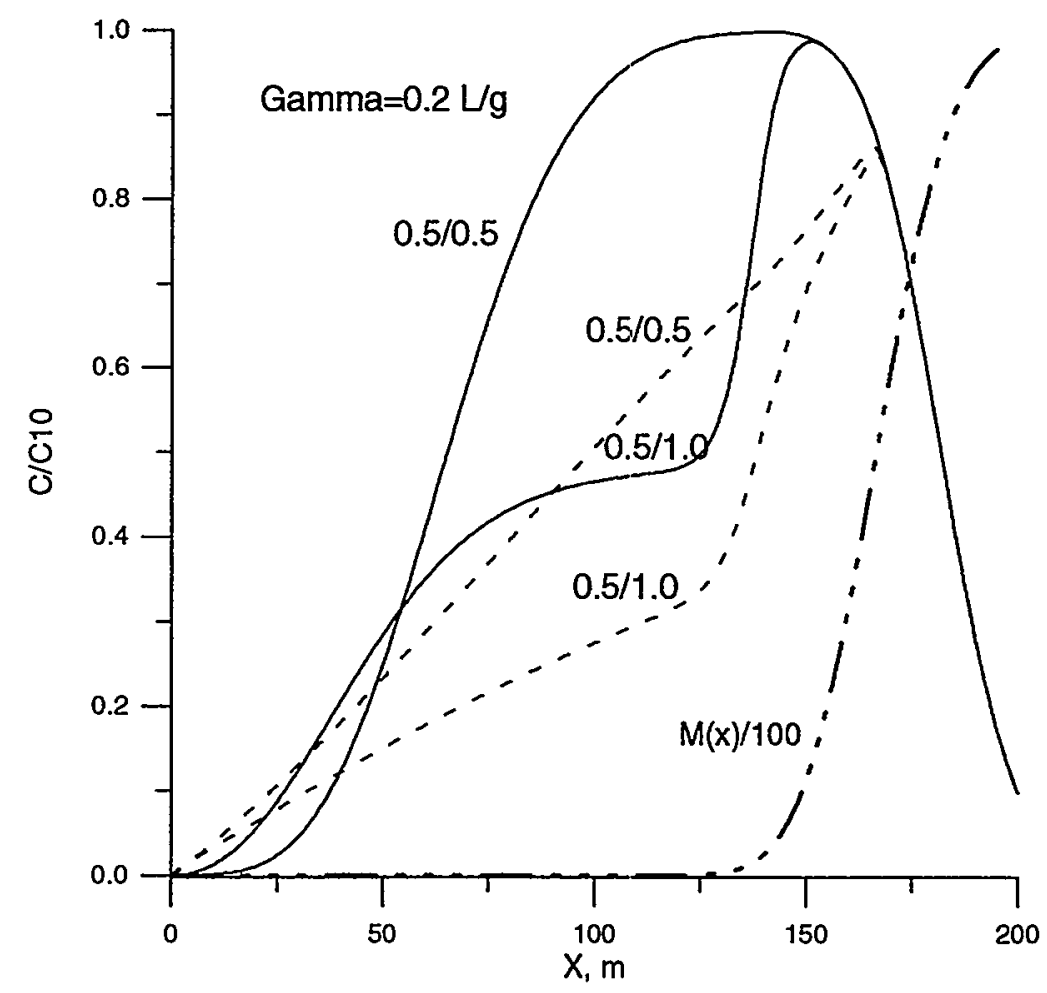

Fig. 5.5. Effect of the equilibrium coefficients ratio $K_{2} / K_{1}$ and the kinetic desorption constants $\left(\alpha_{1}\right)$ on the concentration distributions numerical solution $\left(\alpha_{1}=0.01 \mathrm{~d}^{-1}\right.$ - solid-lines, $\alpha_{1}=0.001 \mathrm{~d}^{-1}$ dashedlines); $v=0.1 \mathrm{~m} / \mathrm{d}, n=0.3, \alpha_{2}=10 \mathrm{~d}^{-1}, M=100 \mathrm{~g} / \mathrm{L}, \gamma=0.2 \mathrm{~L} / \mathrm{g}$,

$$
N_{O}=0, t_{n}=1000 \mathrm{~d}, t=1500 \mathrm{~d}, \lambda=0
$$

equilibrium adsorption on the advancing front. It is seen that due to these processes adsorption and desorption fronts begin to interact earlier than suggested by the sharp-interface analytical model. This earlier interaction leads to a flattening of the concentration peaks. 
Another numerical solution is more illustrative. Fig. 5.6 depicts behavior of the concentration functions $(C$ and $N$ ) for long-term migration when irreversible adsorption takes place $\left(N_{0}>0\right)$. At the initial stage of the process, parameter $N_{0}$ controls mostly the magnitude of the intermediate wave. Then, after interaction of passive (neutral) and advancing adsorption fronts, the overall process begins to depend on the parameter $N_{0}: 1$ ) the greater $N_{0}$, the slower the adsorption front migrates, and 2) the greater $N_{0}$, the more rapidly is the concentration wave $C$ over-taken. For the given examples according to formula (5.11), the water clean up period $t^{* *}$ is estimated to be $5500 \mathrm{~d}\left(N_{0}=0.2 \mathrm{~g} / \mathrm{L}\right)$ and $3300 \mathrm{~d}\left(N_{0}=0.3 \mathrm{~g} / \mathrm{L}\right)$. This is fairly consistent with the modeling results (Fig. 5.6) if we take into account that the adsorption/desorption process is kinetically controlled, a situation not reflected by formula (5.11).

\subsubsection{Preliminary results of the numerical assessment}

Experimental data, theoretical findings and modeling developments allow us to carry out a preliminary assessment in order to quantify the role of adsorption/desorption processes at the site. It is assumed that the process is characterized by average values of transport and adsorption parameters as follows:

Darcy velocity:

Fractured porosity:

Specific surface of porous blocks:

Boundary concentration of Sr-90:

$\mathrm{NaNO}_{3}$ concentration:

Exponential coefficient in formula (5.5):

Kinetic constants:

Dispersion coefficient:

$$
\begin{aligned}
& \nu=0.0013 \mathrm{~m} / \mathrm{d} \\
& n=0.01 \\
& S_{b}=1 \mathrm{~m}^{-1} \\
& C_{10}=1.4 * 10^{-5} \mathrm{Ci} / \mathrm{L} \\
& M=70.0 \mathrm{~g} / 1 \\
& \gamma=0.2 \mathrm{~L} / \mathrm{g} \\
& \alpha_{1}=\alpha_{2}=10^{-4} \mathrm{~d}^{-1} \\
& D=10^{-4} \mathrm{~m}^{2} / \mathrm{d} \\
& \left(D / n=10^{-2} \mathrm{~m}^{2} / \mathrm{d}\right)
\end{aligned}
$$

Adsorption / desorption constants:

$$
\begin{array}{ll}
K_{1}=S_{b} * K_{a 1}=0.01 \div 0.03\left(K_{a 1}=1 \div 3 \mathrm{~cm}\right) & K_{\text {IAVER }}=0.02 \\
K_{2}=S_{b * K_{a 2}}=0.0005 \div 0.001\left(K_{a 2}=0.05 \div 0.1 \mathrm{~cm}\right) & K_{2 A V E R}=0.0007 \\
N_{0}=(0.5 \div 1.0) * K_{2} * C_{10}\left(N_{0}^{\prime}=5 * 10^{-6} \div 2 * 10^{-5} \mathrm{Ci} / \mathrm{m}^{2}\right) & N_{\text {OAVER }}=5.9 * 10^{-9}
\end{array}
$$



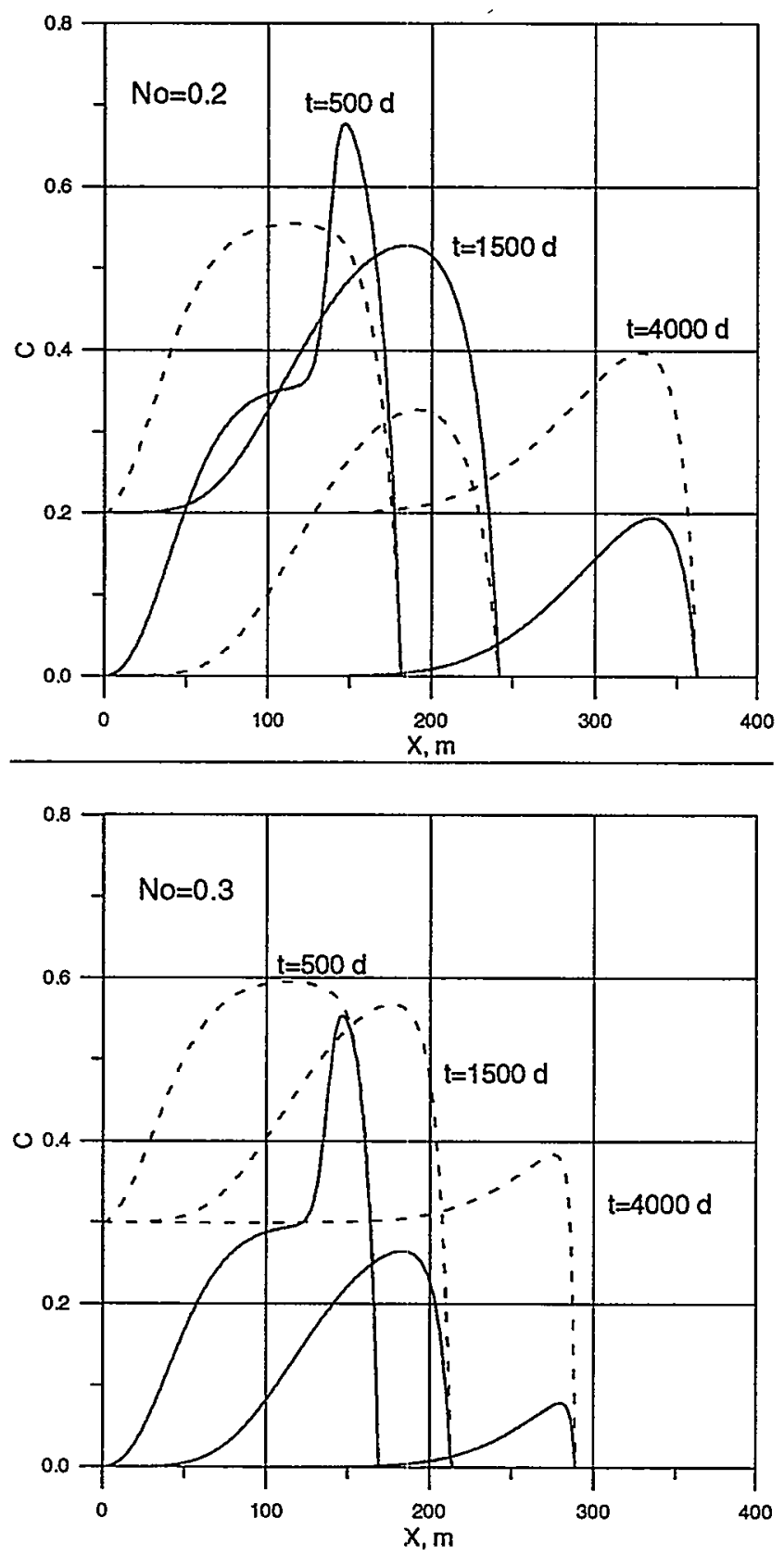

Fig. 5.6. Influence of the irreversible adsorption capacity on the concentration distributions (concentration in aqueous phase solid-lines, adsorbed concentration - dashed lines): a $-N_{0}=0.2$ $\mathrm{g} / \mathrm{L}, \mathrm{b}-N_{0}=0.3 \mathrm{~g} / \mathrm{L} \quad\left(K_{1}=1, K_{2}=0.5, \alpha_{1}=0.01 \mathrm{~d}^{-1} \alpha_{2}=10 \mathrm{~d}^{-1}\right.$, $\nu=0.1 \mathrm{~m} / \mathrm{d}, n=0.3, D=0.0001 \mathrm{~m}^{2} / \mathrm{d}, M_{0}=100 \mathrm{~g} / \mathrm{L}, \gamma=1.0 \mathrm{~L} / \mathrm{g}, C_{10}=1$ $\mathrm{g} / \mathrm{L}, t_{n}=1000 \mathrm{~d}, \lambda=0$ ) 
Fig. 5.7 illustrates the behavior of the concentration distributions obtained with the help of a numerical simulation of the problem $\lambda=0$ case).

Based on the relationships represented in Section 5.2.1 it is easy to show that essential differences in constants $K_{1}$ and $K_{2}$ result in forming intermediate concentration wave with a rather low magnitude of the concentration function $C=C_{20}$. Its desorption front migrates at least ten times slower than the advancing adsorption front. The velocity of the latter is close to the velocity of the conservative component. It means that

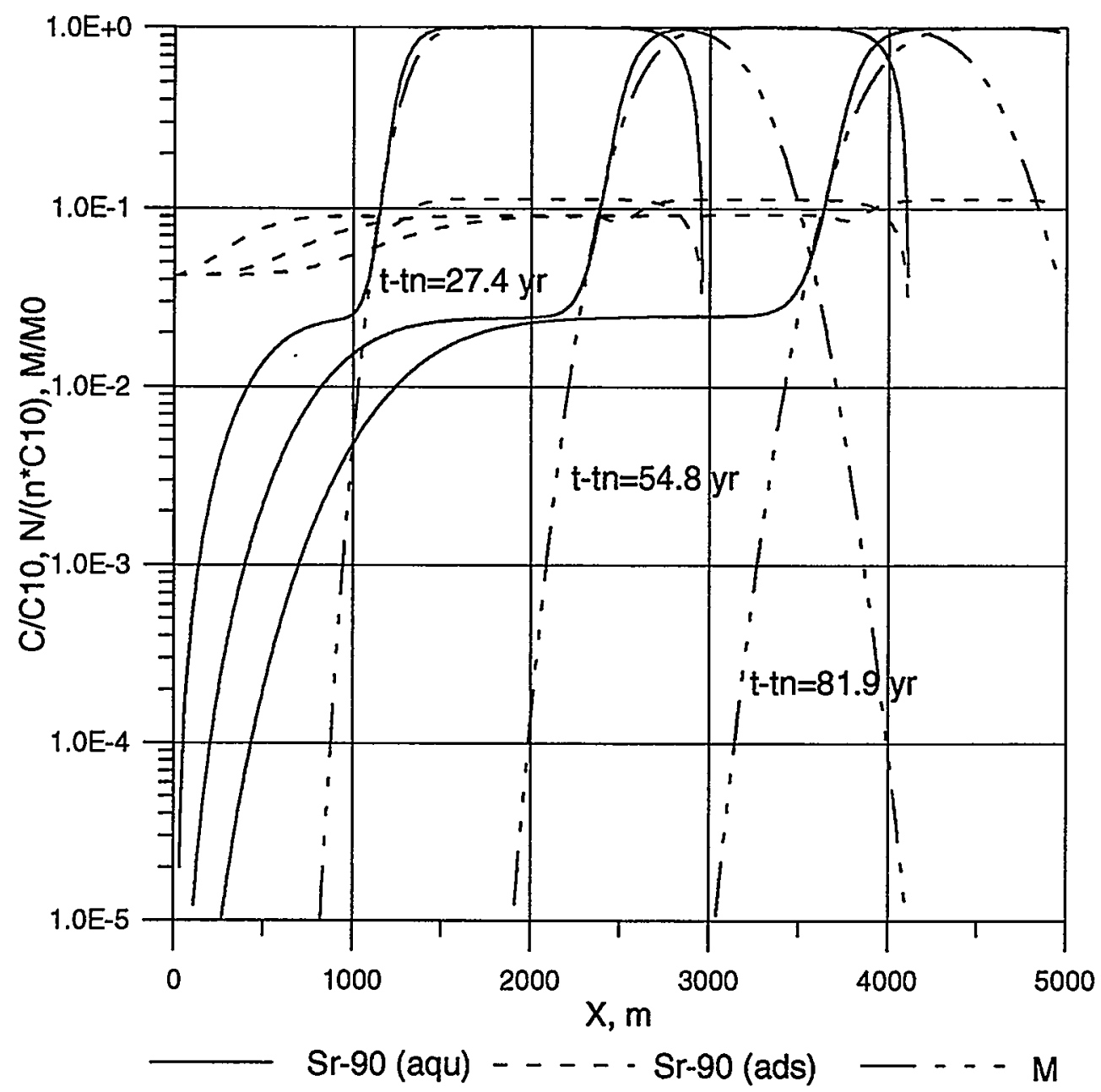

Fig. 5.7. Character of the concentration waves during natural remediation of the Site ("aqu" - component in aqueous phase, "ads" - in adsorbed state, $M-\mathrm{NaNO}_{3}$ content) 
after the radioactive waste leakage from the surface reservoir ends, the desorption front will reach the discharge boundary $(L=3500 \mathrm{~m})$ after several hundred years. Within this period ground water contamination will be determined by the magnitude of the intermediate wave, i.e. concentration $C_{20}$.

The value of $C_{20}$ strongly depends on the $K_{2} / K_{1}$ ratio and the irreversible sorption capacity $N_{0}$ (see formula 5.7). For the accepted range of adsorption/desorption parameters, concentration $C_{20}$ can reach a maximum value of $0.05 * C_{10}$ when $\bar{N}_{0}=N_{0}\left(K_{2} * C_{10}\right)=0.5$ and a minimum value of about 0 when $\bar{N}_{0}=1$. Despite of the partial irreversibility of the adsorption, the first value of $\mathrm{C}_{20}\left(\cong 1 * 10^{-6} \mathrm{Ci} / \mathrm{L}\right)$ is still very high compared with the safety concentration standard (about $10^{-9} \mathrm{Ci} / \mathrm{L}$ ). At the same time the concentration can dramatically decrease when $\bar{N}_{0} \rightarrow 1$.

Thus, the remediation stage of the process is very sensitive the irreversible adsorption capacity. Depending on the actual values of this parameter, natural remediation of contaminated sites will vary greatly in efficiency.

Further modeling development will require an approach that does not use the simplified $\mathrm{Kd}$ concept.

\section{Study of multi-solute transport in the double-porosity reservoir}

\subsection{Geochemistry of the contaminated subsurface waters}

\subsubsection{Introductory remarks}

Modeling studies have been conducted to improve our understanding of physical-and-chemical processes accompanying migration of the radioactive waste at the Lake Karachai site. Based on a computer code SOFAMA developed by Ozyabkin and Ozyabkin (1996), the behavior of stable dissolved substances and radioactive isotopes has been studied within different hydrogeochemical zones of the contamination plume. SOFAMA employs the equilibrium constant method. For calculation of activity coefficients of each component, the Debye-Huckel equation with an empirical extension term 


$$
\Delta_{i}=a_{i}\left(e^{b_{i} I}-1\right)
$$

is used [I is the ionic strength, $a_{i}(<0)$ and $b_{i}(>0)$ are empirical coefficients for the $i$-th species]. Such an approach was originally developed and verified to simulate equilibrium thermodynamic systems with solution ionic strengths up to 5.0 .

Like other geochemical codes, SOFAMA calculates the distribution of the basic components among aqueous complexes and the saturation indices of minerals potentially associated with the ground water.

\subsubsection{The main modeling results}

Eight hydrochemical analyses (Table 2.1) of ground water samples taken from different monitoring wells within the plume body and from wells located away from the contaminated site were considered as basic data for the modeling study. The wells are adjusted to the traverse (Fig. 3.1) which corresponds to the preferable flow path of waste migration.

The principal modeling results are summarized as follows.

1) Cesium migrates mostly in dissociated ion form (80-100\%). However, when the nitrate concentration exceeds $20 \mathrm{~g} / \mathrm{L}, 15-20 \%$ of the cesium forms nitrate complexes. Sulfate and oxalate complexes are present in negligible amounts.

2) Strontium migrates both in ionic $\left(\mathrm{Sr}^{2+}\right)$ and complex $\left(\mathrm{SrNO}_{3}{ }^{+}, \mathrm{SrCO}_{3}{ }^{0}\right.$, $\mathrm{SrSO}_{4}{ }^{\circ}$ ) forms. The extent of complexation depends on the nitrate content and increases dramatically in the vicinity of the Lake (Fig. 6.1).

3) Uranyl ion exists in the solution primarily as a carbonate complex $\mathrm{UO}_{2} \mathrm{CO}_{3}{ }^{0}$ (> 99\%). Anions of weak acids including $\mathrm{OH}^{-}$as well as $\mathrm{Cl}^{-}$do not affect its migration ability. Taking into account the similarity in chemical properties of uranium and trans-uranium elements, we consider that the sixvalent-state $\mathrm{Np}, \mathrm{Pu}$ and Am behave similarly to uranium.

4) According to the calculations for well $41 / 47$ (the well water contains about $5 \mathrm{~g} / \mathrm{L}$ of carbonate- and bicarbonate ions), cobalt migrates in the carbonate complex $\mathrm{CoCO}_{3}{ }^{\circ}(80 \%)$ and in form of ionic $\mathrm{Co}^{2+}$. Modeling assessments for samples from wells located downstream showed that the extent of cobalt complexation has to be strongly dependent on the $\mathrm{pH}$ (Fig. 6.2). Other ions including $\mathrm{OH}$ do not affect the complexation process.

5) Ruthenium (according to modeling assessments for water from well 41/47) is present as neutral hydroxy species $\left[\mathrm{Ru}(\mathrm{OH})_{4}\left(\mathrm{H}_{2} \mathrm{O}\right)_{2}\right]^{0}-99.2 \%$. 
Based on introduced results one can conclude that contaminated subsurface water composition changes according to the total dissolved solids and the geochemical character of the water. Therefore, in solute transport models, which include options for heterogeneous exchange

Fig.6.1. Distribution of strontium migration forms .

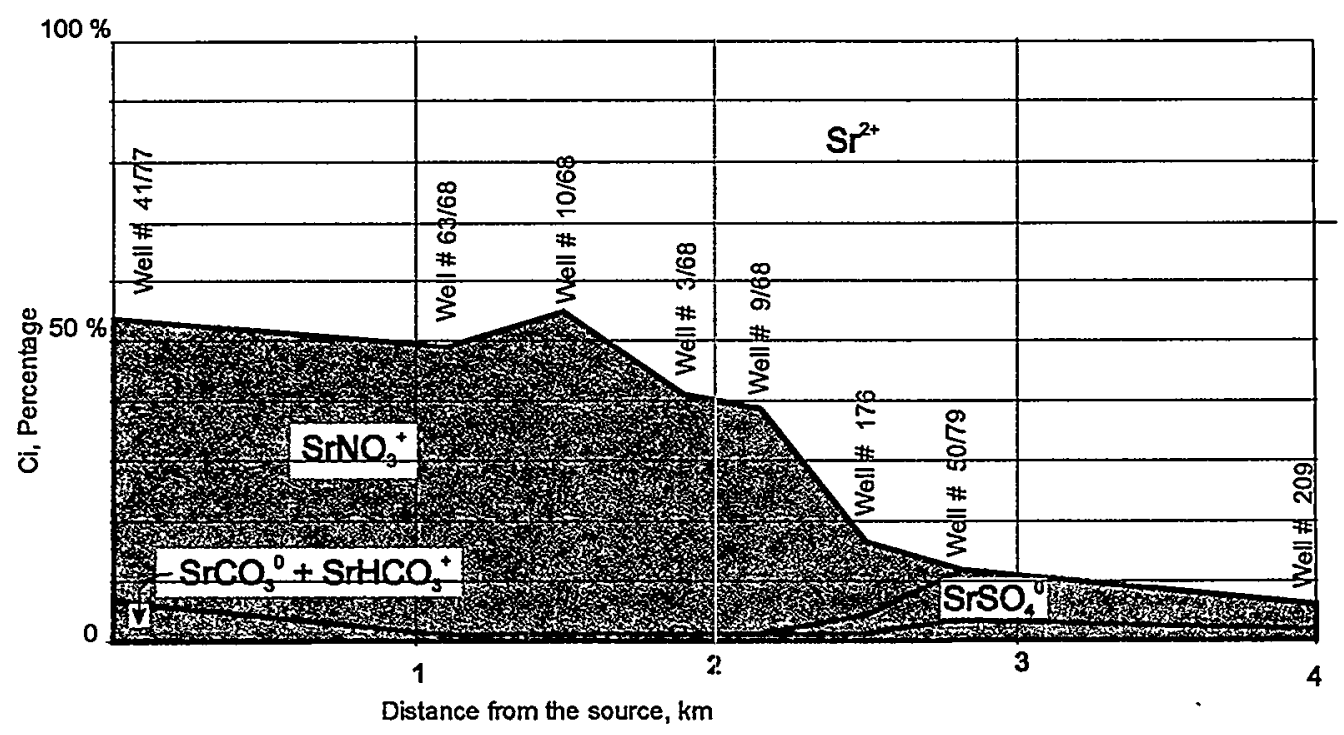

Fig. 6.2. Cobalt migration forms distribution versus $\mathrm{pH}$

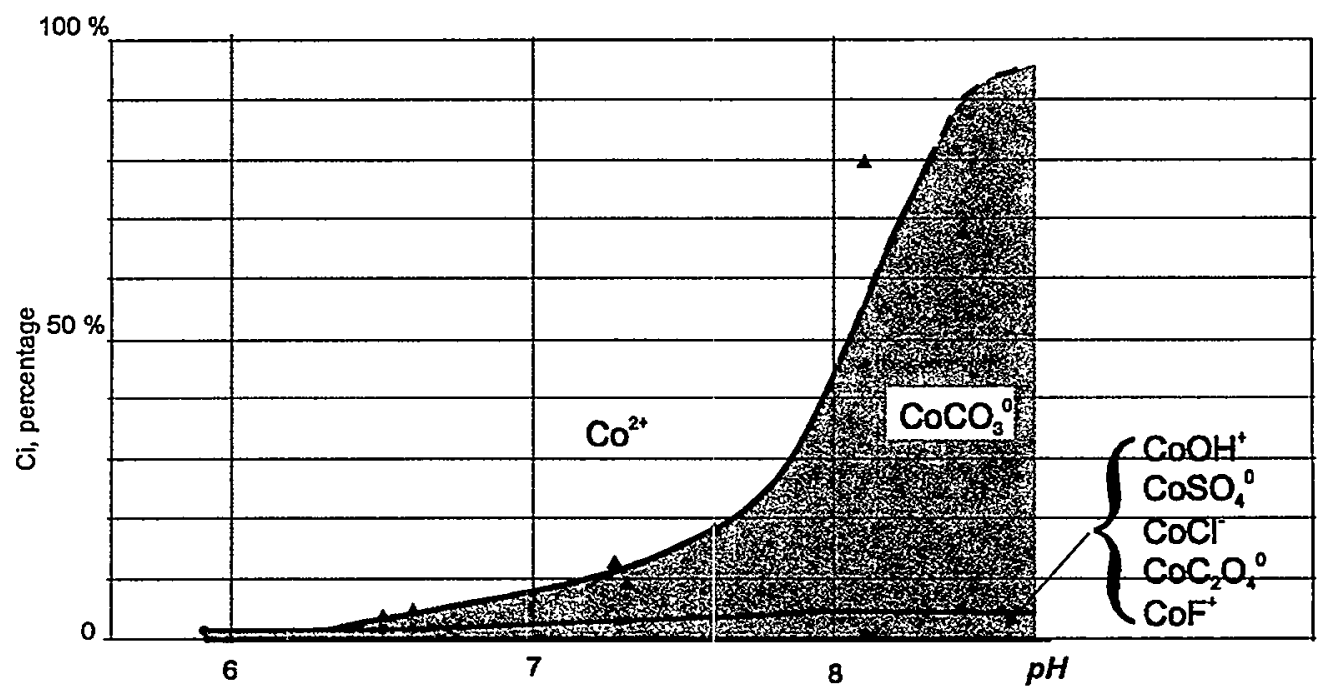


processes (like ion-exchange), the component complexation has to be taken into consideration.

Additionally, the saturation indices in relation to potential minerals were calculated. It was established that brines are supersaturated with respect to carbonate minerals. In particular, relatively high level of supersaturation may induce co-precipitation of radiostrontium. This problem is the subject for the further modeling investigations.

It should be mentioned also that the presence of stable strontium which goes into solution along with $\mathrm{Ca}^{2+}$ and $\mathrm{Mg}^{2+}$ through ion exchange can effectively dilute the ${ }^{90} \mathrm{Sr}$ concentration in the liquid wastes by nearly three orders of magnitude (according to calculations conducted by J. Apps, LBNL, private communication). At the same time, strontium could

be potentially removed from solution through co-precipitation with $\mathrm{Ca}^{2+}$ and $\mathrm{Mg}^{2+}$. Because dissolved $\mathrm{Ca}^{2+}, \mathrm{Mg}^{2+}$ and $\mathrm{Sr}^{2+}$ are mostly products of ion exchange, which is induced by migration of the bulk solution, such a process has to be analyzed in the framework of multicomponent transport models. One of the approaches for construction of such models is represented in the next Section.

\subsection{D model for multicomponent transport study}

\subsubsection{Model description}

A computer code (SONED) has been developed by Dr. V. Ozyabkin to model reactive chemical transport when solute transport is coupled with chemical equilibrium to consider the interaction among species and how they are transported by subsurface flow. The model is able to compute the chemical equilibrium of a system with: 1) aqueous complexation, 2) ionexchange, 3) precipitation/dissolution, 4) acid-base reactions, 5) radioactive decay.

The model uses the law of mass action to describe chemical equilibrium. The governing equations for chemical transport are derived based on the principle of conservation of mass and flux (Ozyabkin and Ozyabkin, 1996).

The initial conditions for chemical transport are obtained by preliminarily solving a system of chemical equations for chemical equilibrium in background water. Boundary conditions are specified as Dirichlet boundary conditions. A variable boundary condition is applied: the influent concentrations for all components can be changed following any given 
schedule, e.g. to model a cleanup process these concentrations are assumed to be the same as the total dissolved component concentrations under pre-initial conditions.

Twenty-nine component species, more than 100 complexed species (167 homogeneous reactions in aqueous phase) and 13 ion-exchange species $\left(\mathrm{Na}, \mathrm{K}, \mathrm{NH}_{4}, \mathrm{Cs}, \mathrm{Ru}, \mathrm{Pd}, \mathrm{Mg}, \mathrm{Ca}, \mathrm{Sr}, \mathrm{U}, \mathrm{Ba}, \mathrm{Co}, \mathrm{Ni}\right.$ ) are taken into consideration.

To simulate ion exchange, $\mathrm{Na}^{+}$was selected as the basic ion, - it is regarded as a "changed coin" which is used to calculate equilibrium between other exchangeable ion pairs i.e. it replaces other cations from the mineral surface, or they replace it.

The code is able to simulate mass exchange between mobile and immobile zones of the flow domain. The process is formalized as a first order kinetic reaction. It permits us to simulate the effect of a porous matrix on mass transport in double-porosity reservoirs. The computer program algorithm also includes an option for simulating adsorption onto fracture walls.

\subsubsection{Verification and application}

\section{Verification}

SONED has been verified with two example problems: 1) computation of nonreactive transport in double-porosity media, 2) computation of tworeactive component transport complicated by ion-exchange in a homogeneous medium. The verification showed the numerical formalization of the coupled chemical equilibrium and solute transport processes to be correct. A comparison between numerical and analytical solutions shows that they are in a good agreement.

\section{Application}

The model can be applied to several fields: 1) a demonstration of the capability of the code to solve a complex coupling problem; 2) model calibration on the basis of field data, 3) the evaluation of the nature of physical-and-chemical exchange processes in a double-porosity reservoir and quantifying mass-exchange parameters; 3) an assessment of the feasibility of simplifying the coupling structure between chemical equilibrium in multicomponent systems and solute transport, in particular in order to assess 
the applicability of the Kd-concept for the system description; 4) radionuclide transport prediction.

The first stage of model investigations deals with identification of migration mechanisms and model calibration based on an analysis of the principal component behavior within the plume. This is a necessary step for further study of subsurface radionuclide transport processes at the Site.

I. Modeling analysis of the principal component distributions. The main idea of the analysis is as follows. The basic (principal) constituencies such as $\mathrm{Na}^{+}, \mathrm{Ca}^{2+}$ and $\mathrm{Mg}^{2+}$ participate in the ion-exchange (of $2 \mathrm{Na}^{+}$for $\mathrm{Ca}^{2+}$, $\mathrm{Mg}^{2+}$ and, possibly, $\mathrm{Sr}^{2+}$ ) process. $\mathrm{Ca}^{2+}$ can be removed from primary alumino-silicates, e.g. amphibole and epidote, and $\mathrm{Mg}^{2+}$ from amphibole and chlorite of the rock matrix; $\mathrm{Ca}^{2+}, \mathrm{Mg}^{2+}$ and $\mathrm{Sr}^{2+}$ exchange takes place in secondary clays in the weathered zone at covering fracture walls as well (Solodov et al., 1998). The role of this process is noticeably exhibited in the component distribution within the plume. Thus in Fig. 6.3 it is clearly seen that after leaving the Lake, the brine changes its cationic character. Almost free of $\mathrm{Ca}^{2+}$ and $\mathrm{Mg}^{2+}$ in solution in the vicinity of the reservoir, contents of these components increase in the direction of the discharge area. About 1.5 $\mathrm{km}$ downstream from the contamination source, concentrations of $\mathrm{Ca}^{2+}$ and $\mathrm{Mg}^{2+}$ removed from the exchanging rock's complex reach magnitudes that exceed by tens to hundreds of times their initial and boundary concentrations. Then, at about of $2.5 \mathrm{~km}$ downflow from the source, the concentrations of these ions again diminish and tend to the background values. So, the concentration peaks are distinguished very well. The concentration of the replacing component, $\mathrm{Na}^{+}$, is monotonically decreasing and one can see in Fig. 6.3 that this component retarded in its movement relative to the major principal anion, $\mathrm{NO}_{3}$.

There are two competitive ion-exchange capacities providing accumulation of $\mathrm{Ca}^{2+}$ and $\mathrm{Mg}^{2+}$ in mobile solution. Both the porous matrix and the mineral surface of fracture walls may appear to release adsorbed cations. $\mathrm{Ca}$ and $\mathrm{Mg}$ being released from the ion-exchange complex of the rock serve like environmental tracers.

Molecular diffusion within the porous matrix is the process which facilitates the transfer of components from the mineral to the aqueous phase. Therefore the magnitudes of the $\mathrm{Ca}^{2+}$ and $\mathrm{Mg}^{2+}$ peaks and the extent of $\mathrm{Na}^{+}$ retardation depend both on the cation exchange capacity $\left(Q_{\nu}\right)$ and combined mass-exchange parameter $\left(\alpha_{M}\right)$. Based on numerical simulation of the multicomponent transport problem, one can try to match observed and 
modeling data incorporating these parameters. This approach has showed be supplemented by a sensitivity analysis.

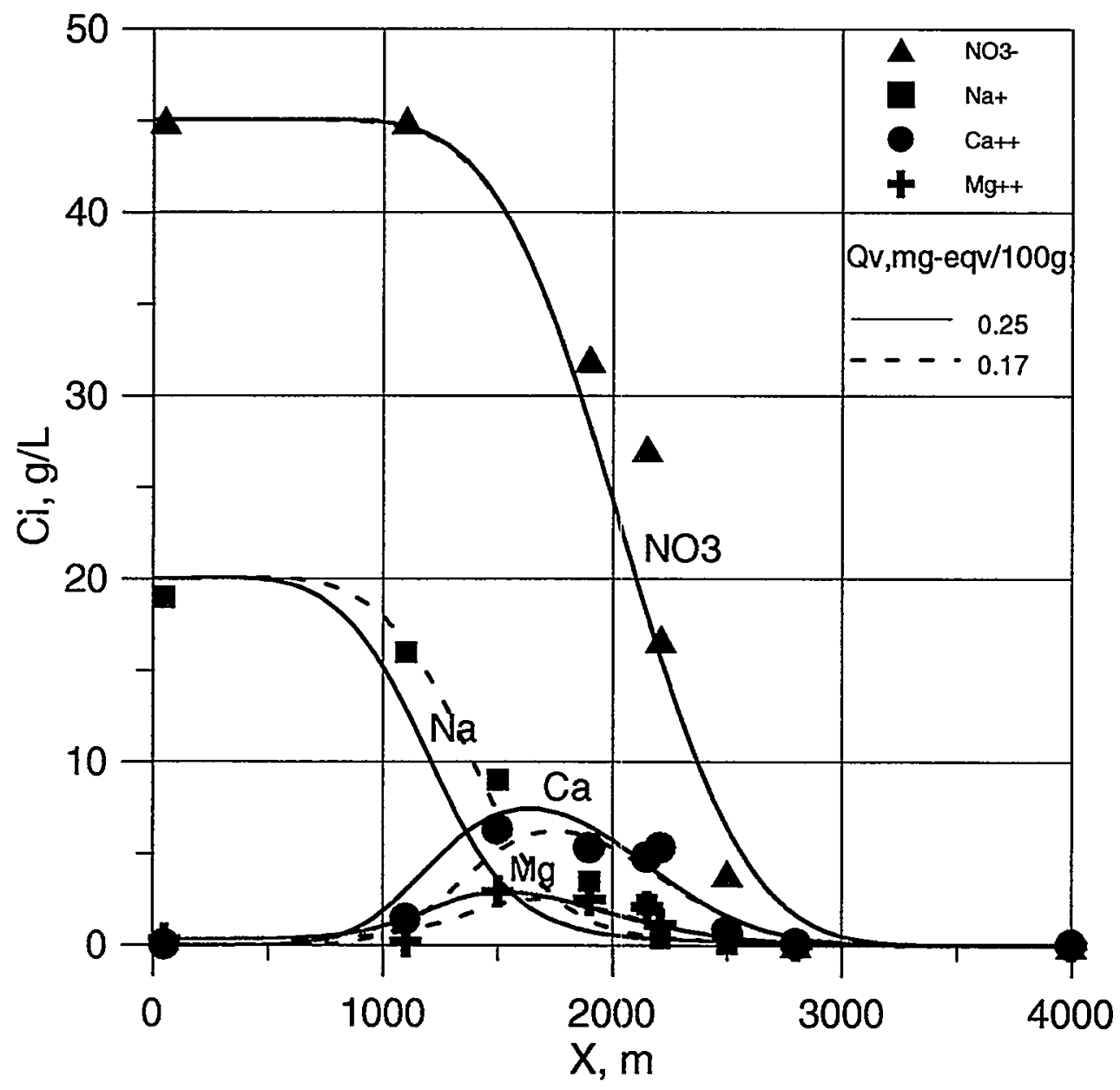

Fig. 6.3. Field data on the principal component distribution within the plume (along the major flow path) and

fitting modeling curves $(t=15000 \mathrm{~d})$

In the applied fitting procedure, the mentioned parameters varied within the range: $Q_{v}$ - from 0.1 to $3.0 \mathrm{mg}$-eqv/L and $\alpha_{M}$ - from $10^{-4}$ to $10^{-7}$ day $^{-1}$. Total porosity $n_{t o s}$ which includes fracturing $\left(n_{f}\right)$ and matrix $\left(n_{0}\right)$ porosity, was assumed to be $0.1 \%$; the case when $n_{f}=n_{0}=0.005$ was investigated. The latter parameters correspond to the average values obtained in independent field and laboratory investigations (Sections 2, 3 and 4). The 
Darcy velocity (v) is assigned to be $0.0013 \mathrm{~m} /$ day (that is an effective characteristic of the process, - taking into account the actual $3 \mathrm{D}$ velocity field).

Fig. 6.3 displays one of the modeling variants which yielded the best fitted curves for the observed data. As it is seen, the modeling curves approximate the field data fairly well. The results of solving the inverse problem are as follows: $Q_{\nu}=(0.17 \div 0.25) \mathrm{mg}$-eqv $/ 100 \mathrm{~g}$ and $\alpha_{M}=7 * 10^{-6}$ day $^{-1}$. The first range is of the same order of magnitude as the average value of the cation exchange capacity $\left(Q_{v}=0.6 \mathrm{mg}\right.$-eqv $\left./ 100 \mathrm{~g}\right)$ that has been obtained under laboratory conditions. The combined parameter $\alpha_{M}$ is within the range which was calculated on base of field and laboratory tests (Section 4.4).

The implemented procedure has been carried out in the framework of 1D modeling approach. It is justified by the low sensitivity of the magnitudes of the calcium and magnesium concentration waves to the actual velocity field at the long-term stage of the process (Fig. 6.4, a). Variations in Darcy velocity within a wide range of magnitude practically do not affect the values of maximum of $\mathrm{Ca}^{2+}$ and $\mathrm{Mg}^{2+}$ concentrations. Meanwhile variations of parameter $\alpha_{M}$ result in the dramatic changes of the peak's magnitude (Fig. 6.4 , b) illustrating a high sensitivity of the observed hydrogeochemical data to the mass-exchange processes in the double-porosity reservoir.

As it was mentioned above, the previous model calibration can be based on another hypothesis. It could be assumed that the major contributor in the accumulation of $\mathrm{Ca}^{2+}$ and $\mathrm{Mg}^{2+}$ in mobile solution is the exchange between components adsorbed onto fracture walls and the dissolved solutes. The preliminary model results showed that, once included in the simulation procedure, this exchange process provides for concentration distributions that are close to the previous case. A combined parameter $N_{s}=Q_{s} S_{b}\left(Q_{s}\right.$ is the surface exchange capacity, $S_{b}$ is the specific surface of the blocks) was estimated to be within the range $(1 \div 2) * 10^{3} \mathrm{mg}$-eqv/ $\mathrm{m}^{3}$.

So, there are two alternative approaches for simulating the exchange processes in the fractured reservoir. It seems both of them are applicable for forecast modeling if diffusion in the porous matrix is taken into consideration for the bulk solution. 
a

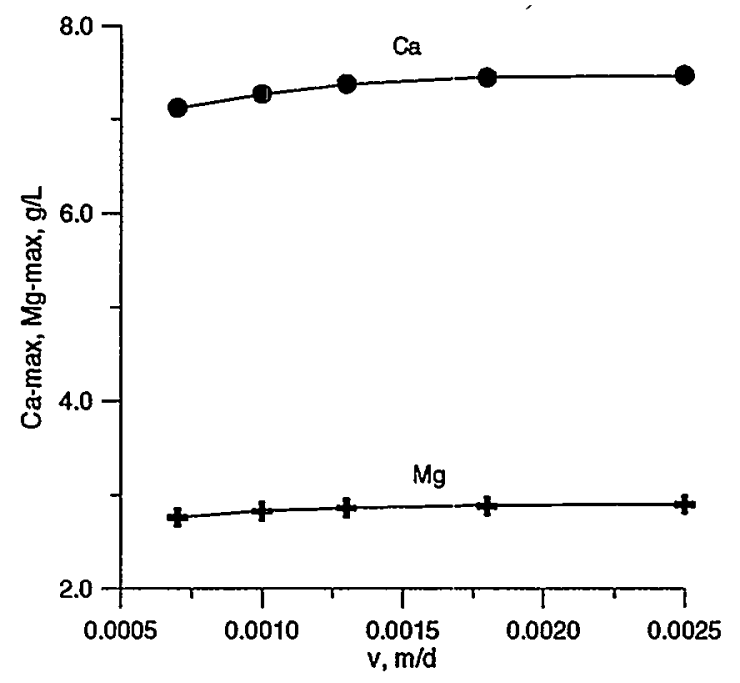

b

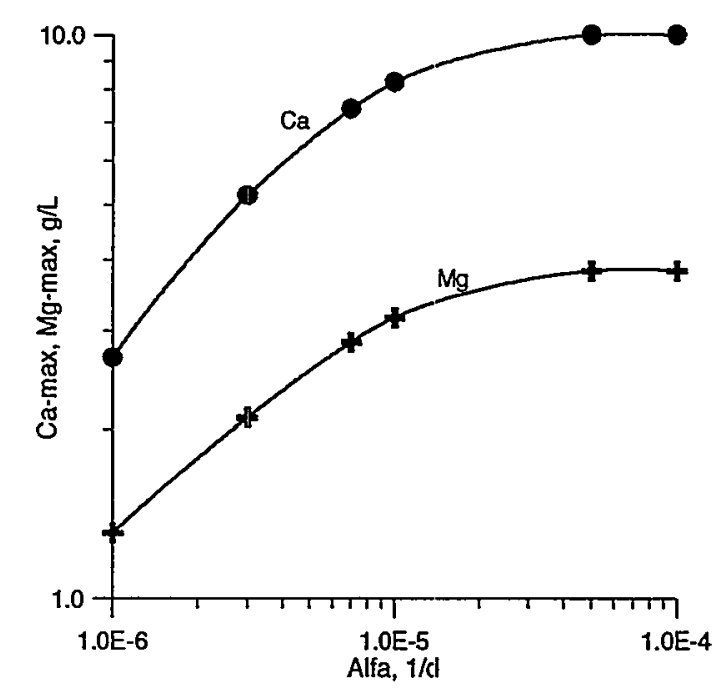

Fig. 6.4. Influence of flow velocity (a) and kinetic mass-exchange parameter (b) on the magnitude of $\mathrm{Ca}^{2+}$ and $\mathrm{Mg}^{2+}$ concentration waves within the plume

Thus, modeling interpretation of the hydrogeochemical data made it possible to obtain values of the ion exchange capacity and the combined kinetic parameter, which seem to be useful for further modeling study of the radionuclide transport at the site. The main advantages of the considered 
approach over traditional analysis based on the "one-component modeling interpretations" are: (a) lower sensitivity of the exchange process in regard to dimensionality of the overall migration process, and (b) the possibility of using extremal characteristics of several concentration functions. The above is true for plumes with a fairly sharp interface between brines and the replaced ambient ground water. In any event, such additional information enhances the reliability of the migration reconstruction.

II. Radionuclide transport modeling. Transport of four principal radionuclides has been simulated. They are Sr-90, Cs-137, Co-60 and Ru106. The results of modeling were compared with actual distributions of the isotopes established for the major flow path of the brines at the contaminated site (the southern direction of the plume body spreading) - Fig. 6.5 and 6.7. Unfortunately, measured data on the concentration distributions of isotopes of cobalt and cesium are rather restricted. At the same time it is known that mobility of radiocesium in contaminated water is very low due to its high adsorptive properties: noticeable concentrations were found only in wells located in the vicinity of the Lake (not far than several hundreds meters downflow direction). As for radiocobalt, the field

a

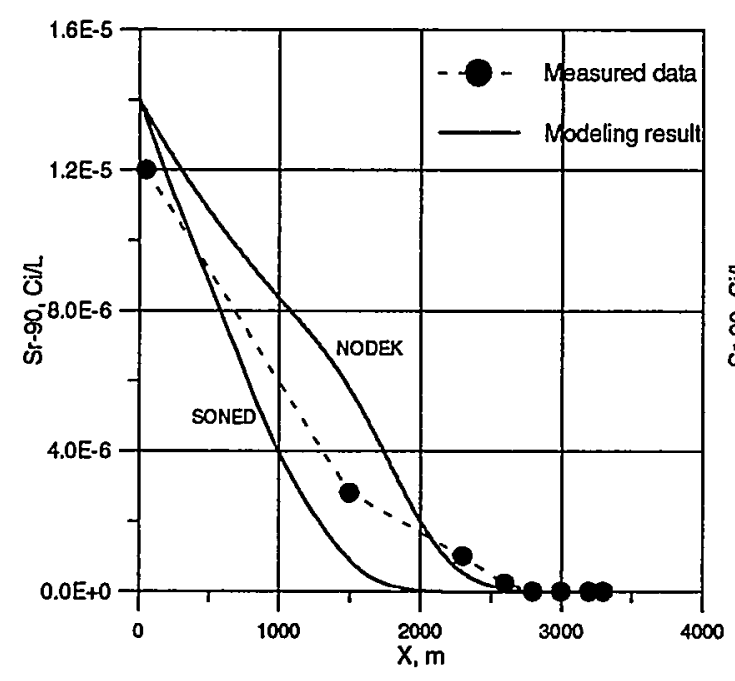

b

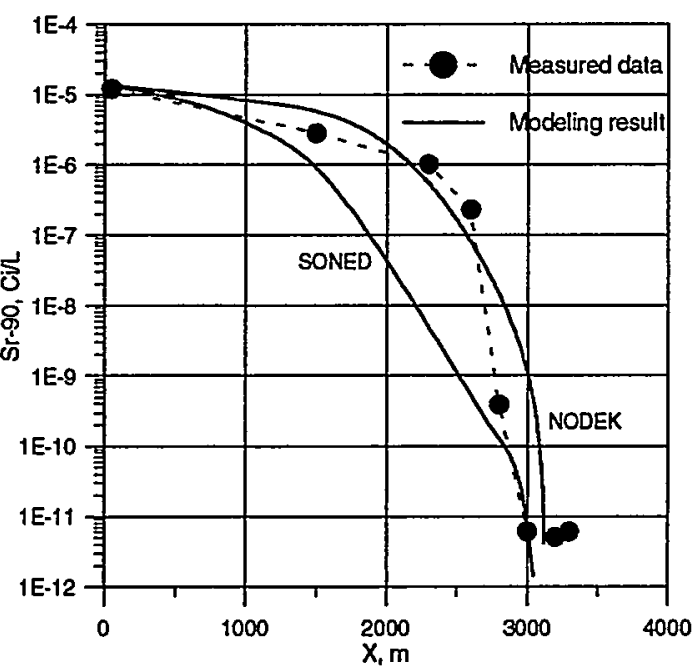

Fig. 6.5 Modeling and actual distribution of radiostrontium in ground water ( $a$ - linear scaled and $b-\log$-scaled axes) 
data are represented by three well-samples (Fig. 6.7). More representative information is concerned with Sr-90 and Ru-106.

The major results of the modeling analysis are as follows.

1. Fig. 6.5 shows that the modeling curve describes behavior of $\mathrm{Sr}-90$ fairly well within the range of dimensionless concentrations from 1.0 to 0.2 . Essential disagreements between the modeling and actual distributions are observed for the advancing front, which is characterized by low value of concentrations (that is seen well in the log-scaled graph - Fig. 6.5,b).

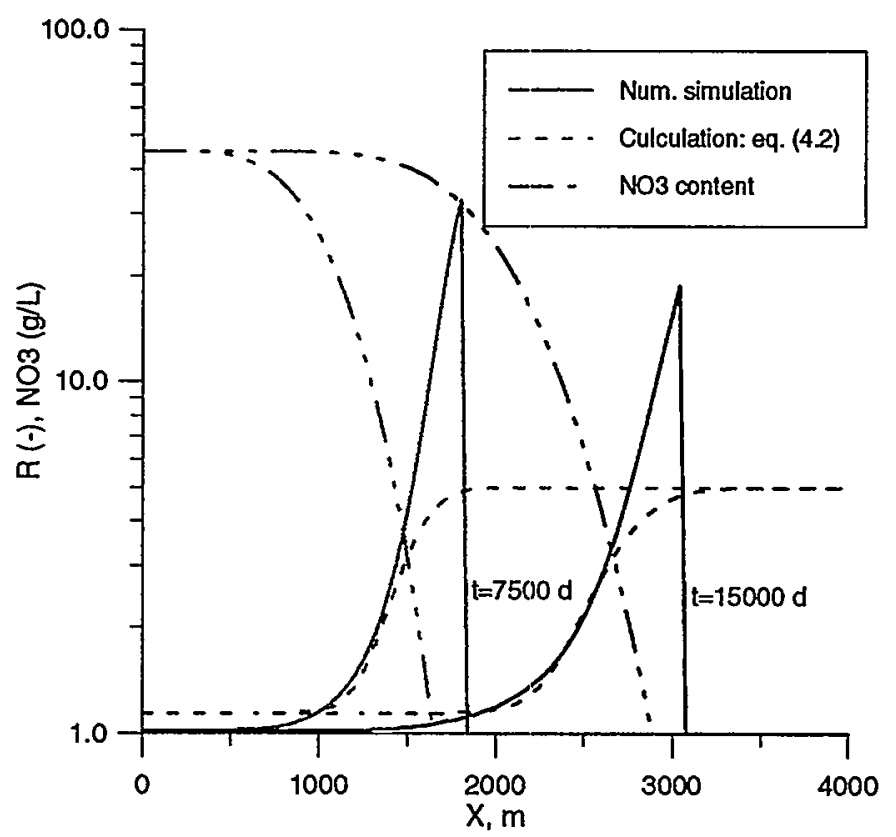

Fig. 6.6. Retardation factor variations

2. Fig. 6.6 illustrates variations of current values of the effective retardation factor $R=R(x)$ calculated on base of: (a) multicomponent modeling results $[R=1+N / n C$, where $N$ and $C$ are the concentrations of Sr-90 in the mineral surface and liquid phase], and (b) formula (4.2), where the adsorption distribution coefficient $K_{a}$ was assumed to be dependable on sodium nitrate content (equation 4.1; the averaged migration parameters referred to in Section 5.2.3 were used for analytical calculations). One can see that in the back front of the concentration wave modeling and analytical curves for the $R$-factor almost coincide: values of the retardation factor are close to 1 . In the advancing concentration front the ion-exchange model gives higher magnitude 
of the coefficient $R$ in comparison with the analytical calculations. Increased $R$-values lead to decreasing velocity of radiostrontium front propagation and decreasing concentration in comparison with the observed values.

3. Further NODEK computer code developed on base of the $\mathrm{Kd}$ approach (Section 5.2.2) was used as an alternative for the multicomponent modeling. Double porosity of the domain was taken

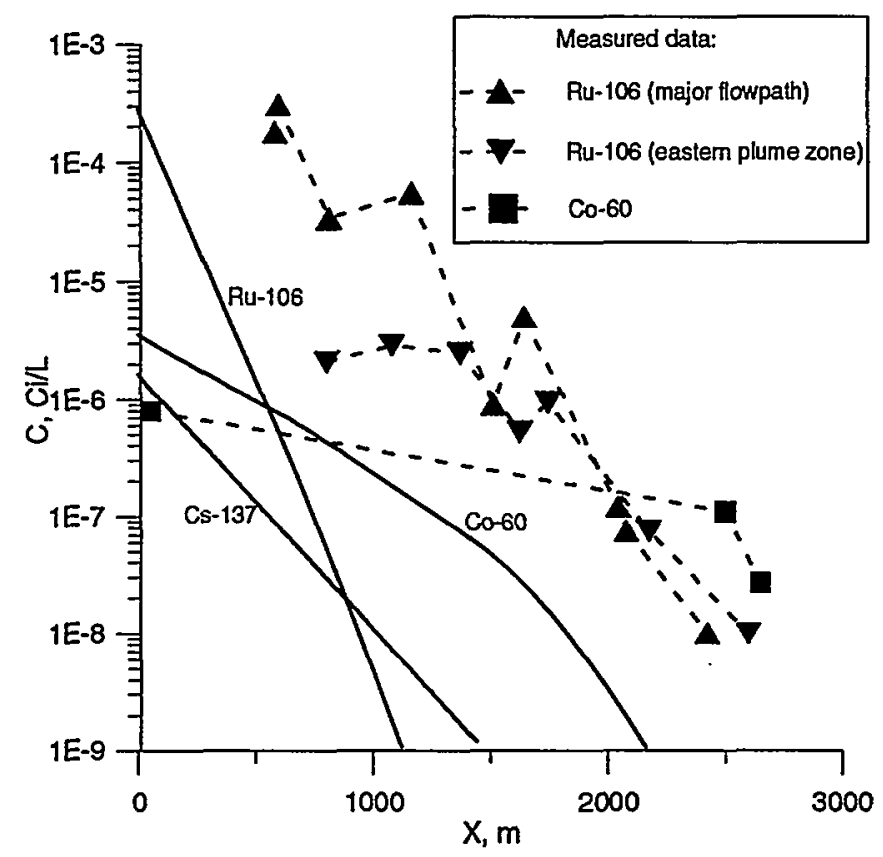

Fig. 6.7. Modeling (solid lines) and actual distributions of $\mathrm{Ru}-106$ (dashed line and triangles) and Co-60 (dashed line and squares) in ground water

into consideration through effective migration parameters (Mironenko and Rumynin, 1986): $n^{*}=n+n_{0}, D^{*}=\delta^{*} v^{2}\left(\delta^{*}=\alpha_{M}{ }^{-1}\right)$; experimentally determined adsorption parameters were assumed according to Section 5.2.3. As one can see in Fig. 6.5 the numerical modeling results in quite realistic concentration distribution of Sr-90. So, the simplified Kd approach leads to results which are fairly competitive with the discussed above results of the multicomponent transport simulation.

4. Modeling curves for $\mathrm{Ru}-106$ and $\mathrm{Co}-60$ (obtained in the framework of modeling procedures with the SONED code) are not consistent with the measured concentrations of these radionuclides within the selected area of the contaminated water plume (Fig. 6.7). The relevant discrepancies reach several 
orders of magnitude. They can not be explained by drawbacks of the ionexchange approach for simulation of the solution-rock interactions because these isotopes migrate primarily as neutral molecules (Section 6.1.2). Having excluded from the modeling input data porous matrix capacity (i.e. assuming $Q_{\nu}=0$ and $\alpha_{M}=0$ ) we could not noticeably improve the modeling results. Moreover due to intensive decay process (half-life periods are 5.67 year and 1.01 year for Co-60 and Ru-106 respectively) concentration distributions are almost steady state. It means that at present the observed area of ground water contamination by $\mathrm{Ru}-106$ and Co-60 is limited by the current values of concentrations as a maximum. Disagreement between modeling and measured data on Ru-106 can be explained by the fact that there is another source of this isotope in ground water, i.e. $\mathrm{Ru}-105$ is a daughter product of radioactive decay of a radionuclide (probably, an isotope of technetium), which was not included in the modeling procedure. Further investigations will focus on this problem.

\section{Conclusions}

1. Radionuclide transport at the Lake Karachai site is very complex due to:

a) heterogeneity and anisotropy of flow properties at several levels of 3-D heterogeneity,

b) extensive density convection of brines which essentially controls the radionuclide migration;

c) brine spreading is strongly influenced by the local slope and large undulations in the semi-permeable base of the aquifer and its storage capacity;

d) subsidiary 3-D spreading of contaminants because of transverse dispersion and convective velocity field fluctuations;

e) the strong impact of solute diffusion into the porous matrix, as well as nonlinear sorption and irreversible desorption from fracture surfaces and in porous matrix;

f) evidence of several levels of heterogeneity during the migration process which could be quite different for some sub-processes mentioned above;

g) a very wide range of radionuclide concentrations to be accounted for in predictive evaluations. Many of these factors are very poorly substantiated 
by the input information. Meanwhile, even small variations of the input parameters could dramatically change the model behavior.

2. The results of flow and transport model calibration using previous field observations data can not be considered as a proof of their validation, for the calibration procedures have not permitted discrimination of the impacts of the above mentioned factors. The models could therefore simulate more or less properly the results of the previous observations, but that does not prove by any means their suitability for the further predictions of mass-transport, or radionuclide transport in particular.

3. The last conclusion would be even more obvious if we take into account the supposed further decrease salinity (TDS) due to cessation of liquid waste disposal into the Lake Karachai. In this case the brine plume would become separated from the lake while the lake bottom deposits would remain a long-term source of radionuclides. The same could be said about the radionuclides removed from the brine plume surface by the upward convection, transverse dispersion and diffusion. It is feasible that the transport from these two sources of radionuclides would not be entrained by the brine, but would take another easterly direction according to the main uncontaminated groundwater gradient. On the other hand, the «old»dense brine plume will slowly spread laterally and downward the low-permeability lower zone of the aquifer and (which is most important) using the aquitard's presumed large storage capacity. All these processes could be accounted for properly only if sufficient data concerning the profile inhomogeneity and anisotropy of the flow properties, the transverse dispersivity, the parameters of nonlinear and irreversible sorption-desorption as well as other physicaland-chemical interactions (ion exchange in particular) are available. However, current information concerning these parameters is poor or non existent ${ }^{2}$, which also means that the predictive capacity of the developed models is questionable.

4. In such a situation the reliable prediction of radionuclide transport in the range of relative concentrations over 7-8 orders of magnitude at least, with proper consideration of their possible discharge into the river system, seems to be completely unrealistic at present. However, this essential drawback of the modeling activity does not necessarily lead to dramatic consequences from

\footnotetext{
${ }^{2}$ Let us add that it is practically impossible now to say something definite about the range of initial concentrations of radionuclides which will be flushed from the lake bottom by the ambient and infiltrating water.
} 
the practical point of view, particularly if we take into account two major aspects of the problem:

a) in all cases the contamination process should be (and, as we hope, would be) controlled by a proper monitoring system which will progressively provide for new and valuable information for improving the predictive capability of the model;

b) it is most probable, that besides liquidation or localization of the surface and near-surface sources of contamination, the only realistic approach concerning groundwater remediation at the Lake Karachai site is the natural attenuation processes, which do not require urgent measures for «deep» in situ remediation and, in this sense, do not depend critically on the quality of the previously developed predictive models. Specifically, the latter are not suitable for the proper analysis of the natural attenuation processes and these processes need special and thorough investigations, with emphasis on modeling.

5. In this overall context, a major role in the analysis of the Lake Karachai site should emphasize conceptual modeling to help understand and evaluate properly the major mechanisms of radionuclide transport. More precisely, these models should be directed towards:

a) finding out, the physical and mathematical description and assessing the main migration sub-processes;

b) conducting a sensitivity analysis of these subprocesses and assessing of their controlling parameters;

c) performing a multivariant evaluation of the possible environmental impacts of radionuclide migration, which will link these modeling results with risk-assessment;

d) analyzing the efficiency of different remediation strategies, including the natural attenuation approach in particular;

e) substantiating of methods for the further field tests at key sites as well as conducting additional hydrogeological observations.

Thus, the modeling approach will be developed in the future investigations, in conjunction with additional physical and chemical experimental studies concerning groundwater-rock interactions. 


\section{Acknowledgements}

We wish to express our gratitude to Dr. Chin-Fu Tsang, Director of the Russian American Center for Contaminant Transport Studies at LBNL, and to Dr. J. Apps and Mr. H. Wollenberg, for their cooperation and encouragement in this work and for critical discussion during the preparation of this report for publication and for editorial improvement the text. The authors would like to express their appreciation to Dr. E.G. Drozhko, Deputy Director of MAI, Dr. L.M. Samsonova, principal specialist of the "Hydrospetzgeologia" and Dr. V.I.Velichkin, deputy director of IGEM, for the substantial assistance in the collection of field material and for discussions concerning approaches for modeling the migration processes at the Lake Karachai Site. The authors thank Dr. V.N. Ozyabkin for useful discussions, hydrogeochemical modeling, and for development of the computer codes SOFAMA and SONED.

This work was partially supported by EC, "Inco-Copernicus" program (Contract No ERBIC15CT960211), Russian Foundation for Basic Research (Projects No 96-05-64338 and No 97-05-64419), and the Fulbright grantee program.

\section{References}

Belkin I.V., Petrov A.V. , 1993. Assessment of fracturing porosity and calculation of hydrogeological parameters on base of telephotometrical logging of wells. - Science-and-technical enrichments in geology and prospecting. Moscow, pp. 18-25.

Drozhko E.G., Samsonov V.A., Samsonova L.M., 1996. Radionuclide retarding by rocks at the Lake Karachai site. - Problems of the radiation safety. N 2, pp. 22-27.

Drozhko E.G., Glagolenko Y.U., Mokrov Y.G., Postovalova G.A., Samsonova L.M., Glagolev A.V., Ter-Saakia S.A., Glinsky M.L., Vasilkova N.A., Skokov A.V., Wollenberg H.A., Tsang C.-F., Frangos W., Solbau R.D., Stevenson K.A., Lowder W.M., Foley M.G., 1997. Joint RussianAmerican hydrogeological-geochemical studies of the Karachai-Mishelyak system, South Urals, Russia. - Environmental Geology, v. 29, N 3/4, pp.216227. 
Drozhko E.G., Glagolenko Y.U. Environmental problems at the Mayak Site. - Joint Russian-American Hydrogeology Seminar. July 8-9, 1997, PUB-804, LBNL, Berkeley, California. pp. 5-14.

Drozhko E.G., Ivanov I.A., Aleksakhin A., Samsonova L.M., Vasilkova N.A., 1997. Mayak Site Characterization: Interpretation of field tests for evaluation of hydrayulic properties of fractured rock. - Joint RussianAmerican Hydrogeology Seminar. July 8-9, 1997, PUB-804, LBNL, Berkeley, California. pp. 15-33.

Drozhko E.G., Samsonova L.M., Vasilkova, Pozdniakov S.P., Tsang C.-F., 1997. Mayak Site Characterization: Spatial hydraulic heterogeneity. - Joint Russian-American Hydrogeology Seminar. July 8-9, 1997, PUB-804, LBNL, Berkeley, California. pp. 303-311.

Kipp K. L., Jr., 1987. HST3D: A Computer code For Simulation of Heat and Solute Transport in Three-Dimensional Ground-Water Flow Systems. U.S. Geological Survey, Water-Resources Investigations Report 86-4095, Denver, Colorado.

Mc Donald M.G. and Harbough A.W., 1988. MODFLOW, A Modular D3 Finite-Difference Ground-Water Flow Model USGS. Tec. Water-Resources Inv., Bk 6, Chap Al. Washington. DC.

Mironenko V.A., Rumynin V.G., 1986. Field tests and ground water quality monitoring in aquifers. Moscow, Nedra, $240 \mathrm{p}$.

Mironenko V.A., Rumynin V.G., Konosavsky P.K., Pozdniakov S.P., Shestakov V.M., Roshal A.A., 1994. Development of analytical and numerical models for the assessment and interpretation of hydrogeological field tests.- Summary Report (1993-1994) of Russian - American Nenter for Contaminant Transport 'Studies. Earth Sciences Div., Lawrence Berkeley National Laboratory, Iniversity of California, $93 \mathrm{p}$.

Myasoedov B.F., 1997. Problems of radioactive contamination of some Russian regions. - Geoecology, N 4, pp.3-18.

Omelianenko B.I., Nikonov B.S., R.yzhov B.I., Shikina N.D., 1994. Weathering products of Basic rocks as sorptive materials of natural 
radionuclides. - Lawrence Berkeley Laboratory Report Series, LBL-37337, UC-603, 7 p .

Ozyabkin V.N., Ozyabkin S.V., 1996. Program imitators for modeling of geochemical migration of non-organic pollutants. - Geoecology. N 1, pp. 104120.

Petrov A.V., Samsonova L.M., Vasilkova N.A., Zinin A.I., Zinina G.A., 1994. Numerical modeling of the groundwater contamination transport for the Lake Karachai Area: The methodical approach and the basic two-dimensional regional model. Lawrence Berkeley Laboratory Report Series, LBL-38262, UC-600, $38 \mathrm{p}$.

Pickens J.F., Jackson R.E., Inch K.J., 1981. Measurement of distribution coefficient using a radial injection dual-tracer test. - Water Resources Research, v. 17, N 3, p.p. 5529-544.

Pozdniakov S.P., 1996. Stochastical modeling of hydrogeodynamic processes. - Doctoral dissertation. Moscow State University.

Samsonova L.M., Drozhko E.G., 1996. Migration of high-density industrial waste solutions through fresh groundwater. In: Deep Injection Disposal of Hazardous and Industrial Waste (Scientific and Engineering Aspects). Edited by J.Apps and Chin-Fu Tsang, Academic Press, p.669-680.

Solodov I.N., Velichkin V.I., Zotov A.V., Koshkin B.T., Drozhko E.G., Glagolev A.V., Skokov A.N., 1994. Distribution and geochemistry of contaminated subsurface waters in fissured volcanogenic bed rocks of the Lake Karachai Area, Chelyabinsk, Southern Urals. Lawrence Berkeley Laboratory Report Series, LBL-36780, UC-603, 46 p.

Solodov I.N., Zotov A.V., Khoteev A.D., Mukhamet-Galeev A.P., Tagirov B.R., and Apps J.A., 1998. Geochemistry of natural and contaminated subsurface waters in fisured rocks of the Lake Karachai area, Southern Urals, Russia. Applied Geochemistry. In press.

Vandergraaf T.T., Abry D.R.M., 1982. Radionuclide sorption in drill core material from the Canadian Shield. Nuclear Technology, v.57, p.p.399-412 
Wels C., Smith L., Vandergraaf T.T., 1997. Influence of specific surface area on transport of sorbing solutes in fractures: An experimental analysis. - Water Resources Research. V. 32, N 7 pp. 1943-1954.

Zheng C.A., 1990. Modular 3D Transport Model for Simulation of Advection, Dispersion and Chemical Reactions of Contaminants in GroundWater Systems., S.S.Papadopulos and Associates, Ine. 